\title{
Music and Politics in Figure Skating: American and Soviet Nationalism, Cultural Diplomacy, and Identity at the Winter Olympics, 1968-1988
}

\author{
Mary Bridget Golden \\ mbg0015@mix.wvu.edu
}

Follow this and additional works at: https://researchrepository.wvu.edu/etd

Part of the Musicology Commons

\section{Recommended Citation}

Golden, Mary Bridget, "Music and Politics in Figure Skating: American and Soviet Nationalism, Cultural Diplomacy, and Identity at the Winter Olympics, 1968-1988" (2020). Graduate Theses, Dissertations, and Problem Reports. 7886.

https://researchrepository.wvu.edu/etd/7886

This Thesis is protected by copyright and/or related rights. It has been brought to you by the The Research Repository @ WVU with permission from the rights-holder(s). You are free to use this Thesis in any way that is permitted by the copyright and related rights legislation that applies to your use. For other uses you must obtain permission from the rights-holder(s) directly, unless additional rights are indicated by a Creative Commons license in the record and/ or on the work itself. This Thesis has been accepted for inclusion in WVU Graduate Theses, Dissertations, and Problem Reports collection by an authorized administrator of The Research Repository @ WVU. For more information, please contact researchrepository@mail.wvu.edu. 
Music and Politics in Figure Skating: American and Soviet Nationalism, Cultural Diplomacy, and Identity at the Winter Olympics, 1968-1988

Mary Bridget Golden 
Music and Politics in Figure Skating:

American and Soviet Nationalism, Cultural Diplomacy, and Identity at the Winter Olympics, 1968-1988

Mary Bridget Golden

Thesis submitted

to the College of Creative Arts

at West Virginia University

in partial fulfillment of the requirements for the degree of

Master of Arts in

Musicology

Travis D. Stimeling, Ph.D., Chair

Evan A. MacCarthy, Ph.D.

Andrew Kohn, Ph.D.

Kasi Jackson, Ph.D.

School of Music

Morgantown, West Virginia

2020

Keywords: Figure skating, music, politics, Olympic Games, Cold War, identity, cultural diplomacy, nationalism

Copyright 2020 Mary Bridget Golden 


\begin{abstract}
Music and Politics in Figure Skating:

American and Soviet Nationalism, Cultural Diplomacy, and Identity at the Winter Olympics, 1968-1988

Mary Bridget Golden
\end{abstract}

This thesis situates figure skating, music, and Cold War politics during three separate Winter Olympic Games held in 1968, 1976, and 1988, examining the impact of this intersection on the sport of figure skating. Through a survey of seven Olympic medal-winning figure skating programs in the men's and women's single divisions and the pairs' division, evidence of the relationship between politics and music is examined in the musical selections of the skaters' programs. This thesis also explores the overwhelming prominence in skating programs of musical selections that appealed to the tastes of an elite majority during the Cold War, while observing which musical repertories and traditions were regularly excluded. The widespread status of art music as the unofficial soundtrack of Olympic figure skating is likely to have been a consequence of nations competing to appear as culturally erudite as possible. While this role of art music is discernable for the case studies in this thesis, it can also be shown that individual skaters or pairs used their music selections from this musical canon to relate their personal ideas. Building on existing historical scholarship on the Cold War history and on Olympic figure skating, this thesis analyzes past and contemporary trends to pose questions about music's function as an ideological weapon of warfare between the United States, the Soviet Union, and other prominent countries in the past. Focusing on issues of cultural elitism, race, gender, sexuality, and class, this thesis also seeks to identify past and present tactics of inclusion and exclusion in the musical repertories associated with figure skating. 


\section{Table of Contents}

ACKNOWLEDGEMENTS ..............................................................

CHAPTER ONE: Introduction........................................................

CHAPTER TWO: “A Generation of Style on Ice”: The History and Politics of Peggy Fleming and the Protopopov's 1968 Winter Olympic Figure Skating Programs................25

CHAPTER THREE: Dance on Ice: Western Ballet and Russian Folk-Art at the 1976 Winter

Olympic Game...................................................... 54

CHAPTER FOUR: "Carmen on Ice” at the 1988 Winter Olympic Games...................85

CHAPTER FIVE: Beyond the End of the Cold War................................ 110

APPENDIX A: Peggy Fleming's Long Program at the 1968 Winter Olympic Games........119

APPENDIX B: Belousova/Protopopov's Long Program at the 1968 Winter Olympic Games 121

APPENDIX C: John Curry’s Long Program at the 1976 Winter Olympic Games..............123

APPENDIX D: Rodnina/Zaitsev's Long Program at the 1976 Winter Olympic Games........125

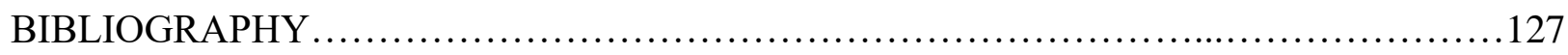




\section{List of Figures}

Figure 1. The 1961 U.S. Figure Skating team............................................ 31

Figure 2. Oleg Protopopov and Ludmila Belousova perform a death spiral in the 1968 Winter

Olympic Games..................................................................... 43

Figure 3. John Curry, free-skate program, 1976 Winter Olympics, Innsbruck, Austria........64

Figure 4: Rudolf Nureyev and Yoko Morishita (left), and Mikhail Baryshnikov and Cynthia Harvey (right) dance to Pas de Deux.......................................................66

Figure 5: Irina Rodnina (left) and Alexander Zaitsev (right), pairs figure skating long program, 1976 Winter Olympics, Innsbruck, Austria.............................................. 78

Figure 6: Debi Thomas, free-skate program, 1988 Winter Olympics, Calgary, Alberta,

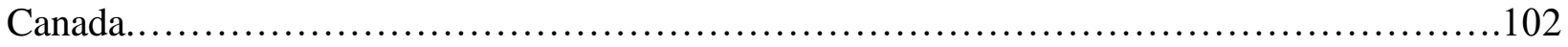

Figure 7: Katarina Witt, short program, 1988 Winter Olympics, Calgary, Alberta, Canada.

\section{List of Tables}

Table 1. Katarina Witt's 1988 Winter Olympic Long Program ..........................95

Table 2. Debi Thomas's 1988 Winter Olympic Long Program ...........................97 


\section{Acknowledgements}

There are so many people who helped with this project, and while I do not feel that the words on this page can truly express the depths of gratitude in my heart, I am humbled and honored to have known and learned from you all.

To my advisor, Dr. Evan MacCarthy: I truly cannot thank you enough for your guidance on this project. You somehow make academic miracles appear out of thin air and your patience is endless. Thank you for entertaining an idea about figure skating and music that I had so long ago and helping make it a reality, and thank you so much for being a good friend and mentor to me. I'm privileged to know you.

To my committee members, Dr. Kasi Jackson, Dr. Andrew Kohn, and Dr. Travis Stimeling: I absolutely could not have made this thesis what it is without you all. Your perspectives and guidance sincerely transformed this project. Thank you for teaching me patience and helping me slow down whenever my brain was running a mile a minute. I value your teaching and the lessons you all have taught me, but most of all, I value your empathy and kindness as human beings.

To Dr. Sarah Gerk: When I spoke to you in your office about pursuing a career in musicology in my junior year of college, I didn't think I would actually get this far. Thank you for introducing me to this discipline, thank you for believing in me, and thank you for caring about your students as much as you do.

To Dr. Paul Schleuse: Thank you for paying attention to the details and reading between the lines, and for encouraging me to achieve everything I set out to do. My writing improved so much in your classroom. Most of all, thank you for sharing your love and passion for musicology with me.

To my good friend, Paige Zalman: You were my rock throughout this project. Thank you for being there through thick and thin.

To my partner, James-Luke Smith: Thank you for being such a patient, kind, and wonderful man. You make me a better person and push me to do things I never thought I was capable of.

Finally, to all of my friends and family: I don't think a day went by where I wasn't leaning on any one of you for support. Thank you for being supportive and pushing me forward 
even when I felt like I couldn't go any farther. I wouldn't have gotten here without your endless and unconditional love and support. I especially want to thank my parents and siblings for being there for me through it all, and also for letting me borrow the kitchen every day to complete this work. 


\section{Chapter 1}

\section{Introduction}

During the Cold War (1947-1991), the United States and the Soviet Union waged ideological warfare through cultural diplomacy, nuclear threats, scientific advances, new alliances forged through imperialism and nationalism, and various highly-visible international events. One such event was the Olympic Games, a worldwide sporting event created in 1894 by Baron Pierre de Coubertin to encourage healthy competition among rival nations and as an alternative to war. ${ }^{1}$ During the ten Olympic Games held between 1952 and 1988, that is, during the Cold War, the Olympics served as a comparatively low-risk battleground for the two combatant nations. While the United States and the Soviet Union never waged a full-scale militaristic war against each other, instead they funded and aided more than eighty violent proxy wars, skirmishes, and insurgencies around the globe. Additionally, American and Soviet athletes battled one another within the Summer and Winter Olympics in individual sporting events held across various continents and nations on behalf of their home countries. One sporting event which featured highly politicized competition was the sport of figure skating.

There is no clear moment in Olympic figure skating during the Cold War that stands out as a singular, significant "moment of war" between the United States and the Soviet Union. For the sport of figure skating, there was no "Miracle on Ice" like the U.S.-Soviet ice hockey match at the 1980 Winter Olympics at Lake Placid, NY, yet American and Soviet figure skaters always

\footnotetext{
${ }^{1}$ Elizabeth Redihan, The Olympics and the Cold War, 1948-1968: Sport as Battleground in the U.S.-Soviet Rivalry (Jefferson, NC: McFarland, 2017), 6.
} 
competed against each other at exceptionally high levels and regularly took home medals. ${ }^{2}$ Over time, the Olympic events of ice hockey and gymnastics became high-profile, politicized team events for the Americans and the Soviets. As a solo and pair sport, however, figure skating stood apart from these team events. ${ }^{3}$ Figure skaters could convey powerful political statements through their individual routines and employed in that effort their musical selections, often the first element in the design of a figure skating routine. ${ }^{4}$ Were there American and Soviet skaters who made these statements through their musical choices during the Cold War? What about other skaters from the East and West?

Since the first Winter Olympics in 1924, when figure skating was among the inaugural competitive events, figure skaters have performed exceptionally difficult choreography filled with jumps and step sequences to music. Initially, rink-side orchestras performed Western art music from a pre-existing list of music until developments in recording and amplification technology enabled skaters to submit pre-recorded music of their choice to skate to during competitions. ${ }^{5}$ While figure skating is considered a physical sport above all else, its choreographic elements allow athletes to "deliver the intent of the music and composition" used and exhibit high levels of passionate artistry. ${ }^{6}$ Therefore, the music chosen for a particular

\footnotetext{
${ }^{2}$ For more on the "Miracle on Ice," see Stephen Hardy, "Remembering and Forgetting America's Hockey Miracles," in Replays, Rivalries, and Rumbles: The Most Iconic Moments in American Sports, ed. Steven Gietschier, (Urbana: University of Illinois Press, 2017), 171-79. See also John Soares, “'Our Way of Life against Theirs': Ice Hockey and the Cold War," in Diplomatic Games: Sports, Statecraft, and International Relations Since 1945, edited by Evelyn Mertin and Andrew L. Johns (Lexington: University Press of Kentucky, 2014), 251-296.

${ }^{3}$ Figure skating did not introduce a team event at the Olympics until 2014.

${ }^{4}$ Carole Shulman, The Complete Book of Figure Skating (Champaign, IL: Human Kinetics, 2001), 204.

${ }^{5}$ Mary Louis Adams, Artistic Impressions, Figure Skating, Masculinity, and the Limits of Sport (Toronto: University of Toronto Press, 2011), 216.

6 "International Skating Union Constitution and General Regulations," International Skating Union, last modified June, 2018, 82.
} 
routine is meant to make a statement, whether that expressive statement is artistic, cultural, political, individual, or otherwise.

Competitive figure skating has long been a sport most easily accessed by white, upperclass individuals in wealthy, developed countries. For the musical selections that accompany skating programs, there is an unmistakable pattern of employing Western art music and its established canon of musical works by predominantly white, upper-class men, and can be heard at least once in nearly every set of Olympic figure skating routines during the Cold War. ${ }^{7}$ Excerpts of popular film scores were also popularly used by skaters, and again, these scores were largely written by people of the same demographic. Meanwhile, during the Cold War, music outside of these two musical traditions and genres, especially music by marginalized or underrepresented groups, such as women and people of color, is essentially absent.

This thesis situates figure skating, music, and Cold War politics during three separate Winter Olympic Games held in 1968, 1976, and 1988, examining the impact of this intersection on the sport of figure skating. Through a survey of eight Olympic medal-winning figure skating programs in the men's and women's single divisions and the pairs' division, evidence of the relationship between politics and music is examined in the musical selections of the skaters' programs. This thesis also explores the overwhelming prominence in skating programs of musical selections that appealed to the tastes of an elite majority during the Cold War, while observing which musical repertories and traditions were regularly excluded. The widespread status of art music as the unofficial soundtrack of Olympic figure skating is likely to have been a consequence of nations competing to appear as culturally erudite as possible. ${ }^{8}$ While this role of

\footnotetext{
${ }^{7}$ A set here means one short program and one long program.

${ }^{8}$ For more on European classical/art music used as a veil of cultural diplomacy, see Danielle Fosler-Lussier, Music in America's Cold War Diplomacy (Berkeley: University of California Press, 2015).
} 
art music is discernable for the case studies in this thesis, it can also be shown that individual skaters or pairs used their music selections from this musical canon to relate their personal ideas. Building on existing historical scholarship on the Cold War history and on Olympic figure skating, this thesis analyzes past and contemporary trends to pose questions about music's function as an ideological weapon of warfare between the United States, the Soviet Union, and other prominent countries in the past. Focusing on issues of cultural elitism, race, gender, sexuality, and class, this thesis also seeks to identify past and present tactics of inclusion and exclusion in the musical repertories associated with figure skating.

\section{Literature Review}

The scholarly literature relevant to this thesis can be organized into the following eight categories: 1) the Cold War, 2) Cold War sports and the Olympics, 3) music during the Cold War, 4) figure skating, 5) related choreographic sports and the place of music in them, 6) dance and choreography, 7) research models relevant to this thesis, and 8) identity. The first category includes literature on the Cold War and its background, involving broader studies on communism and the Cold War, not just in the U.S. and U.S.S.R., but in other countries as well. The next category looks at sports and the Olympics during the Cold War with a particular focus on Games that occurred during the Cold War. The third category includes scholarship on music and cultural diplomacy between the U.S. and U.S.S.R. during the Cold War. The fourth category looks at figure skating, its history, its music, and its cultural influence as a sport. The fifth category focuses on scholarship related to sports that involve music, including synchronized swimming and artistic/rhythmic gymnastics. The sixth category looks at dance and choreography scholarship with an emphasis on classical ballet due to its widespread use as a choreographic 
framework for designing and critiquing programs in figure skating. The seventh category focuses on research models that give more perspective on international cultural exchange and musical diplomacy, including at international events like the Eurovision Song Contest. The final category discusses identity and social categorizations, such as race, class, gender, etc., especially their relationship to sports, the media, and history.

\section{Cold War History}

Identifying the major political issues surrounding the decades-long Cold War and its unfolding influence on global politics contributes to a clearer path toward discovering whether Olympic figure skaters selected music that reflected the politics of their time. Both the U.S. and U.S.S.R. faced various political issues throughout the Cold War, including fights for civil rights, internationalism and globalization, the African diaspora and subsequent decolonization, the Korean and Vietnam wars, the polarization of Germany, the space race, and the nuclear arms race. ${ }^{9}$ Political propaganda between the two countries played a major role in the increasing hostility between capitalist and communist societies. Alan Ball's Liberty's Tears: Soviet Portraits of the "American Way of Life" during the Cold War shows the Soviet efforts in Cold War propaganda, translating primary source documents from the Soviet Union, which depict Soviet attitudes towards Americanism, and therefore destabilizing the more standard Eurocentric Cold War narrative. ${ }^{10}$

\footnotetext{
${ }^{9}$ For an overview of the Cold War and related political developments, see John Lewis Gaddis, The Cold War: A New History (London: Penguin, 2005); Ralph B. Levering, The Cold War: A Post-Cold War History, $3^{\text {rd }}$ ed. (Chichester: Wiley \& Sons, 2016); Jussi Hanhimäki and Off Arne Westad, eds., The Cold War: A History in Documents and Eyewitness Accounts (Oxford: Oxford University Press, 2004).

${ }^{10}$ Alan Ball, Liberty's Tears Soviet Portraits of the "American Way of Life" during the Cold War (New York: Oxford University Press, 2016).
} 
In fact, one of the major issues with Cold War literature is that it lacks deep analysis of global issues. According to Richard H. Immerman and Petra Goedde, many Cold War scholars have failed to consider that the majority of Cold War political issues were not solely faced by the United States and the Soviet Union. ${ }^{11}$ While the two main global superpowers in the world competed to show their superiority, other nations, including the less affluent and obvious ones, played their own part in Cold War politics. Several essays in The Oxford Handbook to the Cold War magnify these other countries and destabilize the bipolarity of Cold War issues, such as the global consequences of American investment in apartheid South Africa, the increasing influence of Great Britain in global affairs, and the aftermath of Western intervention in postcolonial Africa. ${ }^{12}$ Likewise, The Oxford Handbook of the History of Communism's chapter on sports under Communism brings other countries to the forefront of discussion on the Olympics during the Cold War. ${ }^{13}$ Finally, Danielle Fossler-Lussier's Music in America 's Cold War Diplomacy offers insight into how the U.S. and U.S.S.R. treated cultural diplomacy among themselves and other countries, specifically regarding music and the arts. ${ }^{14}$ While this thesis focuses primarily on Olympic confrontations between athletes from the U.S. and the U.S.S.R., as well as one skater from Britain and one from the G.D.R., global perspectives will help facilitate a transnational approach to these issues here and in future scholarship.

\footnotetext{
${ }^{11}$ Richard H. Immerman and Petra Goedde "Introduction," in The Oxford Handbook of the Cold War, ed. Richard H. Immerman and Petra Goedde, (Oxford: Oxford University Press, 2013).

12 Ibid.

${ }^{13}$ Robert Edelman, Anke Hilbrenner, and Susan Brownell, "Sport Under Communism," in The Oxford Handbook of the History of Communism, ed. Stephen Smith (Oxford: Oxford University Press, 2014). For an overview of the place of athletics within Soviet ideology, see Robert Edelman, Serious Fun: A History of Spectator Sports in the USSR (Oxford: Oxford University Press, 1993). For a detailed examination of Soviet sport diplomacy, see Jenifer Parks, "Welcoming the 'Third World': Soviet Sport Diplomacy, Developing Nations, and the Olympic Games," in Diplomatic Games, 85-116.

${ }^{14}$ Fosler-Lussier, Music in America's Cold War Diplomacy. See also Emily Abrams Ansari, The Sound of a Superpower: Musical Americanism and the Cold War (Oxford: Oxford University Press, 2018).
} 


\section{Cold War Sports and the Olympics}

Most of the literature referenced in this next section focuses on the Olympic Games, but some contributions focus on athletics in a more general sense. Reviewing this literature on the Olympics has enabled a clearer exploration of the circumstances of the more politically turbulent Cold War Winter Olympic Games. Some scholarship traces an earlier period of the Cold War Olympic history, while the majority of the remaining scholarship however focuses on the Summer Olympics or on particular issues like when global pressure forced the International Olympic Committee to ban South Africa from the Olympics from 1964 to 1988 for its refusal to allow Black athletes to compete at the Olympics during apartheid. ${ }^{15}$ Unfortunately, the Winter Olympic Games have limited coverage in these sources, perhaps because of the significant popularity of the events of the Summer Olympics over those of the Winter Olympics, which has ultimately made research on Olympic figure skating challenging at times. The diplomatic function of sports has been thoroughly explored by scholars within contexts of historical circumstances and of public and international policy. ${ }^{16}$ In all, it has been clearly demonstrated that Olympic diplomacy, espionage, and sabotage by all sides of those involved in the Cold War proved to create a lasting impact on the sport and on international relations.

\footnotetext{
${ }^{15}$ On the Olympic history of the 1950s, see Toby C. Rider, Cold War Games: Propaganda, the Olympics, and U.S. Foreign Policy (Urbana: University of Illinois Press, 2016); Redihan, The Olympics and the Cold War, 1948-1968; Harry Blutstein, Cold War Games: Espionage, Spies and Secret Operations at the 1956 Olympic Games (Bonnier, 2017). Studies that highlight the Summer Games include Jenifer Parks, The Olympic Games, the Soviet Sports Bureaucracy, and the Cold War (London: Lexington, 2017). On the ban of South Africa, see Erin Elizabeth Redihan, "Winning Hearts and Medals: The Olympics and the Cold War: 1948-1968" (Ph.D. diss., Clark University, 2015), $342-344$.

${ }^{16}$ David Black and Byron Peacock, "Sport and Diplomacy," in The Oxford Handbook of Modern Diplomacy, edited by Andrew F. Cooper, Jorge Heine, and Ramesh Chandra Thakur (Oxford and New York: Oxford University Press, 2013), 708-728; Routledge Handbook of Sport and Politics, edited by Alan Bairner, John Kelly, and Jung Woo Lee (London: Taylor \& Francis, 2016); Aaron Beacom, International Diplomacy and the Olympic Movement: The New Mediators (New York: Palgrave, 2012); Michal Marcin Kobierecki, Sports Diplomacy: Sports in the Diplomatic Archives of States and Non-State Actors (London: Lexington, 2020); Sheldon Anderson, The Politics and Culture of Modern Sports (London: Lexington, 2015); Stuart Murray, Sports Diplomacy: Origins, Theory, and Practice (London: Taylor and Francis, 2018).
} 
According to the aforementioned literature, figure skating was not a turbulent Olympic event throughout the Cold War when compared to other competitive events. Only after the Cold War did figure skating become the central focus of domestic scandal and cultural controversy in the media, starting with the Harding-Kerrigan incident in 1994 in Detroit, Michigan, when American skater Tonya Harding’s ex-husband allegedly attacked American skater Nancy Kerrigan by striking her in the knee, ultimately preventing her from competing against Harding at the U.S. National Championships. ${ }^{17}$ Still, the Soviet Union took an interest in sports that require small bodies and technical artistry such as gymnastics and figure skating. The efforts the Soviets put forth to cultivate young, limber athletes to compete in these sports was not merely coincidental; it was motivated by the Soviet government's desire to make progress in women's sports that the West neglected, just as Romania, another Eastern Bloc state, did with gymnastics. ${ }^{18}$ In fact, the Soviets only began promoting women's sports because their progressive outlook made the United States look worse comparatively. ${ }^{19}$ As Edelman, Hilbrenner, and Brownell argue, "Female participation in sport in capitalist nations was poorly developed, and the Soviets sensed an opportunity to win medals and gain prestige in events where the West was weak." 20 The weakness of the West in women's sports has much to do with

\footnotetext{
${ }^{17}$ For more on the Harding-Kerrigan incident, see Elizabeth L. Krause, "“The Bead of Raw Sweat in a Field of Dainty Perspirers': Nationalism, Whiteness, and the Olympic-Class Ordeal of Tonya Harding," Transforming Anthropology 7, no. 1 (1998): 33-52. See also Cynthia Bauman, ed., Women on Ice: Feminist Essays on the Tonya Harding/Nancy Kerrigan Spectacle (New York: Routledge, 1995).

${ }^{18}$ For more on Romanian women's gymnastics during the Cold War, see Mihaela Andra Wood, "Superpower: Romanian Women's Gymnastics during the Cold War" (Ph.D. diss., University of Illinois at Urbana-Champaign, 2010).

${ }^{19}$ For more on women in American sports, see Adrienne N. Milner and Jomills Henry Braddock II, Women in Sports: Breaking Barriers, Facing Obstacles, 2 vols. (Santa Barbara: ABC-CLIO, LLC, 2017).

${ }^{20}$ Edelman, Hilbrenner, and Brownell "Sport Under Communism."
} 
its unprofitability, as systemic sexism prevents women's sports from garnering extensive media coverage and popularity. ${ }^{21}$

The United States has also long been infamous on the international stage for having severe racial disparity among its people, which led to track-and-field champions Tommie Smith and John Carlos making a Black Power salute on the podium at the 1968 Mexico City Summer Olympic Games. ${ }^{22}$ One of the reasons Smith and Carlos' salute to the Black Power movement is remembered so well is because of the coverage it received by the media. ${ }^{23}$ Sport communications scholar Andrew Billings has demonstrated that the media is an incredibly powerful influence for a high-profile event like the Olympics. ${ }^{24}$ Billings employs databases, statistics, archives, and tables to explain how the number of viewers and the dollars earned by a television station are predicted and tracked for each particular Olympic segment, serving as crucial data when determining the amount of airtime each event gets. Likewise, if a station does not achieve much

${ }^{21}$ Raymond Boyle and Richard Haynes, "Playing the Game: Media Sport and Gender," in Power Play: Sport, the Media and Popular Culture (Edinburgh University Press, 2009), 122-43. See also Helen Lenskyj, Gender Politics and the Olympic Industry (New York: Palgrave, 2013).

${ }^{22}$ For more on the 1968 Olympic Games in Mexico, see Richard Hoffer, Something in the Air: American Passion and Defiance in the 1968 Mexico City Olympics (Lincoln: University of Nebraska Press, 2018). On the roles played by African American athletes in foreign policy, see Damion L. Thomas, "Playing Politics: The Formation of the U.S. Cold War-Era Athletic Foreign Policy," in Globetrotting: African American Athletes and Cold War Politics (Urbana: University of Illinois Press, 2012). For more on racial disparity in the United States, see Carol Anderson, White Rage: The Unspoken Truth of Our Racial Divide, (New York: Bloomsbury, 2017), Khalil Gibran Muhammad, The Condemnation of Blackness: Race, Crime, and the Making of Modern Urban America, (Cambridge, MA: Harvard University Press, 2011), and George Lipsitz, The Possessive Investment in Whiteness: How White People Profit from Identity Politics, (Philadelphia: Temple University Press, 2018).

${ }^{23}$ For more on Tommie Smith and John Carlos and the media, see Dave Zirin, "The Uses of Sports: How People in Power Exploit the Games," in Welcome to the Terrordome: The Pain, Politics and Promise of Sport (New York: Haymarket Books, 2007); Amy Bass, Not the Triumph but the Struggle: The 1968 Olympics and the Making of the Black Athlete (Minneapolis: University of Minnesota Press, 2002). See also Kevin B. Witherspoon, "“An Outstanding Representative for America': Mal Whitfield and America's Black Sports Ambassadors in Africa," in Defending the American Way of Life: Sport, Culture, and the Cold War, edited by Toby C. Rider and Kevin B. Witherspoon (Fayetteville: University of Arkansas Press, 2018), 129-140.

${ }^{24}$ Andrew Billings, Olympic Media: Inside the Biggest Show on Television (London; New York: Routledge, 2008); Andrew Billings, James Angelini, and Paul MacArthur, Olympic Television: Broadcasting the Biggest Show on Earth, (New York: Routledge, 2018). 
revenue or viewership from the Olympics at all, as was the case for NBC in the 1960s, then that station may put them up for bidding by other television stations, which will further influence the amount of airtime of each event. Considering how the media heavily influences culture and politics in many nations, it is crucial for the purposes of this thesis to understand the nuances of American media coverage of figure skating at the Olympic Games and the broader viewership of the sport and these skating programs under study here. ${ }^{25}$ Many of the sources on American media coverage include discussions of racial and gender bias in the media, all of which are particularly important in Chapter Four of this thesis.

\section{Music in the Cold War}

Throughout the early years of the Cold War, the United States was rife with civil unrest due to Jim Crow laws and backlash from the women's movement, dominating perceptions of the country abroad. In an effort to change such impressions, the American government exploited Black cultural products, such as jazz music, and used them to assert cultural superiority over the Soviet Union. ${ }^{26}$ However, the Kremlin had banned Western art forms in 1948, specifically targeting jazz. ${ }^{27}$ Domestic big bands were generally allowed, but "free jazz and improvised music" or any foreign performers were not welcome due to the individualistic and westernized musical expression involved. ${ }^{28}$ Despite the Party's Central Committee decree against Western art

\footnotetext{
${ }^{25}$ Kelli Lawrence, Skating on Air: The Broadcast History of an Olympic Marquee Sport (Jefferson, NC: McFarland, 2011).

${ }^{26}$ Lisa Davenport, Jazz Diplomacy Promoting America in the Cold War Era, (Jackson: University Press of Mississippi, 2009), 5-7.

${ }^{27}$ Gleb Tsipursky, “Jazz, Power, and Soviet Youth in the Early Cold War, 1948-1953," Journal of Musicology 33, no. 3 (2016): 332.

${ }^{28}$ Peter Culshaw, "How Jazz Survived the Soviets," The Telegraph, November 14, 2006.
} 
forms, many Soviets loved jazz, and the genre helped contribute to a "cultural thaw" between the two nations during the $1960 s^{29}$

Jazz was presented by American diplomats abroad as an "authentic expression" of American life, but even with the growing re-popularization of jazz worldwide in the 1960s, especially in Communist countries, perception of the art form was highly complex. ${ }^{30}$ Worldwide musical afficionados representing "high culture" regarded jazz as a "low" art form with low cultural origins." ${ }^{31}$ Some Soviets viewed jazz as music of the black lower-class struggle for "self-expression and autonomy from capitalist oppressors." 32 Many Americans viewed jazz as a "stigmatized art form" of "banality" and "chaos" due to its Black origins. ${ }^{33}$ White American musicians even re-recorded popular jazz songs to separate them from their Blackness and capture the attention of white conservative audiences. ${ }^{34}$ Black Americans were caught in a paradox of whether to "affirm their heritage by struggling against racial oppression or to seek acceptance into white society." 35 Ultimately, jazz symbolized racial and social struggle in America, but it also symbolized freedom and Black cultural consciousness, because despite facing systemic racial oppression and disenfranchisement, Black Americans created and popularized an art form

\footnotetext{
${ }^{29}$ Davenport, Jazz Diplomacy, 3.

${ }^{30}$ Ibid., 11, 14, 23-24.

${ }^{31}$ Ibid., 24.

${ }^{32}$ Ibid., 12.

${ }^{33}$ Ibid., 23.

${ }^{34}$ Ibid., 24.

${ }^{35}$ Ibid., 18.
} 
that signified American authenticity and the "ideal of American nationhood," which was used by the American government in efforts to thwart Communism. ${ }^{36}$

In light of the stigmatized and politicized nature of jazz in America and its association with Americanness overseas, even if many current and prospective figure skaters were listening to it, it was not among the musical selections in figure skating programs by Americans during the Cold War. Nevertheless, the diplomacy of American jazz musicians such as David Brubeck and Cozy Cole in the Eastern bloc in the 1960s reflected positively on the relationship between the U.S. and U.S.S.R. and helped reshape an American image beyond the Soviet Union. ${ }^{37}$

While jazz was the most popular example of cultural diplomacy during the Cold War, other forms of music also aided this mission. For example, as widespread as classical music was at the time, American officials believed that it was the "music that Europeans and citizens of former European colonies would respect the most" and that it "seemed the best music to win respect for America." 38 The United States also believed that classical music could serve as a development aid for countries in Europe and Asia, specifically in countries that had recently achieved total or partial independence from colonizing forces. ${ }^{39}$ Similarly the art music of Americanist composers like Roy Harris, Aaron Copland, and Leonard Bernstein was deployed in a number of ways as tools of Cold War propaganda. ${ }^{40}$

\footnotetext{
${ }^{36}$ Davenport, Jazz Diplomacy, 24-5.

${ }^{37}$ Ibid., 5.

${ }^{38}$ Fosler-Lussier, Music in America's Cold War Diplomacy, 17.

${ }^{39}$ Ibid., 41.

${ }^{40}$ Abrams Ansari, The Sound of a Superpower. For an overview of Soviet and Russian classical music recordings available in the West during the Cold War, see Evgeniya Kondrashina, "Soviet Music Recordings and Cold War Cultural Relations," in Entangled East and West: Cultural Diplomacy and Artistic Interaction during the Cold War, edited by Simon Mikkonen, Jari Parkkinen, and Giles Scott-Smith (Berlin and Boston: De Gruyter, 2019).
} 
Another example is religious music, which was used to show other countries that the United States was not just a country of business, but one of "respectable" spiritual traditions, as well. ${ }^{41}$ Much like how American officials appropriated jazz from African American culture, the use of African American spirituals in diplomacy tours “addressed both America's religious identity and its racial problems." 42

Popular music tours reached the younger audiences that U.S. officials were interested in reaching. These tours "best masked their function as propaganda," with rock-and-roll and blues tours energizing audiences with their "subversive power," and folk music serving as the music of the antiwar movement. ${ }^{43}$ An interesting example of popular music diplomacy is the jazz-rock group Blood, Sweat, and Tears, which toured Eastern European countries like Yugoslavia, Romania, and Poland in the 1970s. ${ }^{44}$ While on tour, the band members were outspoken against the U.S. government, yet they were allowed to continue touring due to their ability to engage "electric" responses from audiences beyond the Iron Curtain. ${ }^{45}$ Although their remarks seemed to undermine American ideals, freedom of expression was an important American principle, so the band was still championing American authenticity, despite its dissenting comments.

\footnotetext{
${ }^{41}$ Fosler-Lussier, Music in America's Cold War Diplomacy, 19.

${ }^{42}$ Ibid., 19.

${ }^{43}$ Ibid., 19-20.

${ }^{44}$ Ibid., 161-162.

${ }^{45}$ Ibid., 163.
} 


\section{Figure Skating}

Studies have been dedicated to the history of social and cultural significance of figure skating. ${ }^{46}$ Technical manuals for figure skating elucidate the major moves in the sport, including turns, spins, and jumps ${ }^{47}$ Much of the existing figure skating scholarship addresses music and figure skating in some way, but the majority of them primarily offer an overview of figure skating's history and technical/artistic moves that figure skaters use in competition without providing detail on music used in programs. Many former skaters, coaches, and judges have observed how figure skating coaches often pick the music that their skaters skate to because they know what the judges are looking for, but it is important to note that this is not the only way that music is chosen for these programs. ${ }^{48}$ As figure skaters age and mature both physically and in their skating technique, their methods of choosing music surely change, as well.

While younger athletes in training regularly entrust their coaches with the musical selections, believing such decisions will help them win, more seasoned skaters generally have more say in their selections with the advice of the coaches still informing the ultimate decision. ${ }^{49}$ This agency on the part of the coach might skew one's perception of music choices for skaters, since the competing skater might not always select music on their own, regardless of age and level of competition. Acknowledging that there are varying degrees of control in how figure skaters and coaches select music for their programs, it is ultimately the skater who must interpret

\footnotetext{
${ }^{46}$ See, for example, James R. Hines, Figure Skating: A History (Urbana: University of Illinois Press, 2006); Ellyn Kestnbaum, Culture on Ice: Figure Skating \& Cultural Meaning (Middletown: Wesleyan University Press, 2003).

47 John Misha Petkevich, Sport Illustrated Figure Skating: Championship Techniques (New York: Sports Illustrated, 1989).

${ }^{48}$ Perspectives on this include autobiographies and sport manuals by well-known individuals in the sport, including Nancy Kerrigan with Mary Spencer, Artistry on Ice: Figure Skating Skills and Style (Champaign, IL: Human Kinetics, 2002); Shulman, The Complete Book of Figure Skating; and Adams, Artistic Impressions.

${ }^{49}$ Shulman, The Complete Book of Figure Skating, 204.
} 
the music on the ice for an entire figure skating season. ${ }^{50}$ Roger Schlueter states that choosing the music to a figure skater's program is usually a team effort by the skater, their coach, and their choreographer, and that more than likely, the skater pays for their music to be mixed by a professional audio engineer. ${ }^{51}$ There are also other considerations when selecting music, such as audience and judges' reactions and how this varies in different cultural contexts. Considering the selection of the music and the skater's physical manifestation and presentation of such music, as well as how audiences and judges react to the program, aids in the analysis of figure skating music trends throughout the Cold War.

Coaches also perpetuate ideas of gender onto their skaters through music, costuming, and skating style. Sex and gender have always been central to sports and the roles that men and women play often differ significantly, but in sports like figure skating where men and women are held to similar artistic and technical standards, the only thing that differentiates them is their masculine and feminine personae. ${ }^{52}$ While coaches continue using gendered practices that helped them and other skaters be successful, it is the patriarchal systems in sports and society that make these practices seem necessary. ${ }^{53}$ As former judge Shulman prescribes, "If you have a girl who looks boyish or who skates like a football player charging down the field, you might want to soften her with a selection of graceful music to challenge her. As you listen to music, you will find that some types seem to definitely fit a male skater. Something that is bouncy and cute is

\footnotetext{
${ }^{50}$ The figure skating season lasts for 12 months from July $1^{\text {st }}$ to June $30^{\text {th }}$ of each year.

${ }^{51}$ Roger Schlueter, "This Is How Figure Skaters Choose the Music for Their Performances," Belleville News Democrat (2018), https://www.bnd.com/living/liv-columns-blogs/answer-man/article204131139.html.

${ }^{52}$ Adams, Artistic Impressions, 204. See also Kestnbaum, Culture on Ice, chs. 3-4; Erica Rand, Red Nails, Black Skates: Gender, Cash, and Pleasure On and Off the Ice (Durham: Duke University Press, 2012).

${ }^{53}$ For more on this, see Joan Ryan, Little Girls in Pretty Boxes: The Making and Breaking of Elite Gymnasts and Figure Skaters (New York: Warner, 2000).
} 
perfect for a little girl." ${ }^{54}$ In 2002, Shulman, a now retired competitive figure skater, Professional Skating Association executive director, professional figure skating judge, figure skating coach, and Professional Skating Association rating examiner, was named to International Skating Magazine's list of the 25 most influential people in figure skating. Not only did Shulman coach her own skaters, but she was also in charge of skating coaches' accreditation examinations, which shows how widespread and accepted her teaching and coaching methods are. ${ }^{55}$ She is certainly not the only influential person in figure skating who thinks that music should be gendered to fit traditional narratives that keep figure skaters in a figurative box. Even classical music has gendered qualities, as evidenced by musicologists like Susan McClary who are concerned with gender and music. ${ }^{56}$ While skaters began breaking out of the gendered musical mold in the 90s, 00s, and 2010s, this was generally a rarity in the competitions throughout the Cold War.

\section{Related Sports and Music}

Figure skating is not the only sport where athletes use music in competition. Artistic or rhythmic gymnastics and synchronized swimming are among other competitive sports where music plays a central role. Somehow, the involvement of music in these sports has made them inherently feminine to spectators, athletes, and scholars alike. Ken McLeod argues that "the use of music in the actual routines $[\ldots]$ has, for some, made them more redolent of art or dance, and thus they have traditionally been considered effeminate sports and often as stereotypical bastions

\footnotetext{
${ }^{54}$ Shulman, The Complete Book of Figure Skating, 207.

55 “Carole Banbury Shulman - St Louis Park Historical Society,” http://slphistory.org/banburycarole/.

${ }^{56}$ See Susan McClary, Feminine Endings: Music, Gender, and Sexuality (Minneapolis: University of Minnesota Press, 2002).
} 
of gay participation." ${ }^{57}$ For example, the floor exercise for artistic gymnastics is performed by both men and women, but music is only present in women's floor exercises. Also, figure skating is a male and female sport, but, in more recent decades, the increasing participation of gay males in the sport and the overwhelming presence of female skaters has associated the sport with femininity. ${ }^{58}$ As for team sports, at the Olympic level, synchronized swimming is an all-female sport. ${ }^{59}$ Similarly, rhythmic gymnastics, which is both an individual and team sport, only allows women to compete at the Olympics.

Something else that these sports have in common is their use of ballet in choreography. Synchronized swimming was initially known as water ballet, and the term "synchronized swimming" would not be coined until 1934 by Norman Ross ${ }^{60}$ Figure skating choreography similarly mimics ballet, and many successful figure skaters are trained in classical ballet. Rhythmic gymnastics also involves ballet in its choreographic elements. It is this common association with arts such as ballet, an inherently feminine dance form, and music, an art form often associated with dance, that makes society cohesively label these sports as effeminate.

\footnotetext{
${ }^{57}$ Ken McLeod, Stan Hawkins, and Lori Burns, We Are the Champions: The Politics of Sports and Popular Music, (Farnham: Taylor \& Francis Group, 2011), 113.

${ }^{58}$ Ibid. For a more nuanced commentary on athleticism, gender, and sexuality, as well as race, see E. Anderson and M. McCormack, "Intersectionality, Critical Race Theory, and American Sporting Oppression: Examining Black and Gay Male Athletes.," Journal of Homosexuality 57, no. 8 (2010): 949-67. See also Vikki Krane, ed., Sex, Gender, and Sexuality in Sport: Queer Inquiries (London: Taylor \& Francis, 2019).

${ }^{59}$ McLeod et al., We Are the Champions, 113.

${ }^{60}$ Dawn Pawson Bean, Synchronized Swimming: An American History (Jefferson, NC: McFarland \& Co., 2005), 11.
} 


\section{Dance and Choreography}

In figure skating, choreography is most often put together after the music is chosen. The choreography should be crafted around the music once the choreographer, coach, and skater have decided on the theme and/or narrative the skater will portray on ice. Figure skating choreography has traditionally been built on ballet for singles and pair skaters, and ballroom dancing and ballet for ice dancers. As Brenda Dixon Gottschild states in The Black Dancing Body, "European forms of dance serve as the norm, while other forms are seen as 'inferior/auxiliary." ${ }^{61}$ In other words, figure skating's elite history has shaped everything about it, including its taste for classical music, its lack of racial representation, its general exclusion of lower-class athletes who are unable to obtain sponsorships, and, finally, the dance forms that skating choreography is built on.

This exclusion of dance forms outside of the European art music model was evidenced by postcolonial cultural diplomacy in the recently decolonized areas of Africa, Asia, and Latin America. Dance troupes like the Martha Graham Dance Company and the Limón Company toured these countries to spread American identity through dance. ${ }^{62}$ However, this American identity and "freedom" was portrayed most often by majority-white dance groups who State Department officials believed performed it in the "correct" way. ${ }^{63}$ African American dance groups and choreographers were often overlooked and used in the same way that African American jazz musicians were exploited in their contributions to cultural diplomacy. ${ }^{64}$ This

\footnotetext{
${ }^{61}$ Brenda Dixon Gottschild, The Black Dancing Body: A Geography from Coon to Cool, (New York: Palgrave Macmillan, 2003), 19.

${ }^{62}$ Victoria Phillips, Martha Graham's Cold War: The Dance of American Diplomacy (New York: Oxford University Press, 2019); Anne Searcy, Ballet in the Cold War: A Soviet-American Exchange (New York: Oxford University Press, 2020); Clare Croft, Dancers as Diplomats: American Choreography in Cultural Exchange (Oxford: Oxford University Press, 2015), 32.

${ }^{63}$ Croft, Dancers as Diplomats, 33.

${ }^{64}$ Ibid.
} 
hegemonized presentation of dance in the European art style as a symbol of American identity instead of the Black, Hispanic, Asian, and other dance forms prominent in American culture speaks to Gottschild's analysis of non-European dance forms as the "other." Therefore, the limitations placed on the sport of figure skating wherein skaters must create their choreography over a ballet-based skeleton shows the European cultural roots ingrained in the sport's history, as without a solid foundation in ballet, one cannot hope to be a successful figure skater.

\section{Research Models}

The Olympics occurs on an international stage accessible to hundreds of countries across the globe. Similarly, the Eurovision song contest also occurs on an international stage.

Eurovision serves as a great research model for figure skating in the Cold War because like the Olympics, Eurovision focuses on national pride, power, and profit. ${ }^{65}$ Similarly as with the Olympics, Eurovision has historically suppressed the voices of marginalized peoples due to systemic racism on the part of participating nations, as well as within international athletic competitions and sporting organizations. ${ }^{66}$ International Olympic Committee president Avery Brundage's (in office 1952-1972) vision of the Olympics was an international stage that was apolitical, but in international events where countries are competing against one another, it is impossible to be apolitical, and Eurovision is no different. ${ }^{67}$

\footnotetext{
${ }^{65}$ Philip Bohlman, "The Politics of Power, Pleasure and Prayer in the Eurovision Song Contest," Muzikologija, no. 7 (2007): 49. See also Lisanne Wilken, "The Eurovision Song Contest as Cultural Diplomacy during the Cold War: Transmitting Western Attractiveness," in Machines of Persuasion: European Soft Power and Public Diplomacy during the Cold War, edited by Óscar J. Martín García and Rósa Magnúsdóttir (Oldenbourg: De Gruyter, 2019), 171190 .

${ }^{66}$ Bohlman, "The Politics of Power, Pleasure, And Prayer," 64.

${ }^{67}$ Andrea Bohlman and Alexander Rehding, "Doing the European Two-Step" in Empire of Song: Europe and Nation in the Eurovision Song Contest, ed. Dafni Tragaki (Lanham: Scarecrow Press, 2013), 246.
} 
Much like Brundage's Olympic vision, the European Broadcasting Union has historically strived for a culture of apoliticism and global celebration in the Eurovision Song Contest. ${ }^{68}$ As Harvard International Review writer David Montoya argues, “The growing politicization of Eurovision demonstrates that, despite the attempts of the EBU to maintain a nonpolitical competition, the song contest exists within a unique political context that determines international perspectives." ${ }^{69}$ As Eurovision receives increasingly politicized musical entries, such as Ukraine's 2016 entry "1944” by Jamala, it follows the same path as the Olympics, where marginalized groups use their international platform to garner awareness of injustices in their countries. ${ }^{70}$ If we perceive international competitions and sports, such as Eurovision and Olympic figure skating, as social constructs where invisible barriers suppress the agency of marginalized groups and amplify the voices of those privileged enough to promote political neutrality, then it is easy to imagine that music trends also follow this pattern.

\section{Identity}

In discussing politics at the Olympics, it is crucial to place identity at the center of such discussions. The literature of this section consists of books and articles on race, class, gender, and sexuality, and they are generally intersectional in nature. ${ }^{71}$ Many of these sources analyze the significance of identity to sports, the media, and history, especially within the United States.

\footnotetext{
${ }^{68}$ Daniel Montoya, “The Eurovision Song Contest: Singing for the Political Upper Hand," Harvard International Review 38, no. 4 (2017): 7-10.

${ }^{69}$ Ibid., 9.

${ }^{70}$ Ibid.

${ }^{71}$ Meaning that the content of these subsections might overlap. Books about race might also address gender, class, and sexuality, etc.
} 
Most of the consulted sources which discuss race in the United States build their foundation on W.E.B Du Bois' seminal The Souls of Black Folk, which uncovers truths about the unequal treatment of Black people in society, specifically in a re-segregating educational system, during the early twentieth-century. He shows that although slavery was abolished in American society, the institutions of racism were (and still are) alive and well and actively prevent people of color from achieving the same opportunities as white people. Some of the literature consulted for this project that builds on Du Bois' work include Khalil Gibran Muhammad's The Condemnation of Blackness: Race, Crime, and the Making of Modern Urban America, Carol Anderson's White Rage: The Unspoken Truth of Our Racial Divide, The Possessive Investment in Whiteness by George Lipsitz, Seeing Race Again: Countering Colorblindness Across the Disciplines, edited by Kimberlè Crenshaw, and From Black Power to Hip Hop: Racism, Nationalism, and Feminism by Patricia Hill Collins. Other sources, such as Media \& Minorities: The Politics of Race in News and Entertainment by Stephanie Greco Larson look at race in American media and how people of color are portrayed in comparison to white people, while sources on the politics of Black hair, such as Ingrid Banks' Hair matters: beauty, power, and Black women's consciousness, show insight into why mainstream images of beauty favor white standards.

Sources consulted for this project that focus on race, gender, and sexuality focus on sports and athleticism, and the media. For example, a chapter in bell hooks' Black Looks: Race and Representation entitled "The Oppositional Gaze: Black Female Spectators" examines Black women's spectatorship in the media, specifically in Hollywood films. Another example is Patricia Collins' Black Sexual Politics: African Americans, Gender, and the New Racism, which discusses Black sexuality in relationship to gender. Out of bounds: Racism and the Black athlete 
by Lori Latrice Martin focuses on Black athleticism and gender, which is particularly pertinent to the discussion of Debi Thomas' Carmen program in chapter four of this thesis.

Finally, a discussion of class features most heavily in chapter two when discussing Peggy Fleming and American exceptionalism. Two of the main sources consulted on class include Facing Social Class: How Societal Rank Influences Interaction by Susan T. Fiske, Hazel Rose Markus, and Hazel Rose Markus, and Stanley Aronowitz's How Class Works: Power and Social Movement. Aronowitz's work discusses class in both the U.S. and other countries outside of it that are aligning themselves with capitalism while Facing Social Class focuses on the myth of a link between American exceptionalism and social mobility in the United States. Overall, both works posit that as much as Americans like to believe they live in a classless society, class factors into every aspect of American (and capitalist) society.

\section{Chapter Outline}

This thesis is organized into five separate chapters, the first of which presently serves as an introduction with background information and a scholarly literature review on music, the Olympics, the Cold War, and figure skating. The three central chapters present a background on the historical context and the political and social developments surrounding the Winter Olympic Games under study in that chapter, then turn to focused case studies of Olympic skating routines that used music of significant historical or cultural importance to a particular nation.

Chapter Two discusses figure skating at the 1968 Winter Olympics, featuring analyses of programs by U.S. figure skater Peggy Fleming of the ladies' singles division, and pairs skaters Ludmila Belousova and Oleg Protopopov of the Soviet Union. Heavily influenced by current events, especially those of their home countries, both programs contain art music that not only 
personally resonated with the skaters, but that functioned as an emblem of pride and perseverance for their countries during times of hardship.

Chapter Three examines figure skating at the 1976 Olympics, specifically John Curry of Great Britain, and Irina Rodnina and Alexander Zaitsev of the Soviet Union. Each program employs a style of Russian music, with Curry using ballet music and Rodnina and Zaitsev using traditional folk, or Eastern-influenced, music that was adopted for ballet. An exploration of gender aids the analysis of these programs, as Curry's program was associated with Western ballet, dance, and the feminine, while Rodnina and Zaitsev had a strong, masculine style that was complimented by their use of folk-art music. Together, these programs show a growing schism between Western and Eastern skating styles and musical choices during Cold War détente.

Chapter Four looks at the 1988 Olympics and the popular use of music from Bizet's Carmen in figure skating programs during the 1987-88 season. As the end of the Cold War drew near, figure skating became less about country alignment and more about how each skater held up individually against a competitive pool of athletes. After exploring the history of Carmen and its relevance in popular culture, I examine closely the long programs of ladies' skaters Katarina Witt of the German Democratic Republic (G.D.R.) and Debi Thomas of the U.S.A., with light analysis of Soviet pairs' skaters Ekaterina Gordeeva and Sergei Grinkov's (U.S.S.R.) short program, which also uses the music of Carmen. Ultimately, this chapter investigates several concurrent approaches in skating to Carmen and explores how race and gender complicate these approaches.

Finally, Chapter Five offers conclusions and insight into the current state of figure skating and music. It explores how musical choices of the past have shaped the musical choices 
of current Olympic figure skaters. This section also discusses figure skating's future and potential changes that could occur within the next decade. 


\section{Chapter 2}

\section{"A Generation of Style on Ice": The History and Politics of Peggy Fleming's and the Protopopov's 1968 Winter Olympic Figure Skating Programs}

This chapter presents the 1968 Winter Olympics through the lens of the Cold War. Examining musical and political elements within the figure skating programs of Olympic gold medalists from the U.S. and U.S.S.R., I will show that figure skaters often used, and were expected to use, art music for their programs. The win by Peggy Fleming (born 1948) for the ladies' singles event and the win by Ludmila Belousova (1935-2017) and Oleg Protopopov (born 1932) in the pairs' event distinguish how, although using art music was the expectation, selections could still be chosen within the genre to represent a figure skater's tastes and country of origin, while also complementing their figure skating style. This chapter begins with the political context of the Cold War leading up to 1968 before proceeding to the events surrounding the 1968 Winter Games, then examines closely the music and routines of Fleming and Belousova/Protopopov.

\section{The Cold War in 1968}

1968 was one of the more intense years of the Cold War for the United States and the Soviet Union. However, this was not due solely to increasing tension among the superpowers. Although John F. Kennedy (in office 1961-63) had been more involved with U.S. international policy during the early 1960s, including the Bay of Pigs invasion, the increasing American role in the Vietnam War, and the Cuban Missile Crisis, Lyndon Johnson (in office 1963-69) instead took a more reserved approach to the war, focusing on domestic policy issues during these 
years. ${ }^{1}$ Leonid Brehznev had a similar but less reserved approach in the Soviet Union by quelling the Czechian Prague Spring uprisings in their attempts to challenge the Soviet status quo.

Despite a change of tactics on the part of Johnson and Brehznev during this period compared to their predecessors, the Olympics continued to function as an international battleground for the West and the Eastern Bloc. ${ }^{2}$ Decisions to focus on domestic policy seeped into the international sporting event as racial tensions and political prejudice caused conflict both at home and within the Games.

\section{The 1968 Winter Olympics}

The tenth Winter Olympic games were held in Grenoble, France in 1968 at Opening Stadium. It was the first Olympics broadcast in color and also the first of which $\mathrm{ABC}$ broadcasted extensive coverage in the United States. ${ }^{3}$ As explained by Edelmann, Hilbrenner, and Brownell in The Oxford Handbook of the History of Communism, "Sport was... a battlefield in the Cold War, where everybody could take part through the mass media and gossip." ${ }^{4}$ In other

\footnotetext{
${ }^{1}$ Erin Elizabeth Redihan, "Winning Hearts and Medals," 326. See also Redihan, The Olympics and the Cold War. On the state of international relations between the U.S. and U.S.S.R. in the late 1960s, see John Lewis Gaddis, The Cold War: A New History (London: Penguin, 2005); Ralph B. Levering, The Cold War: A Post-Cold War History, $3^{\text {rd }}$ ed. (Chichester: Wiley \& Sons, 2016); Jussi Hanhimäki and Off Arne Westad, eds., The Cold War: A History in Documents and Eyewitness Accounts (Oxford: Oxford University Press, 2004).

${ }^{2}$ Thomas B. Hunt, "Sport and American Foreign Policy during the 1960s," in Defending the American Way of Life: Sport, Culture, and the Cold War, edited by Toby C. Rider and Kevin B. Witherspoon (Fayetteville: University of Arkansas Press, 2018), 189-204; Cesar R. Torres and Mark Dyreson, "The Cold War Games," in Global Olympics: Historical and Sociological Studies of the Modern Games, edited by Kevin Young and Kevin B. Wamsley (Bingley: Emerald, 2005), 59-82.

3 Olympic, The Full Grenoble 1968 Winter Olympic Film | Olympic History, February 25, 2015, https://www.youtube.com/watch?v=PnwAYJWygYY; contains color footage of highlights of the game, such as the gold medal-winning figure skating programs. See Stephen R. Wenn, "Growing Pains: The Olympic Movement and Television, 1966-1972," Olympika 4 (1995), 1-22.

${ }^{4}$ Robert Edelman, Anke Hilbrenner, and Susan Brownell, "Sport Under Communism," in The Oxford Handbook of the History of Communism (Oxford: Oxford University Press, 2014).
} 
words, since ABC had exclusive rights to the Olympics up until 1988, it often focused its coverage on sports that the US excelled in and told only the stories and narratives that it wanted to tell. ${ }^{5}$ These stories showcased tales of East vs. West and, more often than not, coverage was male-dominated. ${ }^{6}$

Sex and drug testing were also implemented at this Olympics. Drug testing was understandably done to prevent illegal doping practices. ${ }^{7}$ Sex testing, however, was performed as a Western hetero-feminine gatekeeping tactic. ${ }^{8}$ I refer to this as a gatekeeping tactic because the test was only performed on female athletes, which undermined the athleticism of women participating in the games and also reinforced sports as a male-dominated domain. ${ }^{9}$ Likewise, it also perpetuated the idea of "masculine advantage" in sports which refers to inherent, gendered advantage in favor of males. ${ }^{10}$ Meanwhile, those who otherwise had physiological advantages in their respective sports were not subject to any kind of tests that potentially barred them from

\footnotetext{
${ }^{5}$ Andrew C. Billings, Olympic Media, 40-41. On this pattern of coverage in more recent decades, see Bettina Fabos, "Forcing the Fairytale: Narrative Strategies in Figure Skating Competition Coverage," Sport in Society 4, no. 2 (Summer 2001): 185-212.

${ }^{6}$ Raymond Boyle and Richard Haynes, Power Play: Sport, the Media and Popular Culture (Cambridge: Cambridge University Press, 2013), 125. On the media, culture, and Cold War during the previous decade, see Greg Barnhisel, "American Modernism in American Broadcasting: The Voice of (Middlebrow) America," in Cold War Modernists: Art, Literature, and American Cultural Diplomacy (New York: Columbia University Press, 2015), 217-248.

${ }^{7}$ John T. Gleaves and Matthew P. Llewellyn, "The 'Big Arms' Race: Doping and the Cold War Defense of American Exceptionalism," in Defending the American Way of Life, 49-66; Thomas M. Hunt, Drug Games: The International Olympic Committee and the Politics of Doping, 1960-2008 (Austin: University of Texas Press, 2011).

${ }^{8}$ Lindsay Parks Pieper, “'Wolves in Skirts?': Sex Testing in Cold War Women's Sport,” in Defending the American Way of Life, 85-98.

9 Lindsay Parks Pieper, "Policing Womanhood: The International Olympic Committee, Sex Testing and the Maintenance of Hetero-Femininity in Sport" (Ph.D. diss., The Ohio State University, 2013), 13.

${ }^{10}$ Ibid.
} 
competition. ${ }^{11}$ Eastern European women were especially susceptible to scrutinization and/or unfair dismissal from competition because of concerns about fair play after discovered cases of athletes using anabolic steroids. ${ }^{12}$ Even though they were racially white, their appearances often fell outside of traditional Western hetero-feminine ideals and thus often led to accusations of doping or hiding their biological sex.

Next, both the 1968 Summer and Winter Olympics were extremely racially charged. First, the International Olympic Committee disallowed South Africa to compete in either of the 1968 Olympics because of its refusal to allow non-white athletes to compete under Apartheid law. ${ }^{13}$ Regardless of the implementation of the 1964 Civil Rights Act, the United States supported South Africa, while the Soviet Union did not. ${ }^{14}$ Then, these racial tensions escalated at the 1968 Summer Olympics in Mexico City, where Americans Tommie Smith and John Carlos, after winning gold and bronze medals for the men's 200-meter race, gave Black Power salutes during the playing of The Star-Spangled Banner. ${ }^{15}$ The United States' treatment of racial justice became a "benchmark" during the Cold War by which the Soviet Union and the world assessed the United States' status as a world leader. ${ }^{16}$

\footnotetext{
${ }^{11}$ For example, Olympic swimmer Michael Phelps was "built to swim" because of his body composition (long arms, short legs, double-joined ankles, etc.) but was never subject to tests or barred from competition for these physiological advantages. See Pieper, "Policing Womanhood," 12.

${ }^{12}$ Ibid., 21.

${ }^{13}$ Redihan, "Winning Hearts and Medals," 345. See also Amy Bass, Not the Triumph But the Struggle: The 1968 Olympics and the Making of the Black Athlete (Minneapolis: University of Minnesota Press, 2002).

${ }^{14}$ Redihan, "Winning Hearts and Medals," 342-344.

${ }^{15}$ Ibid., 323-324.

${ }^{16}$ Lisa E. Davenport, Jazz Diplomacy Promoting America in the Cold War Era (Jackson: University Press of Mississippi, 2009), 6. See also Mary Dudziak, Cold War Civil Rights: Race and the Image of American Democracy (Princeton: Princeton University Press, 2001).
} 
Finally, while the United States and the Soviet Union were still competitive rivals during the mid-1950s to the late-1960s, they calmed their respective anti-communist and anti-capitalist agendas in order to focus on domestic policy. Despite this period of competitive coexistence, the media coverage of the Olympics showcased political prejudice and preference for Western athletes over Eastern ones. In other words, the Olympics functioned as a way for Western powers to limit the influence of Eastern powers without escalating tensions and starting a physical war. These limitations and political biases were seen not only in the aforementioned discriminatory sex testing practices, but also with visa issues faced by Eastern Bloc athletes.

For context, at the 1960 Winter Olympics, issues arose regarding East German visas because of the West's refusal to acknowledge the German Democratic Republic (GDR), which was part of the Communist bloc. Many believed that the United States should have been sanctioned for their failure to adequately supply the East Germans with visas as the West Germans received their visas with no problem, but International Olympic Committee president Avery Brundage's fear of political retaliation prevented any action against the American government. ${ }^{17}$ The G.D.R. was eventually acknowledged for the 1968 Olympics and both East and West Germany sent separate teams rather than a unified one. ${ }^{18}$ However, only Eastern athletes continued to face visa issues. Regardless of the American and Soviet governments' attempts to focus on domestic policies and reduce their international politics, their respective spheres of influence led to negative politics throughout the 1968 Olympics.

\footnotetext{
${ }^{17}$ Redihan, "Winning Hearts," 268

${ }^{18}$ For more on this, see Evelyn Mertin, "Steadfast Friendship and Brotherly Help: The Distinctive Soviet-East German Sport Relationship with the Socialist Bloc," in Diplomatic Games: Sport, Statecraft, and International Relations Since 1945, edited by Evelyn Mertin and Andrew L. Johns (Lexington, University Press of Kentucky, 2014), 53-84.
} 


\section{The Case of Peggy Fleming}

Seven years before the Games at Grenoble, on the night of February 14, 1961, the U.S. figure skating team posed for a picture on the steps of a Sabena Airlines jet (Fig. 1). They would then board the plane for Sabena Airlines Flight 548 to Brussels, Belgium for the World Figure Skating Championships in Prague. However, they would not make it. The following morning, the world of figure skating changed forever when the plane failed to land and crashed near Zaventem Airport, killing all 72 people aboard, including the 18-member U.S. figure skating team and its delegation. ${ }^{19}$

Immediately following the tragedy, the International Skating Union cancelled the 1961 World Championships to honor the U.S. figure skating team. In the weeks and months following the incident, young U.S. figure skaters were thrust prematurely into the limelight. Bereft of American coaches due to their untimely deaths, the United States turned to coaches overseas to train the young figure skaters and prime them for competition. Among these young skaters was 12-year-old Peggy Fleming. ${ }^{20}$

\footnotetext{
${ }^{19}$ Nikki Nichols, Frozen in Time: The Enduring Legacy of the 1961 U.S. Figure Skating Team (Cincinnati: Clerisy Press, 2008); Bonnie D. Ford, "OTL: An Enduring Legacy for Ice Skating," ESPN.Com (blog), http://www.espn.com/espn/eticket/story?page=110215/skatingcrash.

${ }^{20}$ Bonnie D. Ford, “OTL: An Enduring Legacy for Ice Skating."
} 
Figure 1. The 1961 U.S. Figure Skating team stands on the steps of a Sabena Airlines jet headed for the World Figure Skating Championships in Prague.

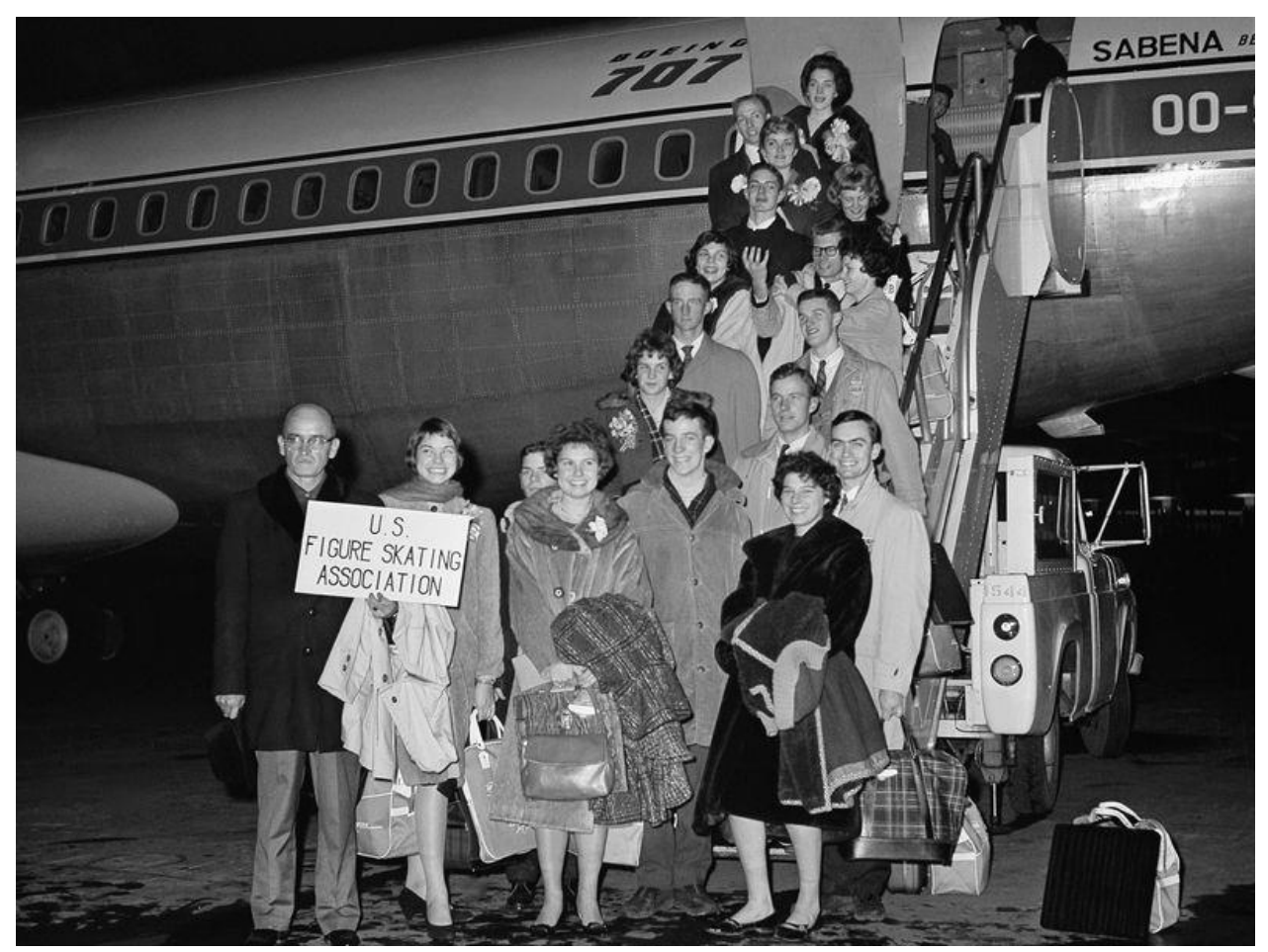

A memorial fund was created in honor of the 1961 U.S. figure skating team, and it was this fund that would allow skaters like Fleming and fellow teammate Scott Allen to continue skating despite financial hardship. ${ }^{21}$ Allen went on to win the U.S. a bronze medal at the 1964 Olympics in Innsbruck at the young age of fourteen, but it was Fleming who would arguably launch figure skating's modern era. ${ }^{22}$ Fleming won a national championship in 1964 and placed sixth at the 1964 Olympics in Innsbruck, and from 1964-1968, she won five consecutive World Championship titles. However, it was her gold medal winning performance at the 1968 Olympics in Grenoble that cemented her legacy. Fleming brought the American spirit back to American

21 Conor Friedersdorf, "Peggy Fleming and the 1968 Winter Olympics," The Atlantic, February 7, 2018, https://www.theatlantic.com/entertainment/archive/2018/02/peggy-fleming-and-the-1968-winter-olympics/552635/.

${ }^{22}$ Ibid. 
figure skating that had initially been lost along with the 1961 U.S. figure skating team. Out of tragedy, thus, came triumph.

\section{Music for Fleming's Program}

During the 1967-68 season, Fleming skated to the same program for each competition: the opening of the development section of the first movement of Tchaikovsky's Symphony No. 6 "Pathetique" (1893), "Ebben? che diavol fate?" from Giuseppe Verdi's La Traviata (1853), and excerpts from Samson and Delilah (1877) of Camille Saint-Saëns and La Gazza Ladra (1817) of Gioachino Rossini. Each of these nineteenth-century works has balletic, dance-like elements that work in Fleming's artistic favor. Likewise, each composition is rooted in Western cultural and musical traditions of the Romantic period, including Tchaikovsky's. As shown in the introduction, figure skaters had a higher chance of being successful and well-received if they (and their team) chose music and choreography that aligned with hegemonic, Western values. Consequently, the musical choices for Fleming's program perfectly matched her flowing, balletic skating style.

Tchaikovsky’s Symphony No. 6 in B minor, Op. 74, "Pathetique," was written between February and March of 1893, with further orchestrations written in July and August. ${ }^{23}$ It had its first public performance in October of 1893 in Saint Petersburg by the Russian Musical Society, and it would be the last symphony Tchaikovsky wrote. ${ }^{24} \mathrm{He}$ claimed that he was more proud of it

\footnotetext{
${ }^{23}$ For detailed studies on this symphony, its origins, and its musical features, see Timothy L. Jackson, Tchaikovsky, Symphony no. 6 (Pathètique) (Cambridge: Cambridge University Press, 1999); Marina Ritzarev, Tchaikovsky's Pathètique and Russian Culture (Farnham: Ashgate, 2014).

24 Tchaikovsky Research. "Symphony No. 6," Tchaikovsky-research.net, http://en.tchaikovskyresearch.net/pages/Symphony_No._6.
} 
than any of his other works. ${ }^{25}$ Verdi's La Traviata was similarly written in a short window of time between 1852 and its premiere at the Teatro La Fenice on March 6, 1853 in Venice. ${ }^{26}$ The portion of the score Fleming uses comes from Act I, Scene II, "Ebben che diavol fate?," wherein Violetta gives Alfredo a flower after he confesses his love for her, and she tells him to return after it (the flower) has faded. ${ }^{27}$

Saint-Saëns' opera Samson and Delilah premiered in Weimar at the Grossherzogliches Theater on December 2, 1877. Taken from the biblical story of Samson and Delilah, the libretto is based on chapter sixteen of the Book of Judges. For her program, Fleming uses Delilah's aria, "Mon coeur s'ouvre à ta voix," which is the most well-known piece in the opera. ${ }^{28}$ This aria is a confession of love to Samson, but it is merely a ruse to get him to confess the source of his strength. ${ }^{29}$ Rossini's La Gazza Ladra (“The Thieving Magpie”) premiered in May 1817 at the Teatro alla Scala in Milan. ${ }^{30}$ Fleming uses excerpts from the overture to this opera for the end of her program.

\footnotetext{
25 Ibid.

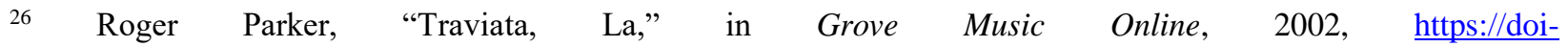
org.www.libproxy.wvu.edu/10.1093/gmo/9781561592630.article.0005794.

${ }^{27}$ Ibid. It is worth noting that the music does not occur in the opera in the version that Fleming used. The opera includes voices and is in another key, and Fleming's music here is an orchestral arrangement, since of course music with singing or lyrics was banned.

28 Hugh Macdonald, "Samson et Dalila," in Grove Music Online, 2002, https://www-oxfordmusiconlinecom.www.libproxy.wvu.edu/grovemusic/view/10.1093/gmo/9781561592630.001.0001/omo-9781561592630-e$\underline{5000904621 .}$

${ }^{29}$ Ibid.

30 Richard Osborne, "Gazza Ladra, La," in Grove Music Online, 2002, https://www-oxfordmusiconlinecom.www.libproxy.wvu.edu/grovemusic/view/10.1093/gmo/9781561592630.001.0001/omo-9781561592630-e$\underline{5000002717 .}$.
} 
In her autobiography, Fleming claims that she knew what was at stake during these Olympics and that Americans needed a hero. ${ }^{31}$ Her decision to use these musical selections during the 1968 season reflects that, because even though none of these works is by an American composer, Fleming's program music still reflects the choices of a bright-eyed, hard-working American. She represented the American dream during a time when Americans were struggling to find their collective identity. It is important to note that Peggy Fleming was the perfect candidate to represent this American construct, as she embodied the ideals of white, heterosexual western femininity with her white skin, her straight, sleek black hair, and her delicate, petite frame. ${ }^{32}$ Likewise, she worked her way up the ranks of an elite sport from a working-class background into the international spotlight, perpetuating the idea of equal opportunity that supersedes class if you work hard enough for it, which is a common trope of American exceptionalism. ${ }^{33}$ In Figure 1, we see what the ambassadors of U.S. figure skating looked like in 1961; all of them were white and fit into hegemonic images of femininity and masculinity. It was assuredly easy for the U.S. Figure Skating Association to justify giving money from the memorial fund to skaters who looked like Peggy Fleming and Scott Allen, as there were no political implications involved. Had a Black or brown skater from a similar class background attempted Peggy's feat during such a racially turbulent time in America's history, they would have had to play by a different rulebook. ${ }^{34}$

\footnotetext{
31 This is discussed in more detail later in this chapter.

${ }^{32}$ For details about white western femininity and hegemony in this sport, see chapter four of this thesis.

${ }^{33}$ For more on American exceptionalism, see Godfrey Hodgson, The Myth of American Exceptionalism (Yale University Press, 2009). For more on class and social mobility in America, see Stanley Aronowitz, How Class Works: Power and Social Movement (New Haven, Connecticut: Yale University Press, 2004). See also Susan T. Fiske and Hazel Rose Markus, Facing Social Class: How Societal Rank Influences Interaction (New York: Russell Sage Foundation, 2012).

${ }^{34}$ See chapter four of this thesis for examples of what this rulebook looks like.
} 
In Fleming's Olympic program, wherein she won the only gold medal for the United States at the 1968 Winter Olympics, these musical selections became part of her routine and, subsequently, her legacy. The physicality, music, and choreography merged with Fleming's own sense of identity and her story. To many, this program was a beacon of hope during challenging times. In a 1968 TV special featuring Fleming, she said, "The feeling that I had when I won the Olympics was a feeling so proud and just wanting to belong to the country, and it's the most wonderful feeling anyone could ever have." 35

\section{Fleming's Program}

The footage used for the following analysis of Peggy Fleming's 1968 Olympic figure skating program is available on YouTube. ${ }^{36}$ The description of this program corresponds to the chart in Appendix A, which presents the video timings, musical descriptions with score references, and figure skating techniques used in the program.

Fleming starts her 1968 Olympic program in a third-position ballet stance. Her right foot is positioned in front of her left, and her right arm is outstretched in front of her while her left arm is stretched out to the side. A moment of silence follows before the starting bell rings and she leaps out of her starting pose with a hop to the right of the rink. This leap-and-hop combination chord occurs as the first chord of the Allegro Vivo section of Tchaikovsky's Symphony No. 6 sounds. She is off to a strong, spirited start.

\footnotetext{
35 GoldenAgeofFS, Here's Peggy Fleming (1968) TV Special, YouTube video, July 1, 2015, https://www.youtube.com/watch?v=xnyVYYFfMmk.

36 gem7ini, Peggy Fleming - 1968 Olympics - FS, YouTube video, May 12, 2012, https://www.youtube.com/watch?v=cEeKHqFUTqo. Given the serious challenges and prohibitive costs of accessing Olympic figure skating footage from Olympic archives or sports media archives, YouTube proved to be the most effective means for securing footage for these Games for detailed study. Further research with grant support would surely lead to fruitful discoveries in those archives.
} 
As a quick, upward motion of notes sounds with an abrupt crescendo, Fleming performs a double jump that lands precisely at the beginning of the crescendo. The timing of the jump insinuates that Fleming wanted to emphasize this string of notes just as much as the composer did with this dynamic change here. The passage sounds again just seconds later, but the melody is raised a half-step, while the bass is descending. Fleming once again performs a jump, but this time she lifts off during the crescendo and delays the jump briefly. Her leg kicks out into a leap and then she performs a single jump of one full revolution. As she rotates out of her spin and lands, a loud triplet plays that rings out in the trumpets. Immediately, Fleming has showcased her strength and dominance in the sport by timing her jumps around dramatic moments in the music.

Next, Fleming performs a series of rotational spins across the ice. The strings build tension in an ascending sequence, and Fleming uses the tension from the strings to build anticipation into her next jump. It is a single jump that lands a beat before the strings reach their melodic, harmonic, and metric goal. In the video of her Olympic performance, the audience applauds many of the moments when Fleming sticks a landing. Once again, Fleming has used an impactful part of the music to highlight her technique.

The musical tension begins building once more as the strings ascend in stepwise motion. Instead of waiting for the tension to release, this time Fleming preps her first jump at the start of the tension and performs two single jumps in quick succession right in the middle of the growing tension. Fleming preps her next jump as the music changes to a more fierce, urgent, string-driven sound. She lifts off from the ice as soon as the timpani comes in (a quarter measure before the horns), and she hits the high point of her jump as soon as the trumpets and oboe begin to blare.

There is a melodic sequence as Fleming moves across the ice in an S-shaped (serpentine) motion, kicking one leg up so that she can change from a forward motion to a backwards motion. 
This backwards motion helps her prep her next jump. The trumpet and oboe melody from the previous passage repeat once more, but this time the line descends and arrives at a forceful cadence. Fleming performs a single jump on the fourth note that descends in the passage. ${ }^{37}$

As Fleming changes direction and moves backwards on the ice after her jump, the music changes to "Ebben? che diavol fate?" from Verdi's La Traviata. This music begins as a strong forte chord followed by a dynamic change to piano with a descending stepwise motion. The rest of the motion contains a descending pattern, which includes arpeggiation as well as scalar motion, while the auxiliary notes are chord members and not escape tones. This repeats twice more in this passage. Fleming does each of three technical elements on the escape tone portions of this repeating passage. First, she performs a single jump on the first set of escape tones. Then, as she glides backwards out of the jump, she leaps into the air and clicks her heels on the second set of escape tones. Finally, she glides backwards out of the leap and into the next single jump.

The same musical passage repeats again. As she rotates out of the previous jump, Fleming performs a flying camel spin that starts on the first set of escape tones and morphs into a one-foot spin on the third strong chord of the passage. Then, Fleming uses the next set of pulsing quarter notes and subsequent rests to accent a series of glides on the ice. The glides go in time to the music and it almost seems as if the music pushes her across the ice. In the final measures of the section she uses from "Ebben che diavol fate," she performs a single jump.

After a brief pause, the music changes to "Mon coeur s'ouvre à ta voix" from Act II, Scene 3 of Saint-Saëns's Samson et Dalila. Fleming's technique shifts to a purely balletic style with the change of music. The music for this section opens with a slow harp introduction, leading

\footnotetext{
${ }^{37}$ This is supposed to be a double axel, as performed at the 1968 U.S. Figure Skating Championships. She probably modified her jumps because she was so far ahead in the compulsory figures; GoldenAgeofFS, Peggy Fleming - 1968 U.S. Figure Skating Championships - Long Program, YouTube video, November 22, 2014, https://www.youtube.com/watch?v=qxnWoQq9iMY\&t=100s.
} 
into slow, impassioned music with a dramatic descending melody in the strings, wherein Fleming performs fluid, balletic step sequences across the ice. Fleming makes great use of her arms here, highlighting her dreamy, balletic movements. The same musical passage repeats again and, as it does, Fleming performs a camel spin into an attitude spin, during which Fleming brings her right leg inward, making her spin resemble a pirouette.

After this spin, she performs more balletic step sequences across the ice. In the music, long-held harmonies in the strings build tension ascending to higher pitches before the music climaxes in a rich moment of sentimentality. As Fleming prepares for this climax, which is ultimately the climax of her entire program, she inserts a single jump beautifully between two outside spread eagles. In the aftermath of the musical climax, the strings begin to descend. At this moment, Fleming does not let the crowd down, turning to her strength in this competition: an outside-inside spread-eagle combination, a crowd favorite immediately following the most intense portion of her program.

Fleming then performs a layback spin as the music transitions to the middle section of the overture to Rossini's La gazza ladra. This musical selection begins with bubbly, dancing winds, followed by descending notes, each repeated, that give a sense of spinning or dancing. Fleming capitalizes on the swirling motion in the music by doing three ice-pirouettes on her toe picks, picking each foot up while spinning and landing it on the ice after each rotation. The consequent phrase is played immediately after, but Fleming does four ice-pirouettes this time instead of three.

Following the ice-pirouettes, high winds take the melody and play two measures of triplets. During this, Fleming performs a sit spin into a scratch spin. She times every element of this spin with the music. When the oboe and flute start playing, she crouches for the sit spin. She 
starts to rise just as the winds cadence, but when the two-measure unit returns, she resumes a half-crouching sit spin position. At the beginning of the four-measure unit in the winds, which begins with two measures of triplets (or the continuation and the cadential idea of a period), she lifts herself up, puts both feet on the ice, and performs a scratch spin.

After she finishes this spin, the music jumps ahead 72 measures in the score to grandiose orchestral music of this lively Rossini overture, featuring loud timpani, cymbals, strings, brass, and winds. In this long sequence of leaps, steps, and jumps, in each of her eight leaps Fleming either lifts off from the ice or lands on it at highly emphasized, grandiose elements of the melody. She hits the beat perfectly and was probably very meticulous about the timing when rehearsing. At the coda, the arpeggios in a combination of instruments dominated by the brass, Fleming ends her program with a fast flying sit spin that transitions into a one-leg spin. The crowd begins applauding after Fleming begins her final spin and continues as she poses and curtsies for them.

\section{Reactions to Fleming's Program}

Fleming's ability to please the crowd with her technical combinations is perhaps what made her one of America's most beloved skaters. Throughout skating history, American skaters have not always been embraced for their ability to win gold, but rather for how well they connect with their audience. In the end, unwavering charisma and embodiment of the American spirit is what has immortalized many figure skaters in the eyes of Americans. ${ }^{38}$ With so many negative

\footnotetext{
${ }^{38}$ A more recent example of this is Nathan Chen, an American skater who was a favorite for the gold in the men's singles event at the 2018 Pyeongchang Olympics. He ultimately failed to medal because of a series of mistakes he made in the short program. He fell to $17^{\text {th }}$ place, which put him out of medal contention. Regardless of his horrible short program, he came into the rink the next day and redeemed himself with an amazing long program where he threw an unprecedented sixth quadruple jump into his program. Considering the amount of exhaustion he must have felt after cleanly completing five other quads, this was an extremely impressive feat to witness. Nathan climbed to third place after this performance and was back in medal contention for a short time. He placed fifth overall after the
} 
events impacting American morale in the late 1960s, Fleming knew that she had to give Americans something to cheer about. In her biography, Fleming reflects on her unique position at this time:

Nineteen sixty-eight was the most intense year of the Vietnam War, the year of the deaths of Martin Luther King and Bobby Kennedy. America was looking for a good-news story. Everyone wanted a little relief from the grim headlines. As a regular American girl from a modest background, I was supposed to be the designated feel-good headline. ${ }^{39}$

She did not disappoint the American public, as newspapers were quick to praise and credit her with launching figure skating's modern era. ${ }^{40}$ American news outlets, advertisements, and television specials rocketed Fleming to superstardom. Fleming continues to be an inspiration for many, and in 1994, Sports Illustrated named her "one of the 40 individuals who most significantly altered or elevated sports in the previous 40 years." 41

Fleming's story improved the reception and interest of figure skating in the United States because she took up the mantle for U.S. figure skating at a time when the future of the sport, and also of America itself, was uncertain. She became a national symbol of American values by persevering in times of hardship and rising above tragedy. ${ }^{42}$ Coaches and fellow athletes that she admired, trained with, and enjoyed the company of died in the 1961 Sabena Airlines plane crash, and Fleming dealt with this significant loss and embraced the pressure of helping rebuild the

completion of the men's program, but regardless of his inability to medal, he won the free skate portion of the competition.

${ }^{39}$ Peggy Fleming and Peter Staminsky, The Long Program: Skating Toward Life's Victories, (New York: Pocket Books, 2000), 63.

${ }^{40}$ Conor Friedersdorf, "Peggy Fleming and the 1968 Winter Olympics." See also Doug Wilson with Jody Cohan, The World Was Our Stage: Spanning the Globe with ABC Sports (CreateSpace, 2013), 45-49.

41 Lisette Hilton, "Fleming Launched Modern Era of Figure Skating," ESPN Classic, http://www.espn.com/classic/biography/s/Fleming_Peggy.html.

${ }^{42}$ For more on the history of triumphal narratives in American efforts at the Olympics, see Mark Dyreson, Crafting Patriotism for Global Dominance: America at the Olympics (London: Routledge, 2009). 
sport on both a national and international level. In the end, she won many of her competitions, including five consecutive U.S. National Championships, three consecutive World Championships, and was the 1968 Ladies' Singles Olympic Champion. Significantly, she was the only athlete to win gold for the United States at this Olympics, bringing rapport back to the sport in America. She took a "staid sport shackled by its inscrutable compulsory figures and arcane scoring system and, with television as her ally, made it marvelously glamorous." ${ }^{23}$

And what of the music that Fleming used in her program? It was all music that she claims to have loved, and music that helped fit her figure skating image. She had the best chances of winning the Olympics by using well-known Western art music that matched her quick jumps and balletic movements. By starting her program with well-known portions of Tchaikovsky's Pathètique to catch the attention of the audience and to demonstrate her strength, and then transitioning into softer, balletic art music that finishes with intense, impressive musical peaks in the Rossini, Fleming created a well-rounded program that played to her strengths and that ultimately won over the judges and the audience.

\section{The Case of Ludmila Belousova and Oleg Protopopov}

While Fleming received praise from American news outlets and boosted figure skating's popularity in the United States, pairs skaters Ludmila Belousova (1935-2017) and Oleg Protopopov (born 1932) of the Soviet Union enjoyed their second gold medal win at the 1968 Winter Olympics. Both Fleming and the pairs duo were lauded for their balletic style, and while both Fleming and the Protopopovs competed in the 1964 and 1968 Winter Olympics, Belousova and Protopopov won gold medals at both events.

\footnotetext{
${ }^{43}$ Lisette Hilton, "Fleming Launched Modern Era of Figure Skating."
} 
Belousova and Protopopov are credited with creating "a romantic style that resembled Russian ballet." ${ }^{44}$ Thus, while Fleming cemented figure skating's legacy in the Americas with her elegant, balletic style, Belousova and Protopopov influenced a new generation of Soviet figure skaters by introducing authentic Bolshoi balletic techniques to the ice, transforming a physical sport into a higher art form in Soviet culture. ${ }^{45}$ An example of their contributions to figure skating choreography include their variations on the death spiral (Fig. 2). While Suzanne Morrow and Wallace Distelmeyer were the first pairs skaters to perform a one-handed death spiral in 1948, Protopopov and Belousova built on this innovation to create the Cosmic Spiral, Life Spiral, and Love Spiral. ${ }^{46}$ The Death Spiral is now a popular, required element in pairs figure skating programs. ${ }^{47}$

During an interview in 2011, Dick Button (1948 and 1952 Olympic Champion in Men's Singles) commented on Belousova and Protopopov's innovative yet conservative skating style: "The Protopopovs were the first to be very different. They had a classical, pure style of skating; they were musical and uniform in their skating together. They are classic, balletic skaters; utter perfection. You don't see skaters like them anymore." 48

\footnotetext{
${ }^{44}$ The Editors of Encylopaedia Britannica, "Oleg Protopopov and Lyudmila Belousov,” Encylopaedia Britannica, https://www.britannica.com/biography/the-Protopopovs.

${ }^{45}$ For more on the place of sport and physical education in Soviet society, see Nikolaus Katzer, Sandra Budy, Alexandra Köhring, and Manfred Zeller, eds., Euphoria and Exhaustion: Modern Sport in Soviet Culture and Society (Frankfurt-on-Main: Campus Verlag, 2010); Mike O'Mahony, Sport in the USSR: Physical Culture-Visual Culture (London: Reaction Books, 2006); James Riordan, Sport in Soviet Society: Development of Sport and Physical Education in Russia and the USSR (Cambridge: Cambridge University Press, 1977); Jonathan Wilson, Behind the Iron Curtain: Travels in Eastern European Football (London, Orion, 2006).

${ }^{46}$ Death Spirals had been performed at past Olympics, but always with two hands and not with the same form seen today. Performed on the backward-inside, forward-inside, and forward-outside edges of the blade, respectively.

47 International Olympic Committee, "Canadian Pair Break Figure Skating's Mould with 'Death Spiral,", Olympic.org, February 7, 1948, https://www.olympic.org/news/canadian-pair-break-figure-skating-s-mould-withdeath-spiral.

${ }^{48}$ Christie Sausa, "Skating: Protopopovs, Dick Button Reunite at Tribute," The Adirondack Almanack, September 6, 2011, https://www.adirondackalmanack.com/2011/09/skating-protopopovs-dick-button-reunite-at-tribute.html.
} 
Figure 2. Oleg Protopopov and Ludmila Belousova perform a death spiral in the 1968 Winter Olympic Games.

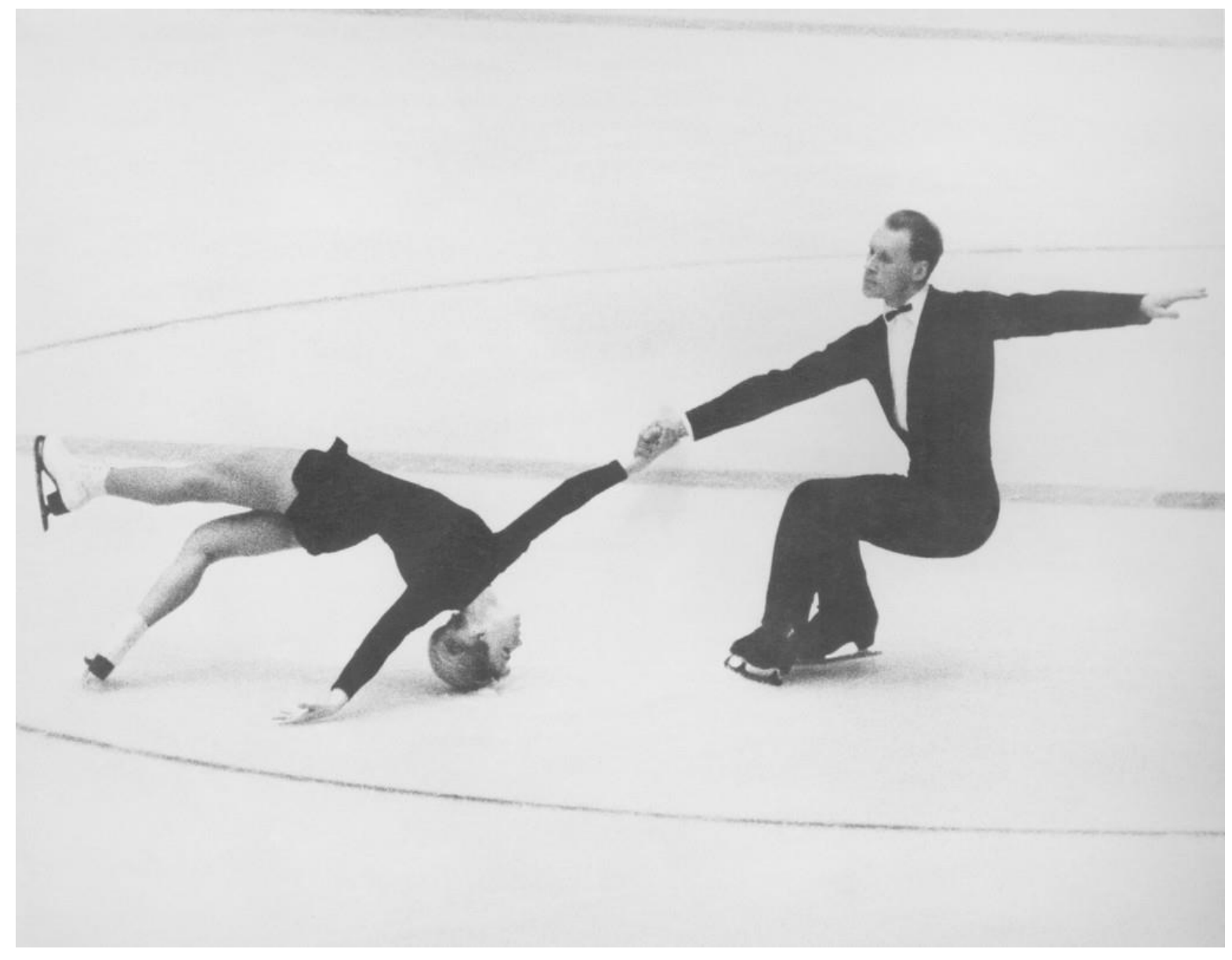

\section{Music for the Protopopovs' Program}

The Protopopovs created an intense and romantic atmosphere in every program they skated to. The 1968 Winter Olympics were no exception. The Protopopov's skating style was "romantic" and "characterized by slow movements," and the musical choices they made usually reflected that. ${ }^{49}$

\footnotetext{
${ }^{49}$ The Editors of Encylopaedia Britannica, "Oleg Protopopov and Lyudmila Belousova," Encylopaedia Britannica, https://www.britannica.com/biography/the-Protopopovs.
} 
For example, their first selection, the Adagio of the Moonlight Sonata, Piano Sonata No. 14 in C\# minor "Quasi una fantasia," by Beethoven, is an excellent choice to start off with not only because of its popularity, but because of its cultural connection to romance and intimacy. It is important to note that the arrangement used in this program is transposed down a semitone to C minor with added strings. This transposition makes for an easy transition to the first movement of Beethoven's Symphony No. 5 in C minor later in the program. The Moonlight Sonata is dedicated to Giulietta Guicciardi, who held Beethoven's romantic interest from 1801-1803 before she ultimately ended up marrying another suitor. ${ }^{50}$ This unrequited love fuels the romantic elements of this piece as interactions between player and listener can actually be interpreted as Beethoven's love for Guicciardi. This romantic meaning is external to the music itself, but is associated with it by those who know the history of the composition.

The use of the piano, a domestic instrument, for this dark, brooding adagio adds to the intimate and bourgeois nature of the piece. ${ }^{51}$ Intimate, because of the domestic atmosphere and proximity between player and listener, and bourgeois because having a piano in one's home during the early eighteenth-century was usually a sign of wealth. ${ }^{52}$ All three of these elements are what Belousova and Protopopov exude in their program: romance, intimacy in regard to closeness, and bourgeois in terms of elegance and class.

The concept of Western art music as music most commonly enjoyed by the bourgeoisie in often elite settings might call into question the Soviet skaters' selection of this music for their figure skating programs, but the musical status quo in the sport required general hegemony

\footnotetext{
${ }^{50}$ Lawrence Kramer, Musical Meaning: Toward a Critical History (Berkeley: University of California Press, 2002), 37.

${ }^{51}$ Ibid., 42.

${ }^{52}$ Ibid.
} 
among figure skating programs. ${ }^{53}$ By including easily recognizable music by Beethoven, who is loved by all, and Soviet ballet music and a Russian piano concerto by Rachmaninoff, which appeals to Soviet audiences in a cultural and emotional way, the Protopopovs used a musical combination that appealed to the widest possible audience while also asserting love and respect for their homeland. This music, especially Beethoven's music, also had other associations in the U.S.S.R., and its popularity in the Soviet/Russian skating community is apparent, as Russian pairs skaters Ekaterina Gordeeva and Sergei Grinkov also skated to a gold medal with Moonlight Sonata in 1994. ${ }^{54}$

\section{The Protopopovs' Program}

The musical timing, description, and choreography of this program appears in tabular form in Appendix B. ${ }^{55}$ As the first arpeggio of Moonlight Sonata plays, Protopopov slowly brings Belousova's arms up over her head and then down towards her shoulder. They push off from the ice and begin skating. After gliding on one foot, Belousova backs up by taking six steps back on her toe picks and then turns forward, taking Protopopov along with her. She then turns backward again as the two extend their arms to display an immense amount of emotion. Protopopov then rotates around her, grabs her gently by the waist and arm, and pulls her around

\footnotetext{
${ }^{53}$ On the place of Western art music, especially the music of Beethoven, in Soviet culture, see Richard Taruskin, Defining Russia Musically (Princeton: Princeton University Press, 2000); Boris Schwarz, Music and Musical Life in Soviet Russia, 1917-1981 (Bloomington: Indiana University Press, 1983).

${ }^{54}$ For more on Beethoven's place in Eastern Bloc political life, see Simon Levin, "Beethoven in Soviet Musicology from 1917 to 1970," in The Beethoven Newsletter, vol. 5, no. 1, 10-18; Frederick W. Skinner, "Lenin and Beethoven: Beyond the 'Appassionata' Affair," in The Beethoven Journal, vol. 18, no. 2, 2003, 62-65; Stefan Romano. "Politicizing Music in Communist Romania: The Personal Memories of a Witness," in The Beethoven Journal, vol. 14, no. 1, 1999, 27-30.

55 Just as with Fleming's program, footage from Belousova and Protopopov's program comes from YouTube: https://www.youtube.com/watch?v=LrL54VzA1T4. This video was last accessible on March 28, 2020.
} 
him in a slow circle on the outside edge of her skate. Belousova is in an arabesque position as she circles around Protopopov.

The interesting thing about the glides is that the change of direction and the push off occur as the arpeggios change from $\mathrm{C} \#$ minor to A major to D major, etc. Belousova prolongs the initial C\# minor arpeggio by taking steps backward, delaying the next glide until the C\# minor arpeggio changes to A major. There is such attention to detail in this program, specifically in regards to how the skating and music work together, in perfect time, to tell a story.

As the piece comes to its first cadence, Belousova and Protopopov come to a stop. Then, as the first sustained note of the melody sounds, they push off from the ice into a forward glide with Belousova leading. The pair perform two more glides along with the previous one in an Sshape motion across the ice as strings harmonize above the piano in the music. They then turn around and perform a similar motion while skating backwards, except the third glide is substituted for regular backward skating across the ice. They continue skating backwards as they perform another serpentine motion across the ice.

Protopopov pivots to face forward and dips Belousova downward, holding her by the waist as the two glide forward. Belousova outstretches one arm toward the ice and another across her chest. The pair separates and they each skate in different directions, rotating once before reuniting in the middle of the ice for a united camel spin. The strings crescendo as Protopopov and Belousova skate across the ice and prep for the lift. It starts to decrescendo as Belousova is lowered to the ground.

Protopopov dips Belousova sideways twice on the inside edge of her right blade. She makes a half-circle motion on the first dip and circles fully around on the second dip. She then does a short camel spin of one revolution. After this short spin, they perform a step sequence 
during the development section of the previous theme. They perform a hand-to-hand lift with a spin of two revolutions while strings decrescendo during this contrasting phrase.

As the Protopopovs glide out of their final step sequence to Moonlight Sonata, they prep for their first jump with arms outstretched. They lift off from the ground as soon as the first note of Beethoven's Symphony No. 5 sounds. They land on the fourth note of the phrase and then repeat the jump again on the second part of the phrase.

As the tension builds in the strings, Belousova and Protopopov skate backwards into a step sequence full of crossovers and quick 360-degree turns. As the first strong chord from the end of the fifth symphony's opening section sounds, they prep their next jump. On the second chord, they rotate once at high speed before jumping and landing on the third chord. As the final chord rings out, Belousova and Protopopov skate forward and prep for a lift. Protopopov lifts Belousova with a hand to hers and the other hand on the small of her back. During this lift, there is complete silence. After the lift is completed and Belousova is lowered to the ice, the opening theme returns. As the theme of four notes plays, Belousova hops out of Protopopov's hold to face forward on the ice.

The two skaters gain speed as they complete a step sequence that covers most of the ice. They skate in a serpentine motion and then do a half loop toward the right side of the ice. Protopopov briefly lifts Belousova to his side as they circle back to the middle of the ice and prep for their next lift. Belousova swings out to Protopopov's right side and he pulls her back in for a hand-to-hand lift right in the middle of a passage full of musical tension.

Curiously, the recording used for the Olympic program is edited to skip the rest of the exposition and moves straight to the coda, highlighting the most recognizable moments of the piece. In doing this, the Protopopovs were better able to connect with their audience and draw 
their interest to the performance, especially considering the widespread popularity of Beethoven's Fifth. Not everyone might have known the exposition, but they would almost certainly recognize the opening and coda. Strategically, Protopopov and Belousova use the first four notes of the coda to prepare for the second part. As the second four-note grouping starts, Protopopov lowers Belousova to the ground for a backward-inside death spiral, otherwise known as the Cosmic Spiral. As Belousova rises from the death spiral position, she extends her left leg outward into a camel position. She glides slowly backward as the music transitions to another musical work, which alas remains unidentified, but the music resembles a work of twentiethcentury Soviet art music, most likely by Shostakovich or Prokofiev.

During the musical transition between Beethoven and the Soviet-style art piece, Protopopov plays with Belousova on the ice as if she is a ballerina doll. He pulls her in, gently pushes her away, slowly spins her around, and does it again. Protopopov and Belousova then perform a dual spiral across the ice that circles directly into the middle of the rink. The music gets climactic in the middle of the impressive spiral to highlight the move and show off its brilliance. Protopopov lets go of Belousova while they are still in the arabesque position and mirrors her, outstretching his arms and then raising them toward the sky as the final chord of the piece sounds.

Protopopov wraps his arms around himself and then swings them out to both sides dramatically when a high note from Rachmaninoff's Piano Concerto No. 3 in D Minor is played loudly and forcefully. He then does a spin on the ice of one revolution as octaves play on either side of the piano, mimicking the circular sounding motion of the music. Belousova skates a circle around Protopopov before he lifts her in the air with one arm around her waist, as if they were dancing. 
Belousova and Protopopov glide forward and turn around for backward crossovers. With both skaters facing backward, Protopopov grabs Belousova by the waist and lifts her up and around in one rotation. She kicks her legs out during the end of the phrase and comes back down to the ice as the next phrase full of whirling octave runs starts. The two skaters mimic the music as they skate into separate camel spins. As they spin, the piano creates a spinning effect with loud, fast octaves that turn into arpeggiate runs.

Protopopov and Belousova appear to dance on ice as they glide across the surface, doing a mix of glides and crossovers. As the strings play an emotional theme, Protopopov lifts Belousova up and over his head in a half-rotation. They continue this dance-like footwork and do yet another lift at the emotional climax of the ending, where the music gets the loudest and the strings get the highest. This is perhaps the most difficult lift in the program, as Protopopov lifts Belousova directly over his head at a nearly 180-degree angle.

The two move their feet in time to the music, performing a step sequence over the ice. As they step out of the previous step sequence, Protopopov spins Belousova over his shoulder so that she is now in front of him. She leads him into forward crossovers and they turn around, prepping for a twist lift with Protopopov facing backwards. By performing a difficult twist lift as the last element of the program, Belousova and Protopopov prove their athletic endurance and cement their place as one of figure skating's finest pair skaters.

\section{Soviet Reactions to the Protopopovs' Program}

From 1961 to 1969 , the Protopopovs medaled in every major competition they competed in. They held four consecutive European and world titles from 1965-1968, not to mention they 
won gold at the 1964 Winter Olympics. ${ }^{56}$ Despite this, the sport was changing rapidly and their classic, "romantic, slow-moving, balletic style" was modeled by young Soviet skaters and infused with new and exciting "demonstrations of power and athleticism." 57 Pairs skaters like Irina Rodnina, Alexei Ulanov, and, later, Alexander Zaitsev were replacing Belousova and Protopopov's elegant and graceful lifts with harder, more athletic ones that often included throws across the ice. ${ }^{58}$

Regardless of the innovations and Bolshoi influences that Belousova and Protopopov brought to the sport of figure skating, Soviet officials soon believed that their style was out of date and that they were too old to continue in the sport. In fact, they were one of the oldest pairs' skaters in Olympic history at 32 and 35 years of age. ${ }^{59}$ The two were barred from competing in the 1972 Winter Olympics in Sapporo, Japan after placing third in the 1969 World Championships. They were encouraged to coach young children instead, which they did for a few years while also performing in professional ice shows. ${ }^{60}$

Ultimately, the pair defected to Switzerland in 1979. However, they said that it was not the politics of the Soviet Union or being banned from amateur competition that led them to do

\footnotetext{
56 Frank Litsky, "Ludmila Belousova, Russian Who Skated With Husband to Olympic Gold, Dies at 81," The New York Times, October 2, 2017, sec. Obituaries, https://www.nytimes.com/2017/10/02/obituaries/ludmila-belousovadead-champion-russian-figure-skater-with-husband-protopopov.html.

57 Ibid.

${ }^{58}$ We will see this with Irina Rodnina and Alexander Zaitsev in the following chapter. On this trend of fading careers, see Jim Riordan, "The Rise and Fall of Soviet Olympic Champions," Olympika 2 (1993), 25-44.

${ }^{59}$ Frank Litsky, "Ludmila Belousova, Russian Who Skated With Husband to Olympic Gold, Dies at 81."

60 Bradley Graham, "Soviet Skaters Defect," Washington Post, September 25, 1979, https:/www.washingtonpost.com/archive/politics/1979/09/25/soviet-skaters-defect/0d2f2711-c9c9-4ace-a2acc8067a6b91a8/.
} 
so, but rather the size of the ice rinks they skated in. ${ }^{61}$ There apparently wasn't enough space for them to be creative in the way that they wanted to on the ice. In a 1980 interview, Oleg Protopopov explained:

Sometimes the reporters wanted to show that some artists in the Soviet Union had no artistic freedom. I wanted to stress on this point, we had artistic freedom. We had it. We had opportunity to perform any kind of numbers because this is our creative work. But... the problem was that we had no opportunity to realize, uh [...] I will explain you [...] For instance, you are a conductor. Or you are a pianst [sic]. For instance, Van Cliburn. And you say to him, 'you can play Tchaikovsky, you can play Beethoven, you can play any composer you want. As you like. But you see, unfortunately, we have only half a piano. If you can do it, have your artistic freedom.' In the same position was our art. ${ }^{62}$

The Protopopov's exit from the Soviet Union came at the same time as other well-known Soviet stars were defecting from the country. For example, Bolshoi ballet stars like Alexander Godunov, Ludmilla Vlasova, Leonid Koslov, and Valentina Koslov were defecting while on tours of the United States. ${ }^{63}$ Likewise, before the pair even started their 1979 Swiss tour, they had brought all of their belongings from the Soviet Union and were prepared to move there. Whether the pair left for political reasons or otherwise, their country stopped them from skating competitively in the middle of their prime. However, the impact their skating style has had on young skaters like Janet Lynn and John Curry is immeasurable. ${ }^{64}$ Dick Button claimed that the Protopopovs started "a generation of style on ice." 65

\footnotetext{
${ }^{61}$ Bradley Graham, "Soviet Skaters Defect”; Lewis Grossberger, "The Protopopovs," Washington Post, February 5, 1980, https://www.washingtonpost.com/archive/lifestyle/1980/02/05/the-protopopovs/854f7f52-97c3-4a93-bcedc71d77fc274e/.

${ }^{62}$ Grossberger, "The Protopopovs."

${ }^{63}$ Bradley Graham, "Soviet Skaters Defect.”

${ }^{64}$ Christie Sausa, "Skating: Protopopovs, Dick Button Reunite at Tribute."

${ }^{65}$ Ibid.
} 


\section{Conclusion}

Both Fleming and the Protopopovs won gold medals at these Olympics with their balletic skating styles, but they came to this international competition under the influence of different domestic political circumstances. Fleming dealt with the tragic fate of the 1961 U.S. Figure Skating team and grew up during some of the most tumultuous moments of the Cold War. Her appearance and ultimate win at these Games made her a beacon of hope for America during the 1968 Winter Olympics as the nation grappled with a series of national tragic events. Meanwhile, Soviet officials would quickly deem the Protopopovs obsolete in their sport after this appearance, because of their age and the promise of younger, up-and-coming talent.

Fleming's figure skating program was set to music that she loved, but that she also knew would work to her stylistic advantage and would be received positively by the Olympic judges, the audience, and her nation. Therefore, these excerpts of recognizable Western art music were an effective approach. Likewise, the Protopopovs turned to familiar strains of Western art music as Fleming did, but their excerpts were also relevant to Soviet and Russian culture. While Beethoven's music appealed to a wider audience outside of the U.S.S.R, it also had a standing political power within the U.S.S.R., and therefore, the Protopopovs were able to broader their program's appeal at home while also choosing music that did not make them stand out negatively among skating officials and judges.

At the height of Cold War tensions, the IOC president Avery Brundage often tried to steer the Olympics away from politics as much as possible, while keeping them in the center of the media coverage. Yet he acknowledged that "it is impossible to divorce international sport 
from international politics. ${ }^{966}$ Situating these two figure skating programs within Cold War politics does not characterize a direct rivalry between Fleming and the Protopopovs, competing in distinct Olympic events, but it does reflect cultural and stylistic differences that will characterize American and Soviet figure skating styles going into the next decade. As a new generation of skaters would take to the ice in the 1970s, we will see in the next chapter that it was at the 1976 Olympics where once again the United States would reign in ladies' singles skating and the Soviet Union would continue to dominate in pairs skating. The emergence of a classic, balletic style in men's skating would occur at this competition, as well.

\footnotetext{
${ }^{66}$ Redihan, The Olympics and the Cold War, 15. For a profile of Brundage's efforts to increase Olympic media coverage and profit, see Stephen Wenn, "Rivals and Revolutionaries: Avery Brundage, the Marquess of Exeter and Olympic Television Revenue," Sport in History 32 (2012): 257-268.
} 


\section{Chapter 3 \\ Dance on Ice: \\ Western Ballet and Russian Folk-Art at the 1976 Winter Olympic Games}

The truly great skater will not be remembered for the number of jumps executed in their programme, but rather for their personality, their originality, the way they move on the ice, the emotion they are able to transmit to the audience and for having set a path in the sport that others will want to follow. These are concepts that make this sport unique and magical. ${ }^{1}$

Anthony Bateman and John Bale's words ring true as today's figure skaters complete more jumps at higher technical difficulties than ever before achieved. While the increasing number of jumps are impressive, it is arguably the character, artistry, and musical interpretation of a skater that reflects back most memorably in the history of the sport. This chapter juxtaposes the 1976 Olympic men's free skate program of the British skater John Curry (1949-1994) with the pairs free skate program of Soviet skaters Irina Rodnina (born 1949) and Alexander Zaitsev (born 1952), demonstrating evidence of a growing schism between Western and Eastern skating styles and musical choices. While Curry used Western-style ballet music and pushed the boundaries of men's figure skating, Rodnina and Zaitsev appealed to their home country by using traditional Russian folk music recorded by the Moiseyev Dance Company. Both programs employed ballet music, but they drew from different styles - the music for Don Quixote was specifically scored for the ballet and the music recorded for the Moiseyev Dance Company borrowed pre-existing music for its choreographic design.

\footnotetext{
${ }^{1}$ Anthony Bateman and John Bale, Sporting Sounds: Relationships between Sport and Music (London: Routledge, 2010), 98 .
} 


\section{Cold War Developments Between 1968 and 1976}

The Cold War in the late 1960s saw both the United States and the Soviet Union retreating to the safe realms of domestic policy, which led to a subsequent reduction in international policy with the onset of détente. Thanks to decolonization efforts in the 1950s, 60s, and 70s, most colonized areas transformed from Westernized nation-states into Westerninfluenced countries dealing with the aftermath of colonization, especially in Africa, where many new independent nations came to power in the $1970 \mathrm{~s}^{2}$ What existed now were postcolonial efforts of decolonized nations to find their identity while entering a rapidly globalizing society.

If the period between the onset of the Cold War and 1970 was a period of re-globalization in the wake of the World Wars, then the 1970s onward were a period of full-fledged globalization and internationalism. ${ }^{3}$ Specifically, non-geopolitical developments, such as the first "Earth Day" in 1970, the 1972 UN environmental conference, the 1972 Palestinian terrorist attacks against Israelis at the Munich Olympics, the 1975 Helsinki Accords, and the United Nations' sponsorship of a series of women's rights conferences beginning in 1975, all showed that "internationalism and globalization proved more enduring than Cold War geopolitics."4

\section{The 1976 Winter Olympics}

The twelfth Winter Olympic games were held in Innsbruck, Austria, in 1976, just twelve years after they were held there for the first time in 1964. These Olympics followed the eleventh Winter Olympics, held in Sapporo, Japan, in 1972, and the 1972 Summer Olympics held in

\footnotetext{
2 Akira Iriye, "Historicizing the Cold War," in The Oxford Handbook of the Cold War, 2013, https://doi.org/10.1093/oxfordhb/9780199236961.013.0002.

${ }^{3}$ Ibid.

${ }^{4}$ Ibid.
} 
Munich, Germany, where the Palestinian terrorist group Black September killed eleven Israeli Olympic athletes and one West German police officer. Although this thesis does not explore either of the 1972 Olympic Games in-depth, this section features important events that occurred before and during these games to aid in framing the history of the 1976 Winter Olympics. ${ }^{5}$

The 1976 Winter Olympics saw the introduction of ice dancing as a medal-contending sport, more than twenty years after it had been added to the World Championships in $1952 .{ }^{6}$ Ice dancing became the fourth discipline added to all major ice-skating competitions, alongside men's and ladies' singles and pairs skating. While innovations in ice dancing go beyond the scope of this thesis, it is important to observe that dance, especially ballroom dance, and ballet are central components to this sport. We will see how John Curry innovated the men's figure skating division with dance, ballet, and theatricality; meanwhile ice dancing, a new Olympic sport, completely normalized these elements from its first appearance at the Olympics. ${ }^{7}$

As Apartheid was still in place in South Africa in 1970 while other countries like the United States passed laws protecting civil rights, the country attempted to regain legitimacy in the global sports arena by hosting its own all-white sports competition. As a result of racist and exclusionary efforts such as these, the country was banned and removed from the Olympics in 1976. ${ }^{8}$ Although the United Nations had issued a sports embargo in South Africa, rugby players

\footnotetext{
${ }^{5}$ The Montreal Olympics witnessed even further profitability for television coverage. On this topic, see Stephen Wenn, “Television Rights and the 1976 Montreal Olympics," Sports Historical Review 27 (1996): 111-138.

${ }^{6}$ Beverley Smith and Dan Diamond, Figure Skating: A Celebration, (Toronto: McClelland \& Stewart, 1999), 29.

${ }^{7}$ For more on the elements of dance in figure skating, see Lynn Copley-Graves, Figure Skating History: The Evolution of Dance on Ice (Columbus, OH: Platoro Press, 1992).

${ }^{8}$ Stephanie Wilson McConnell, "Jimmy Carter, Afghanistan, and the Olympic Boycott: The Last Crisis of the Cold War?,” PhD Diss., (2001), 152.
} 
from New Zealand still toured the country. ${ }^{9}$ African nations thus called for New Zealand's removal from the 1976 Summer Olympic Games, but the IOC ruled that because rugby was not an Olympic sport, there was no reason for the removal. ${ }^{10}$ Just before the Montreal games opened, over twenty African nations withdrew their athletes from competition in retaliation against New Zealand's participation in the Games, even though many were already in Montreal. ${ }^{11}$ This prompted the IOC to bar nations from withdrawing athletes after they already entered them unless there were health concerns. ${ }^{12}$

The 1976 Games were also the first Olympics held under the presidency of Michael Morris, $3^{\text {rd }}$ Baron Killanin. IOC President Avery Brundage had retired following the 1972 Munich Olympics, and Lord Killanin's presidency resulted in the undoing of policies that Brundage personally believed protected the integrity of the Olympics. ${ }^{13}$ One such policy was the disallowing of professional athletes to compete at the Olympics, as Brundage was against the idea of professionals and amateurs playing together. This policy caused much controversy because countries in the Eastern Bloc had different rules of athletic professionalism than Western countries and could stack their teams with players who Western countries deemed "professional." 14

\footnotetext{
${ }_{9}^{9}$ Helen Lenskyj and Stephen Wagg, The Palgrave Handbook of Olympic Studies, (New York: Palgrave Macmillan, 2012), 130, http://public.eblib.com/choice/publicfullrecord.aspx? $\mathrm{p}=1330901$.

${ }^{10}$ Ibid.

${ }^{11}$ Ibid.

${ }^{12}$ Ibid.

${ }^{13}$ Stephen Wenn, "Rivals and Revolutionaries: Avery Brundage, the Marquess of Exeter and Olympic Television Revenue," Sport in History 32 (2012): 257-268.

14 International Ice Hockey Federation, "Story \#17," http://webarchive.iihf.com/iihf-home/the-iihf/100-yearanniversary/100-top-stories/story-17/.
} 
As a result of this double standard, Canada did not compete in ice hockey at the 1972 and 1976 Winter Olympics. They vowed not to compete in Olympic ice hockey until the IOC adopted rules that allowed professional and amateur ice hockey players to play together. ${ }^{15}$ Sweden joined the Canadians on this boycott, as they did not understand the point of sending amateur players to represent the country at the Olympics while countries like the Soviet Union and Czechoslovakia could send their best players.

The 1972 Winter Olympics also saw controversy regarding amateurism, as alpine skiers had received endorsement deals. Karl Schranz, an Austrian who was the most commercialized skier at the time, was banned as an example, but all other skiers accused of taking endorsement deals were not. ${ }^{16}$ Meanwhile, professional athletes from communist countries were not banned or reprimanded at all.

In 1977, the International Ice Hockey Federation (IIHF) eventually adopted rules that allowed professional hockey players from Canada to compete, as they no longer had Brundage around to threaten them with disenfranchisement from the Olympics. ${ }^{17}$ The IOC did away with bans on professional athletes for good in 1986; however, this did not stop national and international sports federations from making their own eligibility requirements for Olympic participation. For instance, although professionalism rules were briefly lifted for the 1993-94 season, the ISU has its own eligibility rules related to professionalism wherein figure skaters who go professional may not compete in amateur competitions such as the Olympics.

\footnotetext{
${ }^{15}$ International Ice Hockey Federation, "Story \#17."

16 “1972 Winter Olympics,” February 11, 2017, https://www.infoplease.com/sports/winter-olympics-throughyears/1972-olympics.

${ }^{17}$ International Ice Hockey Federation, “Story \#17.”
} 
The IOC's handling of the matter of athletes navigating the boundaries of amateurism and professionalism has long been a source of debate, particularly under the leadership of Avery Brundage. One scholar has likened Brundage to a "true Olympic Don Quixote," fighting:

against the windmills of sport commercialization and politicization. Like this hero of the Spanish novel by Cervantes, Brundage was inspired by lofty and chivalrous but impractical ideals. He viewed amateurism and political abstinence as the fundamental Olympic values without which the Olympic Idea was doomed to fail. ${ }^{18}$

While some standards, traditions, and ideals of athletic competition stood strong amid these debates, change more broadly was in the air. As we will see, the skater John Curry's controversial contributions to the sport of figure skating would be warmly welcomed unlike Brundage's ban on professional athletes. While Brundage concerned himself with keeping the Olympics free of politics and professionals, Curry's skating style and public persona would initiate new dialogue about gender norms and heteronormativity in men's skating.

\section{The Case of John Curry}

As a child, John Curry wanted nothing more than to be a dancer. Growing up in England in the 1950s, however, where traditional gender roles dominated social norms, meant that dancing was an unlikely path for him. While Curry's father vehemently forbade his son taking dance lessons, he was not opposed to Curry taking up figure skating, which was more traditionally "masculine" than dance, because it was recognized as a sport and not an art form. ${ }^{19}$ Curry set out to change this notion.

\footnotetext{
${ }^{18}$ Otto Schantz, "The Olympic Ideal and the Winter Games Attitudes Towards the Olympic Winter Games in Olympic Discourses - $\quad$ from Coubertin to https://web.archive.org/web/20130505052232/http://www.coubertin.ch/pdf/schantz.pdf.

19 JohnCurry, The Real John Curry Part 1, YouTube video, February 23, 2010, https://www.youtube.com/watch?v=FBpyePyCpjs; Dennis L. Bird, "Obituary: John Curry," The Independent, April 16, 1994, https://www.independent.co.uk/news/people/obituary-john-curry-1370333.html.
} 
At the young age of six, Curry began skating lessons and by age eight, he had won his first championship. ${ }^{20}$ When Curry was seventeen, he began competing abroad, but money was tight after his father's passing. This motivated Curry to find a sponsor to fund his skating and in the early 1970s, he gained the sponsorship of American Ed Mosler, who also sponsored Peggy Fleming and other U.S. skaters. ${ }^{21}$ After talking with Curry about his circumstances, Mosler offered to help him train in the U.S. but still skate for his home country of Great Britain. ${ }^{22}$

In the early 1970s, Curry moved to the United States to train with Gustave Lussi and Carlo and Christa Fassi. Curry first trained with Lussi to master his jumping technique and then went on to train with the Fassis for the 1975-76 season. By 1975, Curry had been British champion four times (thrice consecutively), placed third in the 1975 World Championships, and placed third and second consecutively at the 1974 and 1975 European Championships. However, in order to truly get his balletic, artistic style of figure skating acknowledged in the men's division, he knew that he would have to win all the upcoming major competitions in the 1975-76 season, including the European Championships, the Olympic Games, and the World Championships.

Before arriving at the training facility in Colorado, Curry had already mapped out an entire free-skating program to Ludwig Minkus' score Don Quixote, which was composed in 1869 for the ballet of the same name. ${ }^{23}$ However, this program was not the result of just one momentary revelation, as Curry had often asserted. Instead, he had been thinking of skating to

\footnotetext{
${ }^{20}$ JohnCurry, The Real John Curry Part 1.

21 Floskate, John Curry - 50 Golden Days Part 3, YouTube video, February 9, 2008, https://www.youtube.com/watch?v=kPXsST9vGFg.

${ }^{22}$ Ibid.

${ }^{23}$ Bill Jones, Alone: The Triumph and Tragedy of John Curry (London, UK: Bloomsbury Sport, 2015$), 121$.
} 
Minkus' score for some time, working out some of the routine during the previous summer. $\mathrm{He}$ took familiar moves and re-sequenced them, editing the Minkus score as needed, and then inserted point-scoring jumps "around the rise and fall of the score." ${ }^{24}$ Training with the Fassis guaranteed that Curry practiced his compulsory figures and performed both his short and long programs consistently until they were flawless. Consequently, Curry did not make any major mistakes in his programs during the 1975-76 season.

In just fifty days between January and March of 1976, Curry swept all three of the most coveted titles in figure skating: the European Championship, the Olympic gold medal, and the World Championship. As evidenced by previous prominent skaters like Peggy Fleming, Oleg Protopopov and Ludmila Belousova, and Janet Lynn, using balletic styles and techniques in figure skating was not new for the sport. For men's figure skating, however, highlighting the artistic over the athletic challenged traditional gender norms that had characterized competitive figure skating since its conception. Curry cemented his balletic style through perfect performances and thereby broke the mold for men's figure skating.

\section{Music for Curry's Program}

For the 1975-76 season, Curry skated to musical excerpts from Sergei Rachmaninoff's solo piano work Rhapsody on a Theme of Paganini (1934) for his short program and from Ludwig Minkus' three-act ballet Don Quixote (1869) for his free skate program. The sections that follow will focus specifically on Curry's free skate program and the music accompanying it. Minkus' score to Don Quixote was composed for the ballet choreographed by Marius Petipa, which draws on the novel Don Quixote de la Mancha (1605-1615) of Miguel de

\footnotetext{
${ }^{24}$ Jones, Alone, 121.
} 
Cervantes; it was first staged by the Imperial Bolshoi Theatre in Moscow in 1869. The ballet received several revivals starting in the 1950s and would have been well-known to many by the mid-1970s. Curry selected music from the final act of the ballet only, where Kitri and Basilio are finally united in marriage and Don Quixote, having successfully brought the two lovers together, sets off with his sidekick Sancho Panza to help others in need. ${ }^{25}$ As Robert Letellier states in his book on Minkus' ballets, "Much of [the] success [of the ballet] was because of the music, which is ablaze with attractive invention, as the world found when entranced by the skating of John Curry." 26 This score is extremely popular, especially the part of the score that Curry chose to skate to, which includes the Pas de Quatre and the infamous Pas de Deux. ${ }^{27}$

In the early 1960s, famous Russian ballet dancer Rudolf Nureyev and ballerina Natalia Makarova defected to the West from the Soviet Union. In an expression of gratitude to their adopted countries, the dancers "sought to transmit their knowledge of the cherished Russian traditions to their adopted countries." 28 This resulted in Nureyev producing Don Quixote in Vienna in 1966, bringing his balletic influence to the West. Not coincidentally, John Curry was often referred to as "Britain's Nureyev on Ice." 29 Tragically, both men would die of AIDS within a year and a half of one another.

\footnotetext{
${ }^{25}$ Robert Ignatius Letellier, The Ballets of Ludwig Minkus (UK: Scholars Publisher, 2008), 265-277.

${ }^{26}$ Letellier, The Ballets of Ludwig Minkus, 167.

27 JohnCurry1, The Real John Curry, Part 3, YouTube video, February 23, 2010, https://www.youtube.com/watch?v=5kGiobYYXoA\&t=7s.

${ }^{28}$ Letellier, The Ballets of Ludwig Minkus, 37.

${ }^{29}$ John Curry1, The Real John Curry, Part 3.
} 


\section{Curry's 1976 Olympic Free Skate Program}

In this program, Curry uses music from Ludwig Minkus'score to the ballet Don Quixote. Interestingly, Curry uses only excerpts from the last fifteen minutes of the ballet. The opening excerpt he uses is from the Pas de Quatre, or dance of four people. At this point in the ballet, there is a celebration for Basilio and Kitri's wedding, and so Kitri's four friends dance to introduce the infamous Pas de Deux, which became so popular that it is often used as a separate showpiece by skilled dancers. ${ }^{30}$ The Pas de Deux is a series of dances performed by Kitri, Basilio, and Mercedes celebrating Kitri and Basilio's marriage, although Curry cuts Variation 1 (L'Amour), the piece that Mercedes dances to, from his program. The description of this program corresponds to the chart in Appendix C, which presents the video timings, musical descriptions with score references, and figure skating techniques used in the program.

Curry starts this program similarly to Fleming's 1968 program, with his arms extended in front of his body (Fig. 1). Instead of being held below the shoulders, though, one is held out to the left slightly behind him and the other is held out in front of him above his head. His right leg is positioned diagonally over his left leg, which allows him to easily rotate out of the position. He then lowers his arms, rotates his head to the left, and quickly jumps out of his pose to do a quick three-step, ballet-inspired move. He lands on his right foot, bends his knees as he steps onto his left foot, and then swings the right foot around behind the left foot with his toepick digging into the ice. He ends up in a fourth-position-ballet-inspired position, complete with his right arm extended vertically above him and his left arm extended horizontally to his left. ${ }^{31}$ Curry

\footnotetext{
${ }^{30}$ Letellier, The Ballets of Ludwig Minkus, 268.

${ }^{31}$ Video timing 0:21-0:27, https://www.youtube.com/watch?v=djadlQLK_ow.
} 
matches the timing of his steps to the beat of the short, descending staccato chords that open up this excerpt.

Figure 3. John Curry, free-skate program, 1976 Winter Olympics, Innsbruck, Austria. Curry here poses with arms outstretched for the beginning of his program.

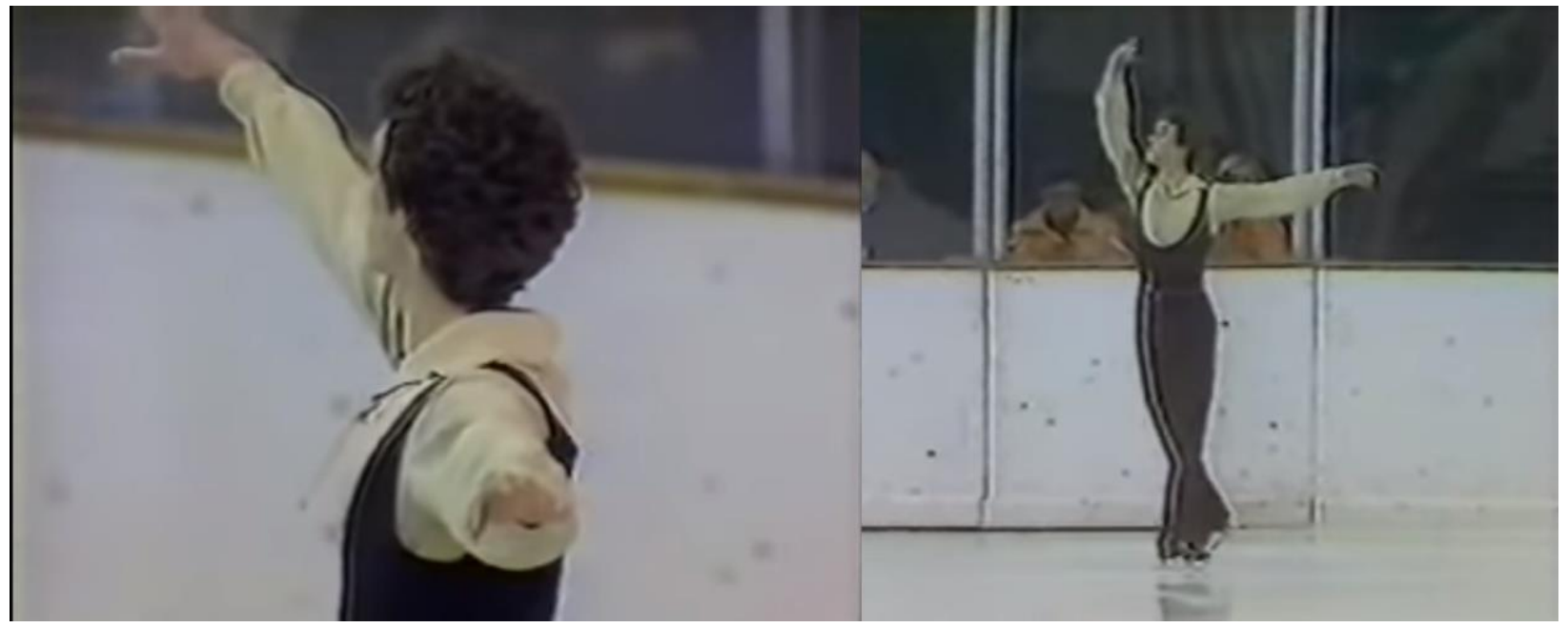

Curry then glides forward out of this pose and lifts his arms and right leg up after the fourth glide into a pose. This program is full of such poses. He drops this pose to glide forward again and then preps the first jump of this program with a right walley before performing a triple toe loop. He lands the jump in such a way that he flows backward right into the same position he presents in the rightmost photo in Figure 1, but with the arm and leg positions switched.

As the music changes from the Pas de Quatre excerpt to the Coda of the Pas de Deux, Curry jumps out of his previous pose with a small hop. ${ }^{32}$ He performs a step sequence where every time there is a forzando chord (as shown in the score and chart provided in the appendix), he does a jump, hop, or pose, in that order. Then, as the music nears the end of the phrase and a

${ }^{32}$ Mm. 1-20, page 164, http://ks.petruccimusiclibrary.org/files/imglnks/usimg/1/11/IMSLP113122-PMLP65356Minkus_-Don_Quixote_PS_rsl.pdf. 
crescendo starts, Curry performs a quick walley jump into a double flip that leads into a repeat of the previous musical phrase.

As this phrase repeats, Curry performs a step sequence similar to the one used during the first rendition of the phrase, and he continues coordinating his movements to the strongest chords. This time, however, he performs just poses instead of the jump, hop, pose sequence he previously performed. He preps for his next jump with backward crossovers and finishes the phrase with a triple jump that leads into the next musical excerpt.

This next excerpt, the Pas de Deux, is slower and more ephemeral than the previous two. Just as before, Curry performs a sequence of poses to poignant moments in the phrase. He uses the two sixteenth-note rests to change poses in a beautiful, flowing way. ${ }^{33}$ His inside spread eagle is perfectly timed with the slurred $32^{\text {nd }}$ and $16^{\text {th }}$ note immediately prior to the first rest. Then, he uses that rest to turn around into a quick forward glide pose on the final $16^{\text {th }}$-note of the measure. He uses the next $16^{\text {th }}$-note rest to lower his leg from the glide pose into a quick step that flows into an Ina Bauer, which is a figure skating move inspired by ballet fourth position. He does more of the same movements for the rest of the phrase and ends with another inside spread eagle that steps into a forward camel spin. The forward camel evolves into a one-legged spin with the bent leg held close to Curry's body. He dismounts from the spin and steps into a smooth forward glide with his arms held above him in a v-shape.

In the next phrase, which contains modal borrowing, Curry skates around the ice and poses on poignant chords again. He performs a triple loop jump on the loudest, most important chord of the phrase, which happens to be a Neapolitan chord, and lands on the chord that follows it. Curry plays out the music as it is performed in the ballet by executing difficult technical

\footnotetext{
${ }^{33}$ Measure 25,pg. 158.
} 
elements during the most important moments of the score. In Marius Pepita's choreography of the ballet, this phrase becomes the most dramatic moment of the Pas de Deux dance, and is technically difficult for Kitri. In some versions of the ballet, Kitri wraps her legs around Basilio's waist from behind and holds herself up without his support (see Fig. 2, right). In others, Kitri goes on pointe while Basilio slowly spins her in a circle (see Fig. 2, left).

Figure 4. Rudolf Nureyev and Yoko Morishita (left), and Mikhail Baryshnikov and Cynthia Harvey (right) dance to Pas de Deux. ${ }^{34}$

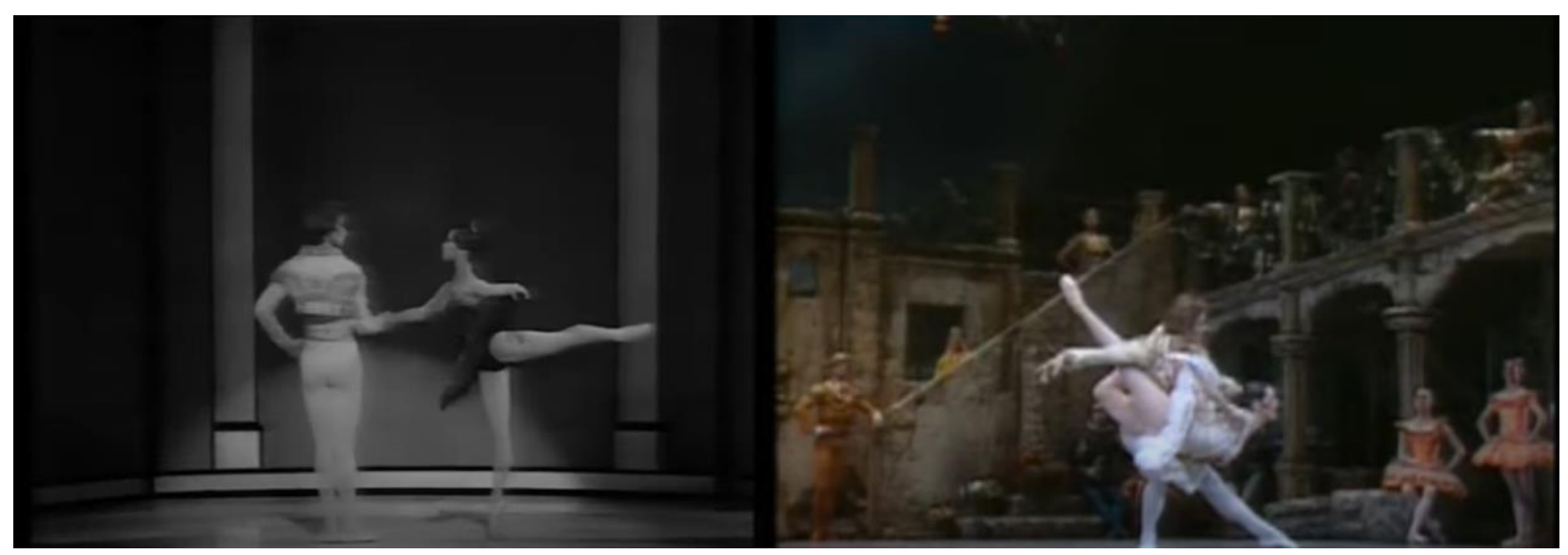

Curry's triple loop leads into an Ina Bauer that takes him across the ice into a forward camel. In the middle of the forward camel, he straightens his back and holds his left leg out while his arms are held out in front of his torso for a combo spin. He flattens his back into the forward camel again to dismount from the spin only to prep for yet another spin. This time, it's a crossfoot spin where the left leg crosses in front of the right leg and slowly lowers to the ice to become a two-foot spin. Curry shifts his weight from his right leg to his left leg and pushes into a forward glide with a pose as this movement ends.

\footnotetext{
${ }^{34}$ Grant Walter, Don Quijote Pas de Deux R Nureyev Y Morishita NYC TV, YouTube video, September 8, 2017, https://www.youtube.com/watch?v=GcgY4qWRI-M\&t=299s; lillyvippomi, Don Quixote-Pas de Deux, YouTube video, December 24, 2008, https://www.youtube.com/watch?v=jdWfKuedOMk.
} 
As the musical excerpt changes to the eighth movement of the ballet's fifth act, Curry brings out his energetic, theatrical side ${ }^{35} \mathrm{He}$ does much of the same stylistic motions as before by posing and using his arms to emphasize specific nuances in the score, such as the meter (in this case, three-quarter time) and important chords/notes. He also jumps to synchronize with the scalar descents in measures 8 and $16 .{ }^{36}$ The descending line almost sounds like something unraveling, and so as Curry jumps, his rotations unravel with the music.

During the following musical phrase, Curry astounds with his step sequences that quite literally outline several elements happening in Minkus's score, highlighting the meter and phrase structure, as well as the contrasts in orchestration between the woodwinds and strings at this moment. He performs a backward step sequence where his poses emphasize the downbeat of each measure of the wind/brass staccato phrase.${ }^{37}$ He then performs a series of spread eagle-spin combinations to the grace note-embellished, slurred, and circular-sounding melodic contour in each of the three one-measure long string responses that follows. ${ }^{38}$ This phrase repeats and Curry performs a one-foot counterclockwise spin which he crouches into halfway through for the first half of this phrase. ${ }^{39}$ Then, during the second half, he rises from the previous spin, quickly whips his arm out to the left, and uses it to propel himself into a two-foot spin going in the other

\footnotetext{
${ }^{35} \mathrm{Pg} .161$ of the piano reduction score, http://ks.petruccimusiclibrary.org/files/imglnks/usimg/1/11/IMSLP113122PMLP65356-Minkus_-_Don_Quixote_PS_rsl.pdf.

${ }^{36}$ Minkus, Don Quixote, mm. 1-18, p. 161, http://ks.petruccimusiclibrary.org/files/imglnks/usimg/1/11/IMSLP113122-PMLP65356-Minkus __Don_Quixote_PS_rsl.pdf.

${ }^{37}$ Minkus, Don Quixote, mm. 18-21.

${ }^{38}$ Minkus, Don Quixote, mm. 22-26.

${ }^{39}$ Minkus, Don Quixote, mm. 18-21.
} 
direction. ${ }^{40} \mathrm{He}$ also uses his arm as an ornament to the spin by placing the hand of the previously outstretched arm directly above his head while the other hand is on his hip.

Next, Curry pops up into a joyous pose on one leg with his arms up in the air as the music returns to the loud, fast-paced section of the waltz. He performs a series of circles around the ice, stretching an arm up gracefully during the first three downbeats of this phrase. He then preps for his next jump by doing backward crossovers and lifting off the ice as the final chord sounds. The jump lands on a rest. Again, in planning this program, Curry clearly worked meticulously on the choreography and timing of each technique to bring out the most musical emphasis that he could, including capitalizing on moments of silence.

As the musical excerpt moves on from the fast-paced waltz to the subsequent slow harp interlude in Minkus's score, Curry continues methodically posing and moving on the ice in a manner that accents the downbeat of the two arpeggiated chords. When the harp starts a long, scalar run, Curry transitions into a counter-clockwise back camel to capture the circular, spinning motion of the music.

Once the harp interlude to this movement is over, it transitions into a fast-paced 4/4 dance led by the winds with a rhythmic ostinato in the strings. Curry clasps his hands behind his back, performing two short forward glides as he turns his head to look both ways. ${ }^{41} \mathrm{He}$ then shuffles his feet on the descending arpeggio. ${ }^{42} \mathrm{He}$ repeats this twice and the third time he does it, he skips the feet shuffling and opts to do Choctaws during the descending broken chords, instead. As the

\footnotetext{
${ }^{40}$ Minkus, Don Quixote, mm. 22-26.

41 Minkus, Don Quixote, mm. 1-2, pg. 148, http://ks4.imslp.info/files/imglnks/usimg/8/84/IMSLP30799PMLP65356-Minkus-DonQuixotePRmuz.pdf

${ }^{42}$ Minkus, Don Quixote, m. 3.
} 
phrase repeats, Curry performs a similar step pattern with spins in place of shuffles and Choctaws.

Curry performs his signature straight-back sit spin twice during the next section of the excerpt, once in the counter-clockwise direction and then in the opposite direction. ${ }^{43} \mathrm{He}$ performs the sit spin during the off-beat eighth-notes and then briefly rises only to reset the spin as the grouped sixteenth-note motive occurs. He does the same with a second spin in the clockwise direction when the phrase repeats. The music goes back to the phrase where Curry was performing glides and shuffles but this time, he skates backwards by rocking his hips from the left to the right and swaying his legs in alternating backwards motions.

The musical excerpt changes once more to the end of the finale of the Coda, that picks up where the second musical excerpt of the program leaves off. ${ }^{44}$ This entire section serves as the ending to movement ten, which we hear earlier in Curry's program, as outlined in Appendix C. Curry performs a double lutz right as this excerpt begins and then performs another step sequence containing hops, leaps, spins, and jumps, and finishes this section with a singlerevolution jump. To end the program, he preps and performs pirouettes on ice to a series of eighth notes and descending sixteenth-note groupings. ${ }^{45}$ The music, especially the sixteenth notes, appears to propel Curry's spins forward. He then skates across the ice, performs a spread eagle during the back-and-forth ostinato leading into the final chords of the movement, and then

\footnotetext{
${ }^{43}$ Changes to a dominant tonal area of B-flat major.

44 Minkus, Don Quixote, mm. 33-53, pg. 154, https://ks4.imslp.info/files/imglnks/usimg/8/84/IMSLP30799PMLP65356-Minkus-DonQuixotePRmuz.pdf

${ }^{45}$ Minkus, Don Quixote, mm. 81-88, pp. 155-56.
} 
performs a double axel on the final chord, kneeling down for his final pose just before the chord finishes sounding. ${ }^{46}$

Even though Jackson Haines brought grace and elegance to figure skating by incorporating ballet movements into the sport in 1860, there was immense stigma around men fully utilizing music, skills, and ballet, but Curry shattered that barrier. ${ }^{47}$ It is important to reference Peggy Fleming and the Protopopovs, here, as they were balletic innovators in their own divisions, as well. Fleming, the Protopopovs, and Curry all skated in the "classical" style, and as one announcer remarks during commentary of his program, John Curry is "the finest stylist in the classical tradition that [he has] ever seen." ${ }^{48}$ Each skater and pair performed this classical, balletic style in a different manor, and with a balletic style by Fleming and music from ballets in Curry's case. With their artistry heavily borrowed from ballet, they were graceful, innovative, and brought pride to their countries by winning Olympic gold. Subsequently, each transformed the sport of figure skating for their division.

\section{Reactions}

During his 50-day competition spree, John Curry fought against heavy bias not only for his figure skating style, but for his nationality, as well. This was first seen in the 1976 European

\footnotetext{
${ }^{46}$ Minkus, Don Quixote, mm. 89-106, pp. 156.

47 International Olympic Committee, "Figure Skating - Winter Olympic Sport," Olympic.org, https://www.olympic.org/figure-skating/?section=ajax-area-6780872eede3420fa60b0f0043a84400\&section=ajaxarea-6780872eede3420fa60b0f0043a84400\&id=box-b680567d08be4889ad97a95ac24b03e1 \&id=boxb680567d08be4889ad97a95ac24b03e1.

48 gem7ini, John Curry - 1976 Olympics - Free Skate, YouTube video, October 18, 2012, https://www.youtube.com/watch?v=ZP9EoSIEBgg\&t=57s.
} 
championships, where the judges' panel was stacked five-to-four in favor of the Eastern Bloc. ${ }^{49}$ Curry was up against many Eastern Bloc favorites, like Vladimir Kovalev, Jan Hoffman, Yuri Ovchinnikov, and Sergei Volkov, which gave him slim chances that an Eastern Bloc judge would place him first. Surprisingly, a Czech judge placed Curry first after the free skate, putting him in first place overall ahead of Kovalev. It was the first time an Eastern Bloc judge had ever placed a Western skater first. ${ }^{50}$

At the Olympics, Curry earned the highest total number of points in the history of men's figure skating under the 6.0 scoring system, with 105.9 points out of a total of $108 .{ }^{51}$ There were nine judges on the panel, with one each from the following countries: Canada, Hungary, the United Kingdom, Czechoslovakia, the United States, France, Japan, the Soviet Union, and East Germany, with an alternate judge from Poland. Significantly, this panel was not split along ideological lines like the panel that judged the men's division of the European Championships earlier that year. The Soviet and Canadian judges were the only two who did not place Curry first. ${ }^{52}$ Not coincidentally, the Soviet Union's Vladimir Kovalev and Canada's Toller Cranston placed second and third, respectively, further supporting Curry's assertion that the figure skating judging system could be manipulated in a biased manner.

Following the Olympics, Curry's sexuality was added to the seemingly never-ending list of things that the figure skating world and the press used to criticize him. Prior to the 1976

\footnotetext{
49 JohnCurry1, The Real John Curry Part 2, YouTube video, February 23, 2010, https://www.youtube.com/watch?v=IPDmczkp_8s.

${ }^{50}$ JohnCurry1, The Real John Curry Part 2.

${ }^{51}$ International Olympic Committee, “John Curry - Olympic Figure Skating | Great Britain,” Olympic.org, January 31, 2017, https://www.olympic.org/john-curry.

${ }^{52}$ International Olympic Committee, “John Curry - Olympic Figure Skating | Great Britain.”
} 
World Championships, American John Vinocur of the Associated Press ran a story about Curry, effectively "outing" him. ${ }^{53}$ Curry still won the World Championships, but the impact Vinocur's story had on Curry's legacy was significant. According to journalist Eoin O'Callaghan, "Even into the mid-1990s, high-profile male skaters who were deemed 'different' were still warned against pushing the boundaries. ${ }^{54}$ In other words, male skaters who were influenced by Curry's style twenty years later were wary of challenging the status quo as vehemently as Curry did under fear that they would be branded as "gay" or "effeminate."

Nevertheless, some skaters performed subtle moves and gestures that pushed against the status quo. For example, at the 1988 Winter Olympics in Calgary, Viktor Petrenko of the Soviet Union (Ukraine) not only performed his long program to Minkus' Don Quixote and dressed in costume for the part, he also was the only man to perform a layback spin. ${ }^{55}$ Layback spins were usually reserved for the ladies' division at that point, so even though Petrenko's general skating style follows much in John Curry's shadow, subtle innovations here and there made him stand apart. Petrenko went on to win the gold medal at the 1992 Winter Olympics in Albertville.

Glenn S. Harman, Sonia Bianchetti and David Forberg commented on the state of musical interpretation in contemporary competitive figure skating:

Often skaters choose music from a movie soundtrack that may be associated with a certain story or character. There may be costume or choreographic choices that are based on the character or story to be portrayed. Certainly, this often occurs with classical music as well. For example, the skater could portray a character from an opera or ballet. All too

\footnotetext{
53 UskateIskate1, John Curry - Maestro Documentary Part 4., YouTube video, December 9, 2010, https://www.youtube.com/watch?v=mMojWgjmupU.

54 Eoin O’Callaghan, “Adam Rippon, John Curry and Figure Skating's Complex History with Gay Athletes,” The Guardian, February 17, 2018, sec. Sport, http://www.theguardian.com/sport/2018/feb/17/adam-rippon-lgbt-figureskaters-john-curry.

55 Dee 'Petal' Redley, Victor Petrenko 1988 Olympics LP, YouTube video, June 30, 2007, https://www.youtube.com/watch?v=52F11-qwewU.
} 
often, the competitive skater puts on the costume but does very little else to interpret the music. $^{56}$

John Curry's carefully choreographed free skate program and musical choices reflect that pushing the boundaries of musical interpretation on the ice pays off. His gold-medal winning program garnered much praise and even led him to be awarded the Order of the British Empire that same year.

Referring to the cultural impact of Curry's victory, Robert LeTellier states, "Just as the victors' specialities are always aped at every move, so their music is also assimilated, and the lovely strains of [Minkus'] wedding pas de deux were suddenly to be heard in ice-rinks around the world." ${ }^{57}$ In other words, just as skaters build their program moves based on what was previously popularized and medal-worthy, so were they influenced by music choices, specifically Curry's in this instance. Since Curry's impressive performance at the 1976 Games, male figure skaters have chosen to marry technical mastery with expressive artistry and to carefully consider, after making their musical selections, the musical interpretation in their choreography in order to win a gold medal at the Olympics. The women were already doing that since at least the 1960s, especially since Peggy Fleming made her winning mark in 1968.

Immediate evidence of this artistic and technical marriage is seen in the 1980, 1984, and 1988 programs of Olympic gold medalists Robin Cousins (GBR, like Curry), Scott Hamilton (U.S.A.), and Brian Boitano (U.S.A.), and this also shows evidence of the interpretive Western skating style beginning to dominate male figure skating. Not by coincidence, Curry, Cousins, Hamilton, Fleming, and Hamill were all coached by Carlo Fassi in the United States. Despite

\footnotetext{
${ }^{56}$ Anthony Bateman and John Bale, Sporting Sounds: Relationships Between Sound and Music, 91.

${ }^{57}$ Letellier, The Ballets of Ludwig Minkus, 37.
} 
Fassi's Italian heritage, he trained mostly American and British skaters in the United States, and so the American influence on this musically interpretive skating style is unmitigable.

The following case study explores how the figure skating style of Eastern Bloc pairs skaters has transformed since the Protopopovs. John Curry, Irina Rodnina, and Alexander Zaitsev all used Russian-influenced music in their programs, but while Curry used music of Rachmaninoff and Minkus, two well-known Russian composers, Rodnina and Zaitsev chose Russian folk music. Interestingly, both their short and long program included some form of Romany-inspired music.

\section{The Case of Rodnina/Zaitsev}

Soviet pairs skater Irina Rodnina was born September 12, 1949 in Moscow, Russia. As a child, Rodnina was fragile in health, so her parents brought her to an ice-skating rink so that she would skate to bring her strength up. ${ }^{58}$ Little did they know how dedicated she would become to the sport of figure skating. For most of the 1960s, Rodnina skated under the supervision of Czechs Milan and Sonya Boulder, with Oleg Vlasov as her partner. ${ }^{59}$ In the late 60 s, she became a pupil of Stanislav Zhuk, and that is when she switched partners to Alexei Ulanov. ${ }^{60}$ Together, she and Ulanov took home the 1972 Olympic gold medal in pairs skating. When Ulanov married another pairs' skater and left Rodnina to skate with her, a nation-wide search was done to find Rodnina a new partner. In 1972, fresh after Rodnina's Olympic win, Alexander Zaitsev not only

\footnotetext{
58 “Легендарная
https://www.peoples.ru/sport/fskating/rodnina/.)

${ }^{59}$ Ibid.

${ }^{60}$ Ibid.
} 
became Rodnina's figure skating partner, but her eventual husband, as well. The two went on to dominate the pairs circuit in figure skating until their retirement in 1980.

\section{Music for Rodnina/Zaitsev's Program}

For their free skate program, Rodnina and Zaitsev turned to Russian folk-art music, specifically as recorded and made popular by the Moiseyev Dance Company. The Moiseyev Dance Company was created in 1937 by esteemed Bolshoi choreographer Igor Moiseyev. ${ }^{61}$ From the very beginning, Moiseyev trained his dancers in a new folk dance tradition, but it was informed by classical ballet. In fact, his dancers were required to be trained in ballet in order to work for the company ${ }^{62}$ This folk dance was so successful that many believed it to be the "authentic Russian dance tradition." ${ }^{63}$ With these performances and recordings, Moiseyev sought "to present a synthesis and summary of a national character in which to reveal 'the soul of the people." ${ }^{64}$ The recordings by the ensemble, which were released in the West in the 1960s and presenting folk dances from Russia, the Ukraine, Moldavia, and other regions, would have been well-known to Western audiences by the 1976 Games in Innsbruck. ${ }^{65}$

The addition of folk-art music to programs of medal contention at the Olympics speaks volumes about the political climate during the 1970 s. ${ }^{66}$ Since Soviet ideology rejected anything

\footnotetext{
${ }^{61}$ Anthony Shay, "The Spectacularization of Soviet/Russian Folk Dance: Igor Moiseyev and the Invented Tradition of Staged Folk Dance," in The Oxford Handbook of Dance and Ethnicity, edited by Anthony Shay and Barbara SellersYoung (Oxford: Oxford University Press, 2016), 246.

${ }^{62}$ Ibid., 247.

${ }^{63}$ Ibid., 247.

${ }^{64}$ Liner notes to 1965 LP Moiseyev: The Moiseyev Dance Ensemble (MFS 451).

${ }^{65}$ LP releases include A Moiseyev Spectacular (ALP(S)-189) from 1961 and Moiseyev (MFS 451) from 1965.

${ }^{66}$ On the revival of folk traditions in late Soviet culture, see Laura Olson, Performing Russia: Folk Revival and Russian Identity (New York: Routledge, 2004).
} 
to do with the bourgeois, Rodnina and Zaitsev appealed to their home country of Russia by using music associated with tradition. According to Anthony Shay, folk dance is a form of "visual symbolic political support for the state." 67 To be sure, company creator Igor Moiseyev worked to spectacularize Russian dance and paint an image of true Russian ethnicity that would "bolster patriotic feelings" amongst the populace. ${ }^{68}$ Therefore, the use of this music by Rodnina and Zaitsev certainly had political and/or emotional implications, as the Russian population is known to react emotionally to performances by the Moiseyev company due to nostalgia for their home country. ${ }^{69}$ Not only would the use of this music appeal to the Soviet state more generally, it would also gain emotional appeal from Russian audiences and judges.

During the middle of Rodnina and Zaitsev's program, one ABC commentator said: "Skating a very folk-art style, the power and the speed that [Rodnina and Zaitsev] have overcomes any lack of style or sensitivity that they might otherwise have, making them the most secure pair I've ever seen." ${ }^{70}$ In other words, Rodnina and Zaitsev's skating style is intentionally matched to the folk-art music that they skate to. By emphasizing power and speed over style and sensitivity, Rodnina and Zaitsev reject the bourgeois, self-indulgent skating styles that Curry, Fleming, and other Western skaters employ.

Curry, Rodnina, and Zaitsev each use music associated with Russianness, and by Russian musicians, but the juxtaposition is in the two wildly different balletic musical/dance styles, which consequently influence their drastically different skating styles. While the Moiseyev

\footnotetext{
${ }^{67}$ Anthony Shay, “The Spectacularization of Soviet/Russian Folk Dance,” 236.

${ }^{68}$ Ibid., 237. For a fuller study of the ensemble's history and choreographic style, see Anthony Shay, The Igor Moiseyev Dance Company: Dancing Diplomats (Bristol: Intellect, 2019).

${ }^{69}$ Ibid., 237.

${ }^{70}$ Video Timing, 3:29-3:46, https://www.youtube.com/watch?v=2hezu89-XrY.
} 
Company's folk dancing is informed and influenced by ballet, Rodnina and Zaitsev do not fully utilize it like Curry does. They rely on their strength, speed, power, and technical prowess while Curry uses balletic style, form, and technique as the basis of every movement he completes.

Rodnina and Zaitsev use Russian folk-art music, but their skating is not obviously influenced by the Russian folk-dance style like how the Protopopovs were influenced by ballet.

\section{Rodnina/Zaitsev's Program ${ }^{71}$}

Rodnina and Zaitsev stand in a standard pairs pose prior to the start of the program, with one of Zaitsev's hands on Rodnina's hip and the other holding her left arm up and away from her body (Fig. 3). Immediately as the first sound comes out of the speakers, which sounds like the entire ensemble shouting, "Hey!", Rodnina lifts her right arm and head up toward the sky with Zaitsev following suit.

\footnotetext{
${ }^{71}$ See the video: https://www.youtube.com/watch?v=2hezu89-XrY
} 
Figure 5. Irina Rodnina (left) and Alexander Zaitsev (right), pairs figure skating long program, 1976 Winter Olympics, Innsbruck, Austria. Here they pose prior to the start of their long program.

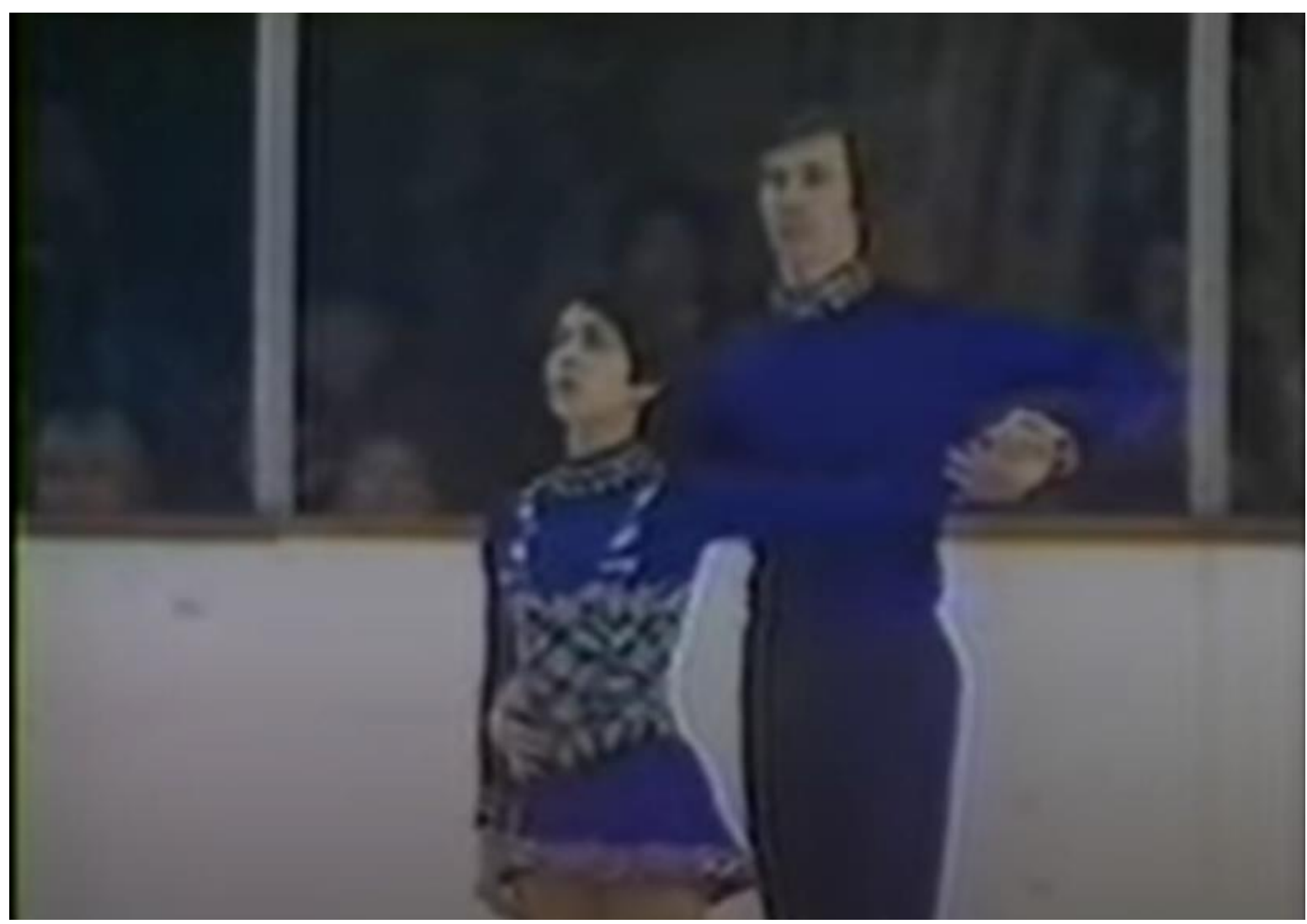

The fast-paced music helps Rodnina and Zaitsev show off their speed and strength as

skaters. As the commentators in the referenced video mention, they skate in a folk-art style, and while they may not be as artistic as other skaters, they compensate with their power and agility. ${ }^{72}$ The first part of their program begins with them moving swiftly across the ice into a two-handed lift that turns into a one-handed lift. They quickly gain more coverage across the ice after the lift and prep for a side-by-side jump combination that includes a single revolution axel jump, double toe loop, half loop, and double salchow in sequence.

\footnotetext{
${ }^{72}$ Video timing 3:34-3:39, https://www.youtube.com/watch?v=2hezu89-XrY.
} 
As they come out of the side-by-side jump combination, the pair turns around to skate backwards into their next lift. This lift is a two-handed overhead lift where Zaitsev flips Rodnina "down and out and over."73 They then gain more coverage across the ice by moving quickly and ending the first musical excerpt with a triple-flip twist.

As the music excerpt changes, so do Zaitsev and Rodnina's pacing and expression. For this next step sequence, they use expressive, slow movements, especially in the arms, that interpret the sorrowful feeling and slow pacing of the music. In the provided video, the commentators paint Rodnina as a delicate skater and emphasize this by mentioning that she is a teacup collector. ${ }^{74}$ This further demonstrates the type of atmosphere Rodnina and Zaitsev attempt to create with this excerpt and choreography.

When the violins come in with higher-pitched notes, Rodnina and Zaitsev perform sideby-side double axels, which Zaitsev falls on. Zaitsev quickly recovers from the mistake as they move across the ice to prep for another two-handed overhead lift that turns into a one-handed lift. As the slow musical excerpt ends, Rodnina and Zaitsev move forward extremely quickly across the ice to match the speed and intensity of the excerpt that follows.

The music changes to another fast-paced excerpt and Zaitsev helps Rodnina do what appears to be two assisted half-loops. First, while they are both facing each other, Rodnina turns over and hops onto one leg before reversing the move and doing it back the other way. This immediately leads into another two-handed overhead lift with Rodnina changing leg positions above Zaitsev's head.

\footnotetext{
${ }^{73}$ Video timing for commentary: 0:48, https://www.youtube.com/watch?v=2hezu89-XrY.

${ }^{74}$ Video timing for commentary: 1:18-1:23.
} 
Rodnina and Zaitsev perform a serpentine (S-shape) motion across the ice and perform a jump combination with two split jumps and what is supposed to be a double toe loop, although from the video, it does not seem that they have fully completed the second revolution. Coming out of this jump combination, Rodnina and Zaitsev perform a pair of side-by-side butterflies. They then skate to the middle of the ice where Zaitsev lifts Rodnina in the air. It is not an overhead lift this time, but she is lifted high enough that she is able to kick her legs out in front of her a few times before being lowered to the ground.

They use the rest of this fast-paced excerpt to skate across the ice and prep for their next big move, a double toe loop. This move occurs after a quick octave jump in the music and is timed to coincide with the following downward scalar run. ${ }^{75}$ They skate out to the middle of the ice as the musical excerpt ends and it almost appears as if this is the end of their program (it is not!).

The next musical excerpt that the pair skate to is from Tsigany (Gypsies) and this is the excerpt that they use for the rest of the program. ${ }^{76}$ This excerpt starts with a somber string refrain accompanied by a harp, and Rodnina and Zaitsev characterize this change by slowing their movements once again and utilizing expressive choreography. Zaitsev briefly lifts Rodnina when the high strings end the first phrase of the excerpt. As the same phrase repeats once more but faster and louder with the strings now accompanied by winds and brass, they perform their choreography quicker and seamlessly transition into a death spiral.

Coming out of the death spiral, the music becomes softer as the piano is the only instrument heard. The pair prep for their next technique, which is a pair combination spin. They

\footnotetext{
${ }^{75}$ Video timing: 3:03, https://www.youtube.com/watch?v=2hezu89-XrY.

${ }^{76}$ See Appendix D.
} 
start off briefly in a camel spin but Zaitsev immediately picks Rodnina off the ice, places her back down, and does it again as they spin on the ice. Then, as she spins on one blade, Zaitsev dips her as if they are ballroom dancing. As the piano fades and the strings return, the pair make more expressive, dance-like movements. They then perform another jump combination with a split jump and then a single jump. Next, they do backwards crossovers across the ice into yet another two-handed overhead lift, with Rodnina keeping one leg folded and the other outstretched. Their lifts get increasingly difficult as the program goes on.

After coming down from the lift, they perform a step sequence full of twists, turns, and footwork. As the music speeds up once again, Zaitsev and Rodnina perform a flying camel that transitions into a forward sit spin. When the music gets even faster, they add yet another step sequence with clever, rhythmic footwork. They then perform a double-twist catch-lift where Zaitsev twists Rodnina twice in the air and then catches her. However, the landing is slightly flubbed.

As they prepare to end the program, Zaitsev lifts Rodnina up once at his side and then lifts her in a half-circle where she kicks her legs up in the air. Their ending is slightly late, as they are supposed to land on the final chord of the excerpt, as evidenced by their World Championship performance of the same year, but they land just after the last chord sounds. ${ }^{77}$

\section{Reactions}

Rodnina and Zaitsev continued the Cold War-long trend of Soviet pairs winning consecutive gold medals at the Olympics. From starting their partnership in 1972 to the end of their amateur careers in 1980, the pair won every single major competition they competed in

\footnotetext{
${ }^{77}$ Video timing: 5:06-5:08, https://www.youtube.com/watch?v=rmPXpGyEN1U.
} 
together, including the 1976 and 1980 Olympics. To this date, no other pairs skater except Irina Rodnina has won gold medals at three separate Olympic games. ${ }^{78}$

Rodnina and Zaitsev's figure skating style "emphasized speed and strength" and they were "considered more athletic than lyrical." 79 Their style is often contrasted with the Protopopovs, who focused heavily on artistry and lyricism in their skating. ${ }^{80}$ This is also in stark contrast to the innovations unfolding in the men's division with John Curry (GBR) and Toller Cranston (CA), and that had already unfolded in the ladies' division with Peggy Fleming, Janet Lynn, and newcomer Dorothy Hamill from the United States. Both John Curry and Rodnina and Zaitsev were breaking new ground, but in different directions. While Western skaters appeared to be focusing on artistry and personal expression, skaters from the Soviet Union focused on their athleticism and physical capabilities.

The idea that Rodnina and Zaitsev focused more on the athleticism of their programs than artistic interpretation is further supported by the fact that at the 1973 World Figure Skating championships, the music stopped in the middle of their program. ${ }^{81}$ The pair continued skating without the music, as they were known for their ability to focus, and they took home the World Championship trophy regardless of having no music to supplement their movements.

\footnotetext{
78 “Легендарная Советская Фигуристка.”

79 "Irina Rodnina | Soviet Figure Skater | Britannica," Encylopaedia Britannica, https://www.britannica.com/biography/Irina-Rodnina.

${ }^{80}$ Ibid.

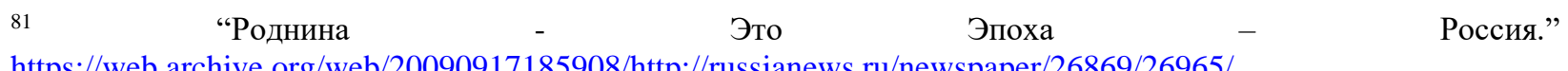




\section{Conclusions}

The triumph of John Curry at the 1976 Winter Olympic Games shows how going against what is popular can result in true change. He revolutionized men's figure skating and opened the door for continued innovation in the sport. Although change in the division following Curry has been slow, it is rare nowadays to see a male skater who is not heavily influenced by this balletic style.

Irina Rodnina and Alexander Zaitsev's use of Russian folk music popularized by the Moiseyev Dance Company showed their commitment to the state and appealed to emotional fans. It also gave them the ability to show off their strength and athleticism without betraying Soviet values. Curry and Rodnina and Zaitsev's skating styles display a growing schism between artistic expression versus powerful speed and athleticism among skaters of the West and East, respectively.

As 1980 Olympic champion Robin Cousins of Great Britain mentions, "You have... the Soviet Union and the East German way of performing and it was somewhat robotic in its nature and certainly there was no finesse or artistry involved." 82 This statement, of course, is biased considering Cousins' association with the Western skating style, but it shows that skaters thought about these stylistic differences and their programs mirrored such thought. Meanwhile, as stated on the Olympic website, John Curry "tended to emphasize grace and artistic expression over athleticism, a style that cost him points with the judges at times." ${ }^{\prime 3}$ Curry is often regarded as an

\footnotetext{
${ }^{82}$ JohnCurry, The Real John Curry Part 2.

${ }^{83}$ International Olympic Committee, “John Curry - Olympic Figure Skating | Great Britain.”
} 
effeminate skater, so this growing schism could be described as a difference of association between the masculine and the feminine, the masculine being Eastern athleticism and power, and the feminine being Western artistic and musical expression. 


\section{Chapter 4}

\section{"Carmen on Ice" at the 1988 Winter Olympic Games}

In the previous two chapters, the contrasting case studies demonstrate the evolving nature of figure skating choreography and musical selections from gold medal-winning skaters in the Soviet Union, Great Britain, and the United States. This chapter focuses instead on how the themes and trends from skaters past built a foundation for Western and Eastern Bloc skaters going into the final Olympic games of the Cold War. As tensions eased during the last years of the war, we see less of an East vs. West narrative occurring, here, and more of a "skater vs. skater" mentality.

This chapter examines the 1988 Winter Olympics and the "Battle of the Carmens," wherein Katarina Witt from the German Democratic Republic (G.D.R.) and Debi Thomas from the United States of America (U.S.A.) attempted to best one another not on the grounds of an "East vs. West" narrative, but instead on which combination of athleticism and artistry would prevail. However, race and gender heavily complicate this narrative, as Debi Thomas was a Black American woman skating at the highest level in a sport tailored for white elites, while Katarina Witt was a white woman who used her sexuality to push the boundaries of women's skating. Debi Thomas was not only the first Black figure skater to medal at the Olympics, but the first Black athlete to ever medal at the Winter Olympics, which was extremely significant for a global sporting contest spanning 92 years. I will explore the implications of race and gender in Witt and Thomas' programs and show how the circumstances of their individuality and artistry reflected the status quo embedded in figure skating's history. 
The 1988 Olympic short program of renowned pairs skaters Ekaterina Gordeeva and Sergei Grinkov of the Soviet Union (USSR) is also mentioned here. ${ }^{1}$ They battled against athletes from their own country for the gold medal. A light analysis of this program is included because like Katarina Witt and Debi Thomas, Gordeeva and Grinkov also use music from Carmen. I conclude with commentary on the use of art music, specifically Carmen, by Witt, Thomas, and Gordeeva and Grinkov, arguing that its position as figure skating's soundtrack had not changed since figure skating became an Olympic sport eighty years earlier.

\section{The Cold War in 1988}

In 1981, less than one year after the 1980 Lake Placid Olympics, Ronald Reagan was sworn into office as President of the United States. Reagan, a Republican, succeeded one-term president Jimmy Carter, reviving conservative politics in America. Meanwhile, the Soviet Union was cycling through leaders, as Leonid Brezhnev (in office 1964-82), Yuri Andropov (1982-84), and Konstantin Chernenko (1984-85) all died in office, with the latter two having served significantly shorter terms than their predecessors. Desperate for a young leader who would reform the U.S.S.R., the Political Bureau of the Central Committee of the Communist Party of the Soviet Union, or Politburo as it was popularly abbreviated, unanimously elected Mikhail Gorbachev (born 1931) as the Soviet Union's next General Secretary in $1985 .^{2}$

During his first term in office, Reagan announced his Strategic Defense Initiative (SDI) plan, which would eliminate threats posed by missiles by rendering them useless via space

\footnotetext{
${ }^{1}$ For a profile of their career, see Ekaterina Gordeeva, My Sergei: A Love Story, trans. E. M. Swift (New York: Hachette, 2009).

${ }^{2}$ William Taubman, Gorbachev: His Life and Times, (New York: W.W. Norton \& Company, Inc., 2018), $211-12$.
} 
technology. ${ }^{3}$ In November 1985, Reagan met with Gorbachev in Geneva, Switzerland so that they could reach an agreement on nuclear disarmament. ${ }^{4}$ However, because of Reagan's attachment to SDI and his unwillingness to use it as a bargaining chip in negotiations, both world leaders left the meeting without an agreement. ${ }^{5}$ The meeting was not a complete failure, though, because it got the two superpowers talking again. ${ }^{6}$

After the 1986 Chernobyl nuclear disaster in the Ukrainian Soviet Socialist Republic, Reagan and Gorbachev held another summit in Reykjavík, Iceland. Gorbachev told Reagan that the Soviet Union would go for the "zero option" and do away with all Soviet missiles, but the United States had to confine SDI to the laboratory rather than launching the program in space. ${ }^{7}$ Reagan declined and the two once again left without coming to an agreement. Despite not reaching an agreement, Gorbachev had called the meeting an "intellectual breakthrough" in relations between the two countries. ${ }^{8}$

During Gorbachev's first official trip to the United States in December of 1987, he and Reagan signed the Intermediate-Range Nuclear Forces (INF) Treaty. This treaty banned the use of short and mid-range missiles, and would lead to a drastic reduction in missiles on both sides. ${ }^{9}$ Reagan and Gorbachev had agreed to the treaty not only because of how well their previous

\footnotetext{
${ }^{3}$ Kiron K. Skinner, Pavel Palazhchenko, and George P. Shultz, Turning Points in Ending the Cold War, Stanford, (Hoover Institution Press, 2007), 23, http://ebookcentral.proquest.com/lib/wvu/detail.action?docID=3301866.

${ }^{4}$ Skinner, Turning Points in Ending the Cold War, 116-17.

${ }^{5}$ Arjen Molen, Cold War-Star Wars, 1981-1988-Part 22/24, YouTube video, September 24, 2015, https://youtu.be/uq2BPTtp00.

${ }^{6}$ Ibid.

${ }^{7}$ Ibid.

${ }^{8}$ Ibid.

${ }^{9}$ Skinner, Turning Points in Ending the Cold War, 126.
} 
meetings had gone, but also because Gorbachev and other Soviet politicians believed that SDI was a pipe dream that would never come to fruition. ${ }^{10}$ This treaty was largely a result of

Gorbachev's promotion of glasnost and perestroika, which led to the restructuring of the Soviet Union's economy and foreign policy. This restructuring led to better relationships with the West, a decrease in military expenditures, and an economic upturn for the kremlin. ${ }^{11}$ The INF Treaty, along with new Soviet foreign and economic policy, was the beginning of the end to the fortyfour-year-long war.

\section{The 1988 Winter Olympics}

The 1988 Winter Olympics opened on February 13 at McMahon Stadium in Calgary, Alberta, Canada. After Americans and other Western/West-sympathizing countries boycotted the 1980 Moscow Summer Olympics and the Soviets and other Eastern Bloc/East-sympathizing countries boycotted the 1984 Summer Games in Los Angeles, 1988 was the first year in many that neither the Summer nor Winter Olympics had major boycotts. ${ }^{12}$ This behavior modeled the political attitudes of the West and the Eastern Bloc in 1988 as tensions eased.

\footnotetext{
${ }^{10}$ Skinner, Turning Points in Ending the Cold War, 126.

${ }^{11}$ Ibid., 125-126.

${ }^{12}$ For more on these boycotts and their political fallout, see Jenifer Parks, The Olympic Games, the Soviet Sports Bureaucracy, and the Cold War, esp. chs. 3-5; Simon Young, "Playing to Win: The Moscow Olympics and the Augmentation of Soviet Soft Power during the Brezhnev Era, 1975-1980," in Machineries of Persuasion: European Soft Power and Public Diplomacy during the Cold War, edited by Óscar J. Martín García and Rósa Magnúsdóttir (Oldenbourg: De Gruyter, 2019), 61-84; Mikhail Prozumenshikov, "Action in the Era of Stagnation: Leonid Brezhnev and the Soviet Olympic Dream," in The Whole World Was Watching: Sport in the Cold War, edited by Robert Edelman and Christopher Young (Stanford: Stanford University Press, 2020); Joseph Eaton, "Decentering US Sports Diplomacy: the 1980 Moscow Boycott through Contemporary Asian-African Perspectives," in Sports and Diplomacy: Games Within Games, edited by J. Simon Rofe (Manchester: Manchester University Press, 2018); Bradley J. Coniglio, "In Defense of a Neoliberal America: Ronald Reagan, Domestic Policy, and the Soviet Boycott of the 1984 Los Angeles Olympic Games," in Defending the American Way of Life: Sport, Culture, and the Cold War, edited by Toby C. Rider and Kevin B. Witherspoon (Fayetteville: University of Arkansas Press, 2018), 205-218; Philip A. D'Agati, The Cold War and the 1984 Olympic Games: A Soviet-American Surrogate War (New York: Palgrave, 2013).
} 
A bidding war played out among American television networks like ABC, CBS, and NBC for the rights to the 1988 Calgary Olympics, and ABC ultimately gained the rights to broadcast the event. Bidding wars for the Olympics and other major sporting events were commonplace as rising viewership and participation garnered massive amounts of ad revenue. Additionally, CBS and NBC often "ran programs with particular appeal to viewers who were unlikely to watch the Olympics."13 This was particularly true for the 1984 Winter Olympics in Sarajevo, as the time zone difference made ABC "more vulnerable than in the past." 14 In other words, news of each days' events usually broke before $\mathrm{ABC}$ had the chance to air them, and networks like NBC and CBS took advantage by scheduling popular programs against ABC's Olympic coverage.

After the U.S. hockey team's "Miracle on Ice" at the Lake Placid Olympics in the 1980s, ABC ramped up its Olympic coverage for subsequent Olympics because of the all-time high viewership. ${ }^{15}$ However, ratings for Sarajevo were far lower than $\mathrm{ABC}$ projected due to networking wars and the U.S. hockey team's poor showing. ${ }^{16}$ As a result, ABC bid $\$ 309$ million on the 1988 Winter Olympics in Calgary, about \$109 million more than expected by the Calgary host committee, to ensure a truly American Olympic viewing experience. ${ }^{17}$ When the IOC

\footnotetext{
${ }^{13}$ Bill Abrams, "Olympics Didn't Give Big Boost to Ratings for ABC; Audience Slips 15\% from 1980," The Wall Street Journal, Feb 22, 1984.

${ }^{14}$ Bill Abrams, "Olympics Didn't Give Big Boost to Ratings," 1984.

${ }^{15}$ For a Cold War studies perspective on the "Miracle on Ice," see Chad Seifried, "An Exploration into Melodrama and Sport: The 'Miracle on Ice' and the Cold War Lens," Olympika 19 (2010), 111-138.

16 Ibid.

${ }^{17}$ Jonathan Rowe, "Calgary Olympics: the Games that TV built," Christian Science Monitor (February 16, 1988$), 1$.
} 
increased the Winter Olympics from a 12-day program to 16 days in 1988, ABC responded by spreading its coverage of the games across three weekends instead of two. ${ }^{18}$

ABC's over-bidding for broadcasting rights and over-spending on increased Olympics coverage ultimately cost the network $\$ 60$ million and the rights to broadcast the Olympics for the foreseeable future. ${ }^{19}$ In contrast, broadcasters in European and Soviet countries spent less than $\$ 10$ million combined for the rights to broadcast the Calgary Olympics in their respective countries. ${ }^{20}$ Ultimately, it was up to each network how they chose to cover the Olympics, which could easily lead to media bias. As we will see in the following case studies, media narratives were often spun to bring in more viewers, sponsors, and excitement to sports broadcasts to counter waning public interest. ${ }^{21}$

\section{"The Battle of the Carmens"}

The stars of the ladies' skating division at the 1988 Winter Olympics were 23-year-old Katarina Witt of the German Democratic Republic (G.D.R.) and 21-year-old Debi Thomas of the United States. In these Games, Witt ultimately secured the gold medal while Thomas earned a bronze, but their rivalry through the Games was a media sensation.

\footnotetext{
${ }^{18}$ Ibid.

${ }^{19}$ American broadcasting rights to the Summer Olympics went to NBC starting in 1988 and CBC broadcasted the Winter Olympics from 1992-1998. NBC now holds broadcasting rights to both events. For a broader survey of international media sponsors, see Garry Whannel, "The Five Rings and the Small Screen: Television, Sponsorship, and New Media in the Olympic Movement," in Global Olympics: Historical and Sociological Studies of the Modern Games, edited by Kevin Young and Kevin B. Wamsley (Bingley: Emerald, 2005), 161-178.

${ }^{20}$ Jonathan Rowe, "Calgary Olympics: the Games that TV built," 1.
} 
Witt was born December 3, 1965 in the G.D.R. ${ }^{22}$ Her figure skating career began at the age of five when she was placed into a school in Karl-Marx-Stadt that focused on children with sporting talents. Winning second at the 1982 World Figure Skating Championships in Copenhagen, Denmark was a breakthrough moment for Witt and led to her securing a gold medal victory at the 1984 Winter Olympics in Sarajevo.

Witt's Western rival, Debi Thomas, was born on March 25, 1967, in Poughkeepsie, New York. ${ }^{23}$ She began taking formal figure skating lessons at the age of nine and the following year, she began working with coach Alex McGowan, who would train her all the way to the Olympics. ${ }^{24}$ Thomas became the first African American to win a national and world championship title, all while pursuing higher education at Stanford University. She was considered the only skater in the line-up who could possibly best Witt at the 1988 Calgary games, as she was the only skater to place ahead of Witt at the World Figure Skating Championships between 1984 and $1988 .^{25}$

\section{Music for Witt and Thomas’ Programs}

Witt, the defending Olympic champion, and Thomas both skated to music from Georges Bizet's opera Carmen (1875) in the free program portion of the competition. Both Witt and

\footnotetext{
${ }^{22}$ Annette F. Timm, “'The Most Beautiful Face of Socialism': Katarina Witt and the Sexual Politics of Sport in the Cold War," in The Whole World Was Watching: Sport in the Cold War, edited by Robert Edelman and Christopher Young (Stanford: Stanford University Press, 2020); Gertrud Pfister, "Cold War Diplomats in Tracksuits: The Fräuleinwunder of East German Sport," in Militarism, Sport, Europe: War without Weapons, edited by J.A. Mangan (London: Frank Cass, 2003), 226-256; Annette R. Hofmann, "Katarina Witt: The Many Faces of a Showcase Athlete," More than Cricket and Football: International Sport and the Challenge of Celebrity, edited by Joel Nathan Rosen and Maureen M. Smith (Jackson: University Press of Mississippi, 2016); Molly Wilkinson Johnson, Training Socialist Citizens: Sports and the State in East Germany. Leiden: Brill, 2008.

23 "Debi Thomas," Biography, November 10, 2015, https://www.biography.com/athlete/debi-thomas.

${ }^{24}$ Ibid.

${ }^{25}$ Anne Heutsche, "Thomas, Debi," in Black Women in America, (Oxford: Oxford University Press, 2005).
} 
Thomas drew their instrumental music selections from the one-act ballet Carmen Suite composed in 1967 by Soviet composer Rodion Shchedrin (born 1932). Considering figure skating's ban on the use of vocal music and lyrics at the time, Shchedrin's Carmen Suite was a convenient means by which Witt and Thomas could obtain an instrumental version of Bizet's well-known music. In addition to selections from Shchedrin's ballet, Thomas also drew on Bizet's version, including the Entr'acte to the opera's third act, which is also included in Bizet's Carmen Suite No. 1, and the "Danse Bohéme" (Gypsy Song) that opens the opera's second act, and which is included in Bizet's Carmen Suite No. 2. Both of Bizet's Carmen suites were published by Ernest Guiraud in 1882 following Bizet's death.

As Shchedrin was a Soviet composer, it is important to consider the reception of the condensed Carmen ballet in the Soviet Union. Shchedrin composed the Carmen Suite for his wife, Bolshoi dancer Maya Plisetskaya, but it was banned by the Soviet Minister of Culture, Yekaterina Fursteva, after its Bolshoi premiere in $1967 .{ }^{26}$ Fursteva only lifted the ban after Plisetskaya agreed to censor her "sexual" dances and costumes. ${ }^{27}$ Soviet composer Dmitri Shostakovich also called Fursteva and expressed his love for the Carmen Suite, which further helped Plisetskaya's cause. ${ }^{28}$

The story of Carmen, of which Bizet's opera is based on, was originally written by French author Prosper Mérimée in 1845. The story chronicles the narrative of a Frenchman who embarks on a quest to Spain to locate the battlefield of Munda, an important location in the

\footnotetext{
26 John Armstrong, "Rodion Shchedrin Carmen Suite Review," BBC, 2002, https://www.bbc.co.uk/music/reviews/v8cz/.

${ }^{27}$ Maya Plisetskaya, Antonina W. Bouis, and Tim Scholl, "How Carmen Suite Was Born," In I, Maya Plisetskaya, (New Haven: Yale University Press, 2001), 275-6.

${ }^{28}$ Ibid.
} 
Roman Civil War. ${ }^{29} \mathrm{He}$ is sidetracked when he meets a Basque bandit named Don José, whom the Frenchman rehabilitates with his "superior French skills." ${ }^{30}$ He then meets a gypsy named Carmen after arriving in Cordoba, and the two retreat to Carmen's room so that she might tell his fortune. ${ }^{31}$ They are interrupted by Don José, and the Frenchman continues his quest by travelling elsewhere. ${ }^{32}$ When he comes back, he finds that Don José has killed Carmen and is in prison for life. ${ }^{33}$ This is the first version of Mérimée's original three-part story, but he added a fourth part in 1846. In this chapter, the narrator "returns and delivers a long-winded disquisition on Romany, the gypsy language."34 Regarding Mérimée’s Carmen, Peter Robinson argues,

The battle that really interests the text is the battle between the sexes. From the very beginning, Woman is marked as the enemy. The battlefield itself, the territory that obsesses the text, is none other than [Carmen's] body, as the text constantly raises the question of who shall own it while describing those who are fighting over it. ${ }^{35}$

This brings us to Bizet's opera, which magnifies this gendered nuance in a condensed and altered version of the story. Some of the alterations to the original storyline include the absence of the narrator, the "softening" of Carmen while simultaneously enhancing her characterization as a femme fatale, the introduction of Micaëla as a pure, innocent foil to the promiscuous Carmen, and the downplaying of Carmen and Don José's history as criminals. ${ }^{36}$ Despite attempts

\footnotetext{
${ }^{29}$ McClary, Georges Bizet, Carmen, 1.

${ }^{30}$ Ibid., 2.

${ }^{31}$ Ibid.

${ }^{32}$ Ibid., 2.

${ }^{33}$ Ibid.

${ }^{34}$ Ibid.

${ }^{35}$ Ibid, 4.

${ }^{36}$ Ibid, 20-22.
} 
to subdue the controversial subject matter, the opera's opening was unequivocally a failure. As we know, failure was hardly Carmen's final destiny, as it is and continues to be a trademark staple of the Western musical canon.

Susan McClary offers insight into discussions of race, class, gender, and sexuality of Bizet's Carmen, discussing "orientalism" and the fetishization of the East in $19^{\text {th }}$-century French culture, specifically the Romany in Mérimée's Carmen. She argues that the "sensual, static, irrational, and nonproductive" nature of the East makes it a feminized space, and its plethora of resources make it desirable and dominatable. ${ }^{37}$ Along with this, women, along with people in suppressed race and class groups, were often depicted as people to co-exist with rather than to humanize and give depth to, which was possible "so long as an unchallenged hierarchy prevailed." 38 This hierarchy, of course, was the subjugation of women and people of color, like the Romany, by the white male patriarchy. ${ }^{39}$

The suppression of sexual expression pervaded nineteenth-century Western culture just as it did the Olympic figure skating ring. ${ }^{40}$ As Carmen was both reviled and desired for her sexual freedom, so was Katarina Witt. She was reviled by the International Skating Union for her choice of outfits in her 1988 Olympic programs but desired by the audience for her flirtatious

\footnotetext{
${ }^{37}$ McClary, Georges Bizet, Carmen, 31.

${ }^{38} \mathrm{Ibid}, 36$.

${ }^{39} \mathrm{Ibid}, 36$.

${ }^{40}$ For more on gender in sports, especially in the Olympic Games, see Kevin B. Wamsley and Gertrud Pfister, "Olympic Men and Women: The Politics of Gender in the Modern Games," in Global Olympics: Historical and Sociological Studies of the Modern Games, edited by Kevin Young and Kevin B. Wamsley (Bingley: Emerald, 2005), 103-126; John W. Loy, Fiona McLachlan, and Douglas Booth, "Connotations of Female Movement and Meaning: The Development of Women's Participation in the Olympic Games," Olympika 18 (2009), 1-24; Dufur, Mikaela J. 'Gender and Sport.' In Handbook of the Sociology of Gender, ed. Janet Saltzman Chafetz, 583-600. New York: Kluwer Academic/Plenum Publishers, 2006; Susan Cahn, Coming on Strong: Gender and Sexuality in Women's Sport (New York: Free Press, 1994; 2nd ed., Urbana: University of Illinois Press, 2015); Hargreaves, Jennifer. Sporting Females: Critical Issues in the History and Sociology of Women's Sports. London: Routledge, 1994.
} 
and alluring skating style. ${ }^{41}$ Had Thomas, a woman of color, transgressed like Witt had, she undoubtedly would have faced harsh racism, criticism, and sexism far beyond what Witt dealt with.

\begin{tabular}{|c|c|c|c|}
\hline Timing of program ${ }^{42}$ & Music used & $\begin{array}{l}\text { Action happening } \\
\text { on the ice }\end{array}$ & Action happening in ballet \\
\hline $0: 10-0: 25$ & $\begin{array}{l}\text { I. "Introduction" (from } \\
\text { Shchedrin's Carmen Suite) }\end{array}$ & $\begin{array}{l}\text { Posing and circular } \\
\text { motions. }\end{array}$ & $\begin{array}{l}\text { Audience is seated, curtain is } \\
\text { closed. }\end{array}$ \\
\hline $0: 25-1: 52$ & II. "Dance" & $\begin{array}{l}\text { Fast skating, jumps, } \\
\text { and technical } \\
\text { prowess. }\end{array}$ & $\begin{array}{l}\text { Carmen performs a solo } \\
\text { dance. }\end{array}$ \\
\hline $1: 52-3: 17$ & $\begin{array}{l}\text { VI/XII. "Carmen Entrance/ } \\
\text { Habañera" }\end{array}$ & $\begin{array}{l}\text { Posing section; } \\
\text { artistic, shows off } \\
\text { Witt's acting } \\
\text { abilities and } \\
\text { portrayal of } \\
\text { Carmen's character. }\end{array}$ & $\begin{array}{l}\text { Duet dance between Carmen } \\
\text { and guards. }\end{array}$ \\
\hline $3: 17-3: 43$ & $\begin{array}{l}\text { VI/XII. "Scene/Fortune- } \\
\text { Telling" }\end{array}$ & $\begin{array}{l}\text { Difficult step } \\
\text { sequences and } \\
\text { choreography mixed } \\
\text { with jumps. }\end{array}$ & $\begin{array}{l}\text { Fate motive; Carmen's alter } \\
\text { ego (Fate) tells her } \\
\text { fortune/Escamillo bullfights } \\
\text { with Fate. }\end{array}$ \\
\hline $3: 43-4: 26$ & XIII. "Finale" & $\begin{array}{l}\text { Step sequence, jump, } \\
\text { and spin that } \\
\text { represent Carmen } \\
\text { dying; ends with } \\
\text { Katarina lying } \\
\text { motionless on the } \\
\text { ice. }\end{array}$ & $\begin{array}{l}\text { Carmen dances with } \\
\text { Escamillo, Fate, and Don } \\
\text { José until Don José kills her. }\end{array}$ \\
\hline
\end{tabular}

In Witt's program, she only uses sections from Shchedrin's suite that are popular and glaringly signify the character of Carmen, such as the opening, the "Habañera," and her overarching theme (she uses the ending version of it specifically). ${ }^{43}$ Witt also performs the femme fatale aspect of the character, which will be analyzed in the next section. She uses the following movements from Shchedrin's suite: I. "Introduction,” II. “Dance,” IV. "Carmen’s

\footnotetext{
${ }^{41}$ Timm, “"The Most Beautiful Face of Socialism.”"

42 3Axel1996, Katarina Witt (GDR) - 1988 Calgary, Figure Skating, Ladies' Long Program (US ABC), YouTube video, https://www.youtube.com/watch?v=57R7aAY5QiM.

${ }^{43}$ See Figure 1.
} 
Entrance \& Habañera," VI/XII. "Scene/Fortune-Telling," and XIII. "Finale." Shchedrin's suite is scored for strings and percussion, only.

In the ballet, the Introduction occurs while the stage curtain is still closed and flows directly into the Dance, wherein the curtain rises and Carmen performs a solo dance to introduce herself to the audience. ${ }^{44}$ In "Carmen's Entrance \& Habañera," Witt uses only the "Habañera." In the ballet, the "Habañera" is a duet dance between Carmen and one of the guards. In the opera, Carmen sings the "Habañera" to a crowd of young men that gathered outside of the factory that she and her friends work at. The music that follows the "Habañera," "Scene/FortuneTelling," is used in two different sections of the ballet, but is present whenever Fate, Carmen's alter ego, shows up to tell someone's fortune. In "Scene," Fate shows Carmen's fortune just as Carmen begins fighting with a band of tobacco smugglers, and in "Fortune-Telling," Fate acts as the bull that Escamillo fights. In "Finale," Carmen dances back-and-forth with Escamillo, Fate, and Don José until she is killed by the latter. Shchedrin's entire ballet is based around Carmen with an ongoing love triangle between her, Don José, and Escamillo, and places an emphasis on Carmen's deviant, sexual nature.

The association of Shchedrin's Carmen ballet with Soviet culture is undeniable because of three things: one, Shchedrin was from the Soviet Union, two, the ballet opened in the Soviet Union, and three, the Bolshoi ballet put on the show. Witt, along with her coaches and choreographers, probably decided on this version to please judges, audiences, and, significantly, state officials from the G.D.R. and the Eastern Bloc while also appealing to Carmen lovers from the West. ${ }^{45}$ Also, considering the censorship of Shchedrin's ballet in the Soviet Union for its

\footnotetext{
44 Louise Lins, Carmen - Svetlana Zakharova - Bolshoi Ballet COMPLETE, 2012, https://www.youtube.com/watch?v=yJlyGNitxz0\&t=72s.
} 
sexual themes, Witt may have felt a particular resonance with this version, especially because of her own sexualized transgressions in this program. Just as Shchedrin's ballet fought back against censorship in the Soviet Union, Witt fought against censorship in the women's figure skating ring. Assuredly, Witt's choice of music from Carmen more generally resulted from her personal interest in and connection to the character. In an interview with BBC News, she remarked, "I can relate to [Carmen]... I always like to be playful on the ice, I like to flirt [...] That music, her character, that story is so much part of my life story... that I always feel I never let her go." 46

\begin{tabular}{|c|c|c|c|}
\hline Timing of program ${ }^{47}$ & Music used & $\begin{array}{l}\text { Action happening } \\
\text { on the ice }\end{array}$ & $\begin{array}{l}\text { Action happening in } \\
\text { ballet/opera }\end{array}$ \\
\hline $0: 38-0: 48$ & $\begin{array}{l}\text { I. "Introduction" (from } \\
\text { Schedrin's Carmen Suite) }\end{array}$ & $\begin{array}{l}\text { Posing and circular } \\
\text { motions. }\end{array}$ & $\begin{array}{l}\text { Audience is seated, curtain is } \\
\text { closed. }\end{array}$ \\
\hline $0: 48-2: 07$ & II. "Dance" & $\begin{array}{l}\text { Fast skating across } \\
\text { the ice, jumps, } \\
\text { posing, step } \\
\text { sequences in time to } \\
\text { the music, and a spin } \\
\text { at the end flowing } \\
\text { into the next musical } \\
\text { selection. }\end{array}$ & $\begin{array}{l}\text { Carmen performs a solo } \\
\text { dance. }\end{array}$ \\
\hline $2: 07-3: 36$ & $\begin{array}{l}\text { "Intermezzo" of Bizet's } \\
\text { Carmen Suite No. } 1\end{array}$ & $\begin{array}{l}\text { Slow, circular } \\
\text { skating with plenty } \\
\text { of turns and poses. } \\
\text { There are a few } \\
\text { jumps as well as a } \\
\text { layback spin at the } \\
\text { end of this section. }\end{array}$ & $\begin{array}{l}\text { Entr'acte to act } 3 \text { of the } \\
\text { opera. }\end{array}$ \\
\hline $3: 36-4: 50$ & $\begin{array}{l}\text { "Danse Bohème" of Bizets' } \\
\text { Carmen Suite No. } 2\end{array}$ & $\begin{array}{l}\text { Jumps, long and fast } \\
\text { step sequence, spins. }\end{array}$ & Opens Act II of the opera. \\
\hline
\end{tabular}

\footnotetext{
${ }^{45}$ For an in-depth discussion of the creation and reception of classical (read: Western art) music in the German Democratic Republic, see Kyle Frackman and Larson Powell, Classical Music in the German Democratic Republic: Production and Reception (Rochester, New York: Camden House, 2015). For general perspectives on art culture in the GDR, see Elaine Kelly and Amy Wlodarski, Art Outside the Lines: New Perspectives on GDR Art Culture (Leiden, The Netherlands: Brill, 2011).

${ }^{46}$ BBC News, "Battle of the Carmens" Katarina Witt - Witness - BBC News, YouTube video, February 9, 2014, https://www.youtube.com/watch?v=aiCL1AT0Idc.

47 3Axel1996, Debi Thomas (USA) - 1988 Calgary, Ladies' Long Program, YouTube video, November 2, 2009, https://www.youtube.com/watch?v=gW4LqC33TiU.
} 
In Thomas' program, she uses the first and second movement, the Introduction and Dance, of the Shchedrin suite, but then switches to Bizet's Carmen suites. Thomas uses the second movement, "Intermezzo," of Bizet's Carmen Suite No. 1 for the slow section of her program, of which the music serves as the Entr'acte to act three of the opera. The use of Bizet's suite instead of Shchedrin's is evident in the use of winds and full orchestration instead of solely strings and percussion. By this point in the opera, Don José has betrayed his duty as a soldier by attacking one of his superiors, Zuniga, and is forced to join Carmen's band of smugglers because he has no other choice. In the Shchedrin suite, this is movement seven, Bolero, and is Don José's solo dance after Carmen seduces him into releasing her. For the final portion of her program, Thomas uses the sixth movement of Bizet's Carmen Suite No. 2, "Danse Bohème.” This movement is the end of the second suite and opens Act II of the opera, wherein Carmen dances and socializes with soldiers and her friends in Lillas Pastia's Inn. Although this piece is not as easily recognizable as "Habañera" or "Les Toreadores" to the audience, the music underscores Carmen at her most carefree and relaxed. Like Witt, Thomas chose pieces that are central to the character of Carmen, but that implicate different moods and emotions from Witt's fiery, sexualized, and fierce Carmen. While still fierce, the music in Thomas's program showcases a more private side of Carmen, specifically her relationship with Don Josè, but also how carefree she acts in social situations with her friends. Just as Bizet's opera softens Carmen, so does Thomas, highlighting possible motivations for including more of Bizet's music than Shchedrin's in this program. 


\section{Witt and Thomas’ Programs}

Although they chose different sections from Bizet's score to Carmen (or Shchedrin's ballet) to showcase the story of Carmen, both programs drew on the music material of Shchedrin's prelude, complete with bells and a dramatic, fiery atmosphere. Both Thomas and Witt start their respective programs in similar ways. As the bell tolls, they each make slow, dramatic movements, before immediately picking up speed and executing a two-jump sequence. $^{48}$

The main difference here is not exactly each skater's characterization of the music, but rather their embodiment of the role of the titular character. Thomas' skating is quite the opposite of the assertion that competitive skaters often put on the costume of the character but do little else to interpret the music. ${ }^{49}$ She does an excellent job of interpreting the music with her choreography and movements (despite a few jumping errors during this specific event), but does little else to wholly embody the character of Carmen the way that Witt does. Her costume is exquisite, but it does not signal Carmen's character like Witt's does. "Carmen is the character that's fearless and fiery, and that's definitely Debi's personality," says one commentator during Thomas' long program at the 1988 U.S. Championships, but this part of her personality arguably does not shine through in her Olympic long program. ${ }^{50}$ As Philip Hersh, an Olympic Sports writer, remarked, "Debi was skating to Carmen, Katarina was Carmen."[51][52]

48 Alicia Hall Moran, Battle of the Carmens, uploaded May 7, 2016, YouTube video, 0:41-1:19, https://www.youtube.com/watch?v=4RRN5LMH3vw.

${ }^{49}$ Anthony Bateman and John Bale, Sporting Sounds: Relationships Between Sound and Music, 91

${ }^{50}$ GoldenAgeofFS, Debi Thomas - 1988 U.S. Figure Skating Championships - Long Program, uploaded November 12, 2018, YouTube video, https://www.youtube.com/watch?v=SdNrD6ysX2A.

${ }^{51}$ Olympic, Katarina Witt - The Diva on Ice with a Huge Heart $\mid$ Legends Live On, YouTube video, February 6, 2018, https://www.youtube.com/watch?v=wKOMgQpxvrg. 
There was something else that certainly influenced Thomas's portrayal of Carmen in comparison to Witt's. Thomas' approach to Carmen was clearly reserved next to Witt's, as she had more subtle costuming and make-up and was not as sexually transgressive as Witt. Likewise, as previously stated, Thomas' musical selections explored a more private, softer, and carefree side to Carmen. Choosing this music and presenting herself as Carmen this way may have been a conscious choice by Thomas and her team to not draw more attention to herself than necessary, as she was already subverting expectations by competing at the highest level of a predominantly white sport as a Black woman. In the media and society in general, especially American society, Black womanhood is portrayed as overtly hypersexual and Black female athleticism is stereotyped as masculine and beyond the realm of white heterosexual beauty. ${ }^{53} \mathrm{In}$ an international sport that adheres very closely to ideals of white western femininity, Katarina Witt was transgressive in her program in ways that that Debi Thomas could not be.

In order to be included in figure skating's exclusive club of white femininity, Thomas needed to conform to white beauty standards and expectations. ${ }^{54}$ White standards of beauty include "long and straight hair (usually blonde), that is, hair that is not kinky or nappy," and in this program, Thomas has long, straightened hair tied back in a ponytail. Despite efforts to conform, she was still seen as masculine and athletic rather than beautiful and graceful - in other

\footnotetext{
${ }^{52}$ Emphasis is my own.

${ }^{53}$ Leonard, David J., "Dilemmas and Contradictions: Black Female Athletes" in Out of Bounds: Racism and the Black Athlete, ed. Lori Latrice Martin (Santa Barbara: Praeger, 2014), 209-230. For more on representations of Black women in the media and society, see Marquita Marie Gammage, Representations of Black Women in the Media: The Damnation of Black Womanhood (New York: Routledge, 2016); Patricia Hill Collins, Black Sexual Politics: African Americans, Gender, and the New Racism (New York: Routledge, 2004). See also "The Oppositional Gaze: Black Female Spectators" in bell hooks, Black Looks: Race and Representation (New York: Routledge, 2015); Delia D. Douglas, "To Be Young, Gifted, Black and Female: A Meditation on the Cultural Politics at Play in Representations of Venus and Serena Williams," Sociology of Sport Online 5, no. 1 (2002).

${ }^{54}$ For a similar study on whiteness in winter sports, see Annie Gilbert Coleman, "The Unbearable Whiteness of Skiing," In Sport Matters: Race, Recreation and Culture, ed. John Bloom and Michael Nevin Willard (New York: New York University Press, 2002), 141-167.
} 
words, she was passable, but could not transcend the boundaries of white femininity. As critical culture, gender, and race studies scholar David J. Leonard states: "Dominant representations commodify and celebrate female athletes who embody a heterosexual beauty and appeal. At the same time, the characteristics of blackness (physicality, athletic superiority, aggressiveness, toughness, strength) within the white imagination that result in hypercommodification of black male bodies precludes black female athletes from both the category of woman athlete and the category of "hot" athlete." In other words, Katarina Witt could wear short skirts, flirt with the audience, and project a sexy image of Carmen on the ice because she was already accepted as an appealing, heterosexual white woman, and she did not have to be imagined outside the margins of her own race to do so. 
Figure 6. Debi Thomas, free-skate program, 1988 Winter Olympics, Calgary, Alberta, Canada. ${ }^{55}$

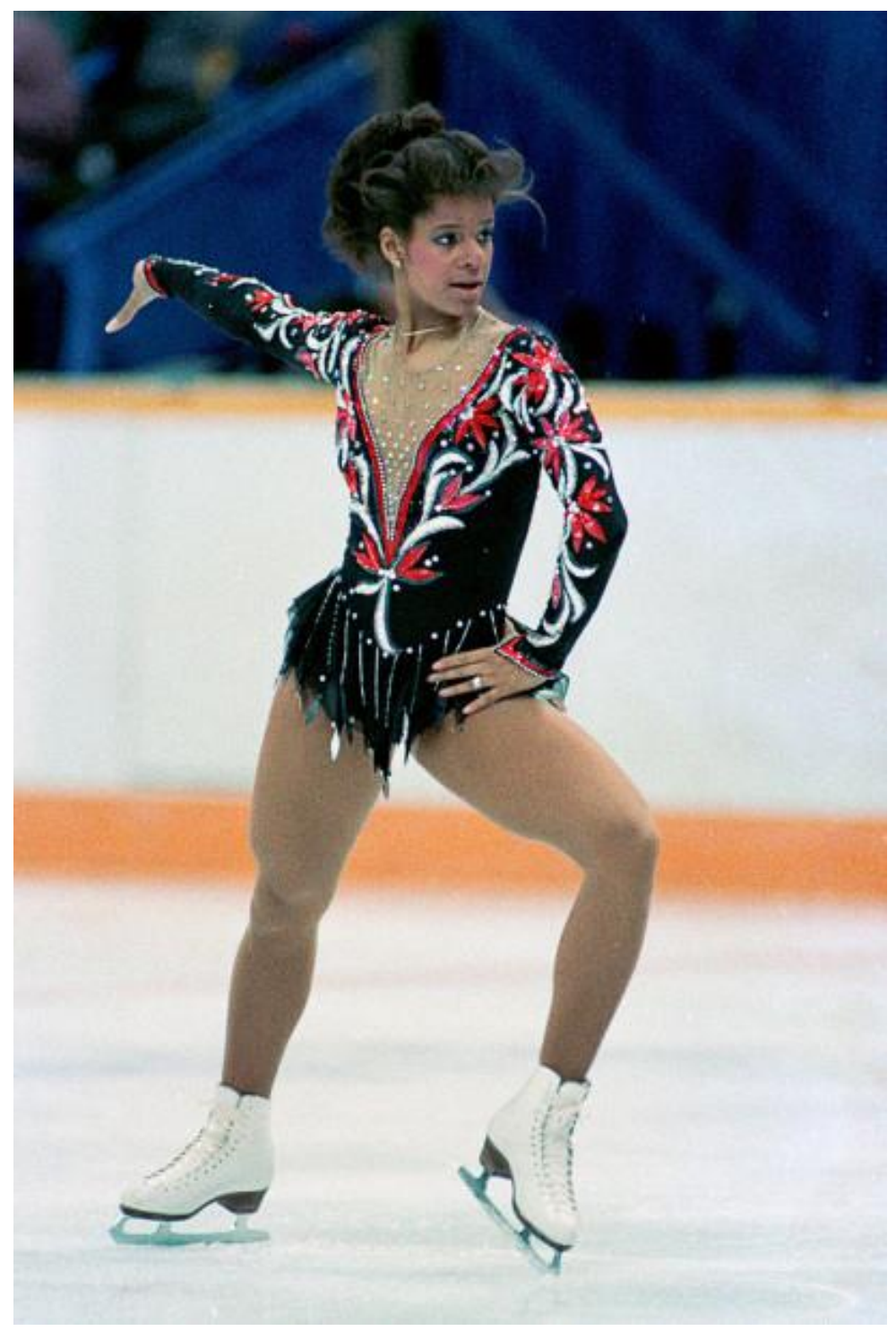

In her short program at the 1988 Winter Olympics, Katarina Witt performed a medley of showgirl tunes complete with tap dancing choreography on ice and all. She even wore a "feathery, skirtless, skin-baring" costume. ${ }^{56}$ This showy costume led to the creation of the

55 Photograph from "This History-Making Olympian Lost Everything - Even Her Medal," New York Post, https://nypost.com/2018/02/17/this-history-making-olympian-lost-everything-even-her-medal/.

${ }^{56}$ Christopher Muther, "The Ice Rink Becomes the Runway for Female Figure Skaters," BostonGlobe.com, January 11, 2014, https://www.bostonglobe.com/lifestyle/style/2014/01/11/the-ice-rink-becomes-runway-for-female-figureskaters/ZfSFpCEEKGGPrwzAcvnGRN/story.html. 
"Katarina rule," which dictated, among other things, that "a skirt covering hips and posterior was required for ladies' competition." ${ }^{57}$ Just like how Carmen's sexuality is policed in the opera and how Shchedrin's Carmen Suite was initially banned in the Soviet Union for its depiction of sexual themes, so Witt's sexuality, along with the sexuality of virtually all future Olympic skaters, was policed when the International Skating Union introduced the "Katarina rule." Debi Thomas might have faced even harsher reprimands if she had done the same thing, as her transgressions would be viewed not only as gendered and sexualized, but racialized, as well.

Figure 7. Katarina Witt, short program, 1988 Winter Olympics, Calgary, Alberta, Canada. This costume resulted in the "Katarina Rule." 58

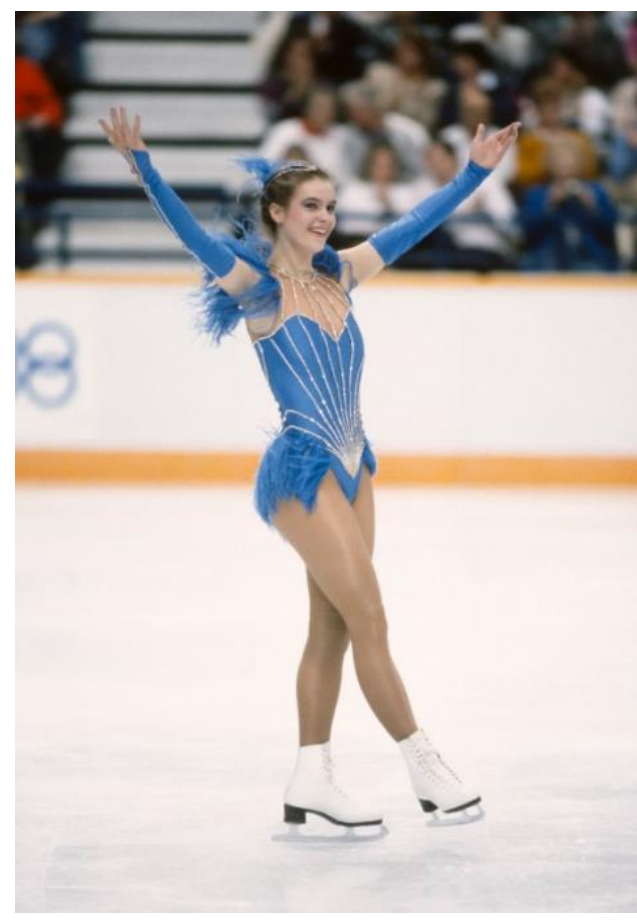

\footnotetext{
${ }^{57}$ Christopher Muther, "The Ice Rink Becomes the Runway."

${ }^{58}$ Photograph sourced from Julia Brucculieri, "Stunning Photos Show The Evolution Of Women's Figure Skating Costumes," Huffpost, February 20, 2018.
} 
Witt's transgressions of gendered and sexualized boundaries in figure skating resemble John Curry's, and while "skaters wishing to become champions tend to model themselves on previous champions," it is also largely their whiteness that allowed them to break such boundaries. ${ }^{59}$ Ultimately, differing approaches by Thomas and by Witt to their respective programs highlight both their individualism as athletes and also shows how figure skating programs were influenced by the status quo. Katarina Witt could be transgressive in sexual and gendered ways while Debi Thomas walked a racial and gendered tightrope, as she had to be passable enough for white heterosexual beauty standards, but she could not transgress as far as Witt or she would face harsh racial and sexual bias and criticism by judges, audiences, and the media alike.

\section{Reception}

Witt found out in the fall of 1987 that Thomas was skating to Carmen, so it is highly likely that she did not know which Carmen selections Thomas chose prior to the start of the 1987-88 competition season. ${ }^{60}$ Therefore, their "Battle of the Carmens" rivalry unquestionably resulted from media headlines rather than Witt and Thomas purposefully attempting to best each other while skating to the same music. CBS asked Witt to be a commentator during the 1992 Winter Olympics in Albertville, which "made her appreciate what TV [was] doing for the sport." ${ }^{\prime \prime 1}$ Before, she was perplexed by how TV had transformed her 1988 Olympic rivalry with American Debi Thomas into "The Battle of the Carmens." "Now I understand," she said, "that

\footnotetext{
${ }^{59}$ Ellyn Kestnbaum, "Critiques of Skating's Feminine Ideals," in Culture on Ice: Figure Skating and Cultural Meaning (Middletown: Wesleyan University Press, 2003), 127.

${ }^{60}$ Ellyn Kestnbaum, "Critiques of Skating's Feminine Ideals," in Culture on Ice, 127.

${ }^{61}$ Ross Atkins, "Katarina Witt Aims to Go for the Gold Again After Six Years Away from Competition, the TwoTime Olympic Skating Champion Is Training for Lillehammer," The Christian Science Monitor, December 14, 1993.
} 
you have to heat it up so more people will watch."62 In other words, for someone who is passive about figure skating and would not normally watch, it becomes more enticing when the media embellishes the storylines. ${ }^{63}$ When storylines are embellished, it also becomes easier for skaters to send a message to a wider audience. This also stems from how female athletes are portrayed in the media, as Witt was able to draw in new fans to the sport because of her feminine sex appeal. $^{64}$

Katarina Witt challenged the social standards for women's skating with her 1987-88 programs. Both her short and long programs rebelled against policing women figure skaters' sexuality through her costuming and her choice to embody a character as commonly "othered" as Carmen. Similarly, Thomas challenged the standards of race in figure skating, as she was the first African American skater to ever win the World Championships and medal at the Olympics. In Ellyn Kestnbaum's cultural analysis of women's skating, she posits that in the 1980s, there were two camps of skaters forming: the artistic and the athletic. She argues that judging was often based on the appearances of skaters and how well each skater fit the image of a female champion, and that judging was never free of personal bias; judging was just as much based on the image of each skater and the politics of each country as it was on the technical evaluation of their programs. ${ }^{65}$ She remarks that by the 1980 s, women's skating was no longer about which

\footnotetext{
${ }^{62}$ Ibid.

${ }^{63}$ See chapter 5's references to the Tonya Harding/Nancy Kerrigan incident. See also Judith Mayne, "Fear of Falling," in Framed: Lesbians, Feminists, and Media Culture (Minneapolis: University of Minnesota Press, 2000), 103-114; Bettina Fabos, "Forcing the Fairytale," 185-212.

${ }^{64}$ Gina Daddario, Women's Sport and Spectacle: Gendered Television Coverage and the Olympic Games (Westport, CT: Praeger, 1998); Andrew C. Billings, "Clocking Gender Differences: Televised Olympic Clock Time in the 19962006 Summer and Winter Olympics," Television and New Media 9, no. 5 (September 2008): 429-41; Michael A. Messner, Gender in Televised Sports: News and Highlights Shows, 1989-2004 (Amateur Athletic Foundation of Los Angeles, 2005).

${ }^{65}$ Kestnbaum, Culture on Ice, 128.
} 
skater could best live up to the ideal image of a female figure skating champion, but whether artistry or athleticism would prevail. ${ }^{66} \mathrm{Witt}$, she argues, was feminine and artistic because of her flirtatious style, while Thomas was considered technically superior and an athletic skater. In this case, artistry won, which is further supported by Midori Ito of Japan placing fourth during the 1988 Olympics after cleanly landing an unprecedented seven triple jumps and two double axels, although she had a poor showing in the compulsory figures. ${ }^{67}$ The Western emphasis on artistry and personal expression stems from the notion that figure skating is a sport for women, and that it is associated with the feminine. Television skating broadcasts have a large say in how they depict women skaters, and they shy away from the athleticism of the sport and focus on the hair, the makeup, the costumes, and the packaging of the skater along with their program. ${ }^{68}$ If we look at this from a racial and gendered lens, then both the sport and the media reject qualities usually associated with Black female athleticism (masculinity, strength, muscularity) and gravitate towards qualities of white femininity (daintiness, slender bodies, straight hair). ${ }^{69}$

\section{Ekaterina Gordeeva and Sergei Grinkov}

Witt and Thomas were not the only skaters to skate to Carmen at the 1988 Winter Olympics. Carmen was a staple across the board and for their short program, pairs skaters Ekaterina Gordeeva and Sergei Grinkov skated to modernized versions of "Les Toreadores" and "La Garde Montante." In the opera, Escamillo enters with the air "Vivat, vivat le Toréro" that

\footnotetext{
${ }^{66}$ Ibid., 133.

${ }^{67}$ Ibid., 138.

${ }^{68}$ Kestnbaum, Culture on Ice, 131.

${ }^{69}$ For a study on the intersections of Eurocentrism, White power, and the Olympic Games more recently, see Richard C. King, "Staging the Winter White Olympics: Or, Why Sport Matters to White Power," Journal of Sport and Social Issues 31, no. 1 (2007), 89-94.
} 
leads into "Les Toreadores" (known as the "Toreador Song," or "Votre toast, je peux vous le rendre"). He then meets Carmen and attempts to woo her, but does so in vain. "La Garde Montante" ("Avec la garde montante") is sung by a chorus of young boys at the beginning of Act I as they mock Don José and another guard.

"Les Toreadores" and "La Garde Montante" were later added to Bizet's Carmen Suite No. 1 and used in 1983 in the Carmen Disco Suite by Camino de Lobo of East Germany. In this mix, funky disco beats and electronics were added to enhance the music and turn it into something one would dance to in a club. ${ }^{70}$ It seems as if the Carmen music that Gordeeva and Grinkov skated to was heavily influenced by Camino de Lobo's suite, especially with the bass and disco beats being similar. Interestingly, no credit is given to a particular composer or orchestra on Gordeeva's website, and in videos of Gordeeva and Grinkov's program, the commentators simply reference Bizet's Carmen.$^{71}$ Therefore, Witt, Thomas, and Gordeeva and Grinkov all used music from the same work in the same season in the same competitions, even if they did not use the exact same pieces.

Using different selections of music from Carmen for all three programs shows the individualism and uniqueness that each skater brings to the table in terms of musical style and preference. Conversely, the use of music from the same opera in three different medalcontending programs in the same year also conveys a lack of originality not only on the part of the skaters, but of the culture fostered by the sport. In a video by Vox entitled "How figure

\footnotetext{
${ }^{70}$ It was difficult to find any information about Camino de Lobo. A Google search pulls up basic information about the record, but nothing substantial. However, famous German session musician and record producer Harold Faltermeyer produced de Lobo's Carmen Disco Suite.

71 "Ekaterina Gordeeva \& Sergei Grinkov / Programs / G\&G," http://www.gordeeva.com/programs/english/index.shtml; CoffeeOnIce, Gordeeva and Grinkov, "Carmen," YouTube, July 24, 2007, https://www.youtube.com/watch?v=Ujb-2rRGMJA.
} 
skaters choose their music, explained with Adam Rippon," Olympic figure skater Adam Rippon and figure skating musical designer Hugo Chouinard address Carmen's overall popularity in figure skating programs. ${ }^{72}$ Particularly, they highlight the strength of her character, the contrast of emotions throughout each act, and the enticing storyline in four acts. They also mention that since the ban on music with lyrics was lifted in 2014, skaters are looking for their "new"

Carmen. Overall, the video concludes that skaters generally want to tell an interesting and emotional story on the ice while also adhering to the fast-slow-fast pattern of most figure skating programs, and Carmen is a great and popular choice for that.

\section{Conclusions}

Throughout the 1987-88 figure skating season, it became clear that Carmen was not just a favorite for opera lovers and musicians, but for figure skaters, as well. Although the Cold War was beginning to wind down by 1988 , the media still found ways to pit countries against one another. For Katarina Witt and Debi Thomas, this was an obvious move because they chose the same music and Witt was from East Germany while Thomas was from the United States. However, Witt's showing at the 1988 Winter Olympics contributed to easing Cold War tensions, as American attitudes towards East Germans shifted slightly as a result of her ability to draw in new fans, especially men, with her feminine charms. For Gordeeva and Grinkov, they were competing for the gold medal against another pair from their home country, so they had a rivalry within their own country to resolve.

\footnotetext{
72 Vox, How Figure Skaters Choose Their Music, Explained with Adam Rippon, 2018, https://www.youtube.com/watch?v=VA_P3p7MI98.
} 
For the men's skating division at the 1988 Calgary games, Brian Boitano (U.S.A.) and Brian Orser (CAN) went head-to-head in what the media called the "Battle of the Brians." This headline puts an emphasis on the names of these two individuals rather than the countries they are competing from, but we can surmise that since both countries had similar, if not the same, economic and political systems, which country they were from was not as important to the media as it would be if one of them was from the Eastern Bloc. For these skaters, it was all about who was the best on an individual level, although of course politics still played a huge role. A skater always wants to win and represent their country to the best of their ability.

Although race and gender heavily impacted Katarina Witt and Debi Thomas' musical choices and presentation of their long programs at the 1988 Winter Olympics, their individual contributions to the sport influenced women's skating going into the next decade. While Debi Thomas broke the mold for Black women competing in figure skating, Katarina Witt pushed hard against gender roles and barriers that suppressed women's individual expression in the sport. 


\section{Chapter 5}

\section{Beyond the End of the Cold War}

From the previous case studies and program analyses, it can be concluded that the music that top-tier figure skaters and their teams chose to use in their programs can be analyzed from a variety of perspectives, including political and racial implications, nationalism and cultural pride, gender norms and expression, innovations and advancements in the sport, playing to strengths rather than weaknesses, considering what has worked well in the past, and factoring in judging bias.

In the 1968 Winter Olympics, Peggy Fleming persevered with her $19^{\text {th }}$-century romanticera influenced art music selections and her motivation to bring pride and joy to her dispirited home country. Meanwhile, the Protopopovs played to their strengths and to the audience/judges with music by Beethoven and Soviet/Russian composers like Rachmaninoff, as their classical, balletic, and expressive style worked well with this recognizable music. They choreographed their own programs and chose music that aligned with figure skating's preference for Western art music while picking choices within that genre that resonated with audiences from their home country.

In the 1976 Winter Olympics, John Curry strived to be an innovator and go against the grain in the men's division. He was consciously aware of the fact that his choices went outside of the judges' favor, especially during the European Championships, but his risks paid off when his marriage of artistic expression and technical prowess won him the gold medal. He choreographed the entire program and chose the music on his own prior to training with the Fassis, so there was not any influence from his coaches on his decisions. For Alexander Zaitsev 
and Irina Rodnina, traditional folk music from their home country likely evoked emotional responses from Soviet judges and audiences alike, and their strong, powerful skating style was complimented perfectly by their musical choice.

In the 1988 Winter Olympics, a multitude of skaters all took different approaches to music from Georges Bizet's Carmen. While Katarina Witt pushed the boundaries of sexuality and gender roles in women's skating with her portrayal Carmen's fiery, flirty spirit through both her musical choices and choreography, Debi Thomas took a more reserved approach and chose selections that depicted Carmen's softer, intimate side. Considering the political and cultural implications of being a Black woman in a white-dominated sport, Debi Thomas could not afford to push the boundaries that Witt was pushing without harsh retaliation. In the pairs division, Ekaterina Gordeeva and Sergei Grinkov skated their short program to a disco remix of music from Carmen. Although they did not specifically evoke Escamillo's toreador character like how Witt purposefully evoked Carmen's character, they still dressed as toreadors and skated in perfect sync.

I will conclude this study with a brief survey of programs, innovations, and changes in figure skating from 1990 to 2020, including the removal of compulsory figures from figure skating programs in 1990, the media sensation of the 1994 Harding/Kerrigan incident, the 2002 Salt Lake City judging scandal, the removal of the ban on music with vocals and lyrics in 2014, the creation and implementation of the figure skating team event, and the popularization of figure skating through anime following the triumph of Japan's Yuzuru Hanyu at the 2014 Sochi Olympics. 


\section{Figure Skating Since 1988}

With the fall of the Berlin Wall, the end of the Soviet occupation of Afghanistan, and the dissolution of the Union of Soviet Socialist Republics, the Cold War officially ended in 1991. At the 1992 Winter Olympics in Albertville, France, countries from the former Soviet Union banded together under the Unified Team to compete together one more time. A newly re-unified Germany won the overall medal count and the Unified Team won second place, which was a tremendous reminder to the world of the power of ally-ship and unification towards a common goal. ${ }^{1}$ Figure skating at this Olympics saw the triumph of Viktor Petrenko (Unified Team) with his signature layback spin in the men's division and Kristi Yamaguchi (U.S.A.) in the women's division, and a final "Soviet" win in pairs skating, with Natalia Mishkutenok and Artur Dmitriev of the Unified Team reigning victorious.

In 1990, the ISU voted to eliminate compulsory figures from competition. This change increased the weight of the short and long program in each competition and changed how coaches trained their skaters. An increase in emphasis on technical jumps began in the $90 \mathrm{~s}$ as women increasingly used triple jumps and men increased their triple jumps to quadruple jumps. In 1994, the ISU voted to allow professional skaters to be reinstated as competitors in the amateur circuit. Following this change, skaters who competed in the 1988 and 1992 Winter Olympics were now eligible to compete at the 1994 Winter Olympics in Lillehammer, Norway. As a result, newly reinstated skaters, such as Ekaterina Gordeeva and Sergei Grinkov (RUS), Brian Boitano (U.S.A.), Katarina Witt (GER), and ice dancers Jayne Torvill and Christopher Dean (GBR), who famously skated to Ravel's Bolero at the 1988 Winter Olympics, all threw their hats into the ring.

\footnotetext{
$1 \quad$ “1992 Albertville Winter Games," Sports-Reference.com, April 17, 2020, https://web.archive.org/web/20200417042616/https://www.sports-reference.com/olympics/winter/1992/.
} 
The Tonya Harding/Nancy Kerrigan incident also occurred in 1994, wherein Harding's (U.S.A.) husband, Jeff Gillooly, hit Nancy Kerrigan (U.S.A.) in the thigh in a practice session prior to the U.S. Figure Skating Championships in Detroit, Michigan. Pending legal action, Harding would still compete on the 1994 U.S. Olympic team, but she ultimately plead guilty to "conspiring to hinder prosecution of the case" and was stripped of her 1994 U.S. Figure Skating title because of the incident. ${ }^{2}$ This scandal became one of the most known stories in figure skating history and the media capitalized on it just as it did with stories like the "Battle of the Carmens" and the "Battle of the Brians" in 1988.

At the 2002 Winter Olympics in Salt Lake City, Utah, a judging scandal occurred in the pairs event. Allegedly, the French judge had struck a deal with the Russian judge to score the Russian pair first regardless of how they perform in exchange for an advantage in the ice dance competition for the French couple. ${ }^{3}$ This led to both the Russian and Canadian pairs' teams receiving gold medals and also resulted in changes to the ISU scoring system. The ISU initially implemented secret judging while overhauling the point system into a Code of Points $(\mathrm{CoP})$ where judges individually score each component of a skaters' program. It was hoped that this change would limit judging bias and scandals like the one in Salt Lake City, but after questions were raised about figure skating scandals in the 2014 Winter Olympics in Sochi, Russia, secret

\footnotetext{
${ }^{2}$ Elizabeth L. Krause, “'The Bead of Raw Sweat in a Field of Dainty Perspirers': Nationalism, Whiteness, and the Olympic-Class Ordeal of Tonya Harding,” (Transforming Anthropology 7, no. 1, 1998), 33.

${ }^{3}$ Scott M. Berry, "Gold Medals, Protests, and Trading Ratings: The 2002 Winter Olympics Figure Skating," (Chance Chance 15, no. 2, 2002), 17-18.
} 
judging was eliminated to "increase transparency."4 The Code of Points scoring system still remains, but its usefulness and partisanship is consistently debated. ${ }^{5}$

In 2014, the International Skating Union piloted the figure skating team event at the Winter Olympics in Sochi, Russia. This was also the year the ISU decided to allow skaters to use music with lyrics and vocals in their program for the first time. These changes were implemented ideally to draw younger and bigger audiences to skating, but they were also moves that changed the landscape of figure skating. ${ }^{6}$ The team event brought greater visibility to the sport at the Olympics and has drawn parallels among gymnastics, which also has a team event element. With the change to permitting vocal music, figure skating has become more accessible to a wider range of people and has also helped diversify the sport. While there are still elitists who believe that the grace and elegance of figure skating relies heavily on the use of music culturally associated with such grace and elegance (i.e. classical music, Western art music), the sport no longer appears shackled to its Western art music tradition.

An example of how figure skating is transcending beyond Western art music comes from MAPPA studio's Yuri on Ice, an anime that explores the competition season of Yuri Katsuki, a nearly washed-up 23-year-old figure skater. The triumph of Japan's Yuzuru Hanyu at the 2014

\footnotetext{
4 Pritha Sarkar, "Sotnikova Win Raises Judging Questions," Reuters, February 20, 2014, https://uk.reuters.com/article/us-olympics-figureskating-judging-idUKBREA1J2DJ20140220; Nick Butler, "ISU Vote to Abolish Anonymous Judging System in Figure Skating to 'Increase Transparency," Insidethegames.biz, June 8, 2016, https://www.insidethegames.biz/articles/1038244/isu-vote-to-abolish-anonymous-judging-system-in-figureskating-to-increase-transparency.

${ }^{5}$ Danny Rosenberg and Kelly L. Lockwood, "Will the New Figure Skating Judging System Improve Fairness at the Winter Olympics?" Olympika 14 (2005), 69-84; Elizabeth A. Hanley, "No Passion at the Palavela': Sonia Bianchetti Garbato and Figure Skating's New Judging System," in Cultural Imperialism in Action: Critiques in the Global Olympic Trust, edited by Nigel B. Crowther, Robert K. Barney, and Michael K. Heine (London, ON: International Centre for Olympic Studies, 2006), 145-156.

${ }^{6}$ Christopher Clarey, “'Rhapsody in Blue' or Rap? Skating Will Add Vocals," The New York Times, February 18, 2014. https://www.nytimes.com/2014/02/19/sports/olympics/rhapsody-in-blue-or-rap-skating-will-add-vocals.html
} 
Winter Olympics in Sochi propelled this show into the limelight of Japanese culture, and it instantly became a hit among audiences over the world. In the first episode of the show, Katsuki asks a close friend, Phichit Chulanont, to help him find music for his free program. This leads to Chulanont contacting a music student who composed a piece for him in the past, and the student writes an original instrumental piece that heavily uses piano and strings to reflect Katsuki's story and essence. Among the show's fans, this piece, named "Yuri on Ice" after the show's title, immediately became popular. The anime itself was so popular among figure skaters and figure skating fans that at the 2018 Winter Olympics in Pyeongchang, South Korea, Japanese pairs skaters Miu Suzaki and Ryuichi Kihara skated to "Yuri on Ice" in their short program. ${ }^{7}$ Although "Yuri on Ice" is not the first music from anime or a television show to be used in a figure skating program, the "scale, significance, and specific sentimentality" of the fan community made the use of the music at the Olympics a "particularly special moment." ${ }^{8}$ Perhaps even forty years ago, skaters would be nervous to skate to music with such associations, but since skaters now realize that choice of music has the ability to attract fans of all different types of music, their musical selections are more diverse than ever. Of course, this does not negate the continued heavy use of classical and Western art music in figure skating programs, but it does show that now more than ever, skaters are pushing beyond the boundaries of traditional skating music without receiving much pushback. ${ }^{9}$ Likewise, Yuri Katsuki's use of original music that specifically represents who

\footnotetext{
${ }^{7}$ Tom Gerken, “Winter Olympics: Yuri On Ice Performed by Japanese Skaters,” BBC News, February 9, 2018, sec. BBC Trending, https://www.bbc.com/news/blogs-trending-43003630.

${ }^{8}$ Bunny Bissoux, "From Yuzuru Hanyu to 'Yuri on Ice': Japan's Fascination With Figure Skating," Tokyo Weekender, March 5, 2018, https://www.tokyoweekender.com/2018/03/from-yuzuru-hanyu-to-yuri-on-ice-japans-fascinationwith-figure-skating/.

9 Jieqian Zhang, "Winter Olympics 2018: How Music in Figure Skating Has Changed," The Wall Street Journal, February 9, 2018.
} 
he is in Yuri on Ice challenges figure skaters to be creative with their own musical choices and selections and go beyond what is easily available and commonly used.

In a 2018 Wall Street Journal article titled, “Winter Olympics 2018: How Music in Figure Skating Has Changed," Jieqian Zhang identifies the musical trends among the top-seven countries competing in figure skating based on the 2018 Pyeongchang Winter Olympics. Zhang found that the United States has largely moved away from classical (Western art) music and has move towards pop/rock and soundtrack music. Meanwhile, Russia still uses classical music the most. Canada and Italy have a decent balance among classical, soundtrack, and pop/rock music, although there were less Italian skaters performing than Canadians. Japan and China use classical and soundtrack music roughly the same amount, but Chinese skaters branch out more into the pop/rock genre. South Korea favors classical and soundtrack music, but has one world music performance at this Olympics. Significantly, the world music and blues/jazz genre is rarely used by any competitors. Interestingly, Japan and China each have one blues/jazz performance, but the United States, the birthplace of these genres, has none. While the sport of figure skating is rapidly moving toward new, uncharted territory, there remains work to be done to further diversify the sport; music is just one way that figure skating is slowly breaking away from its white, hegemonic, and bourgeois roots.

\section{Areas of Further Research}

Essentially, this project identifies skating trends among medal-contending figure skating programs at different Winter Olympics throughout the Cold War. It proves that multiple elements can influence skaters' musical choices, including (but not limited to) historical events, political circumstances, cultural climate, social categorizations and background, such as race, 
class, sex, gender, etc., and more. While Western art music prevailed among all other genres throughout the Cold War (with film soundtrack music being second), skaters chose music within (and occasionally outside of) the genre that expressed sentiments about their home nations, showcased personal motivations and agendas, and revealed political and societal trends and barriers they were facing. Ultimately, this barely scratches the surface of what further research can reveal about the music of this sport.

Further research on music and figure skating at the Olympics during the Cold War could focus on music used in the programs of skaters outside of the United States, Great Britain, the Soviet Union, and East Germany, especially in Asian countries such as Japan and China, and in other American countries like Canada and Mexico. Such research would also benefit from using language that destabilizes Eurocentric narratives of East versus West and communism versus capitalism. The researched skaters do not have to be medal-contenders, although medalcontending programs tend to be more widely available for viewing on the internet. Pursuing research on skaters who did not medal or were out of medal contention would likely need grantaided archival research to access video footage of such programs. More research could also be done on medal-contending programs from the Winter Olympics between 1968 and 1988 that were not covered in this project. Archival research compiling information on all of the music used in every Olympic figure skating program since 1924 would be an incredibly useful reference for future researchers, as one of the most difficult parts of this project was identifying the music used in each program and, when possible, the specific recording used. Looking beyond the Cold War, research on post-Cold War musical choices in Olympic figure skating starting in 1992 could be fruitful, especially because figure skating media coverage increases exponentially in the 1990s and there is more easily accessible data from each program. All of the previously 
mentioned research avenues could also include figure skating programs executed outside of the Olympic ring, such as those of the World Championships, the national championships of different countries, the Grand Prix of Figure Skating and its subsequent competitions (Skate America, NHK Trophy, Cup of China, etc.), the Four Continents, etc. Ethnographic research on modern day figure skaters and their music choices could help frame a dissertation project or book focusing on how location and culture influences contemporary figure skater's musical choices, while situating those decisions within evolving notions of national identity and within the globalized identity and politics that are tightly woven into the ideals of Olympic Games themselves. ${ }^{10}$ Such research could include ethnographic surveying, interviewing, and studying local skaters of different nations (based on the magnitude/scope of the project).

Finally, significant research must be done on skaters of different races, social classes, sexes/genders, and how these social categorizations influence musical choices. While this thesis surveyed some of these elements in select medal-contending Olympic figure skating programs, there is more work to be done. Overall, my hope is that further research on musical trends in figure skating will reveal more about how historical/political events, social trends and patterns, cultural elements, and personal experiences inform skaters' musical choices, and that such research will further explore the use, or lack thereof, of the "world," Blues, and jazz music genres.

\footnotetext{
${ }^{10}$ For broader analyses on sport and national identity and on the politics of the Olympics that could help frame such comparative studies, see Adrian Smith and Dilwyn Porter, eds., Sport and National Identity in the Post-War World (London: Routledge, 2004); Alan Tomlinson, Christopher Young, and Richard Holt, eds., Sport and the Transformation of Modern Europe: State, Media and Markets 1950-2010 (London: Routledge, 2011); Jordan Koch \& Douglas Brown, "Ringleaders: Olympic Athletes who Donned, Inked, and Embodied the Olympic Logo in the Cold War," Olympika 20 (2011), 1-30.
} 


\section{APPENDIX A}

\section{Peggy Fleming's 1968 Winter Olympic Long Program}

\begin{tabular}{|c|c|}
\hline $\begin{array}{l}\text { Video } \\
\text { Timing }\end{array}$ & Music Heard \\
\hline $0: 28$ & $\begin{array}{l}\text { (Video with program: } \\
\text { https://www.youtube.com/watch?v=cEeKHqFUTqo) }\end{array}$ \\
\hline & $\begin{array}{l}\text { First chord of the Allegro Vivo of Tchaikovsky's Symphony } \\
\text { No. } 6 .\end{array}$ \\
\hline $0: 34-0: 36$ & Quick, upward motion of notes on an abrupt crescendo. \\
\hline $0: 42-0: 44$ & Similar to the above entry, but notes are raised a half step. \\
\hline $0: 45-0: 49$ & The strings build tension in an upward, scalar motion. \\
\hline $0: 51-0: 53$ & The quick scale runs build mounting tension and release it. \\
\hline $0: 55-0: 58$ & $\begin{array}{l}\text { More quick, upward motion from the strings, but this time in } \\
\text { groups of three notes that ascend in stepwise motion. }\end{array}$ \\
\hline 1:04-1:05 & Same building tension as in 0:51-0:53. \\
\hline $1: 18-1: 20$ & $\begin{array}{l}\text { Changes from ff to fff and features high note from the strings } \\
\text { that descend in a quick, repeating four note pattern. The horns } \\
\text { and the oboes come in a measure and a quarter later with loud, } \\
\text { dramatic long tones. }\end{array}$ \\
\hline $1: 21-1: 27$ & $\begin{array}{l}\text { Same music as before, but the horns and oboe have the } \\
\text { melody and the strings are a layered accompaniment. }\end{array}$ \\
\hline $1: 27-1: 29$ & $\begin{array}{l}\text { Horn and oboe melody repeats, but now has a long } \\
\text { descending line instead of repeating again. }\end{array}$ \\
\hline $1: 34$ & $\begin{array}{l}\text { Music changes to "Ebben? che diavol fate?" from } L a \\
\text { Traviata. }\end{array}$ \\
\hline $1: 34-1: 40$ & $\begin{array}{l}\text { A strong chord } f \text { followed by } p \text { descending stepwise motion. } \\
\text { The rest of the motion contains escape tones attached to the } \\
\text { descending notes of the scale. Repeats two more times within } \\
\text { this passage. }\end{array}$ \\
\hline $1: 41-1: 46$ & The same passage repeats again. ${ }^{12}$ \\
\hline $1: 46-1: 48$ & $\begin{array}{l}\text { Three measures of one quarter note with an appoggiatura and } \\
\text { two rests each. }\end{array}$ \\
\hline $1: 57-1: 58$ & $\begin{array}{l}\text { The final measures of the section she uses from "Ebben che } \\
\text { diavol fate." It's a chord followed by a quick four note } \\
\text { ascension and the same chord again to close. }\end{array}$ \\
\hline 2:00 & $\begin{array}{l}\text { After a brief pause, the music changes to "Mon coeur s'ouvre } \\
\text { à ta voix" from Act II, scene III of Saint-Saëns's Samson et } \\
\text { Dalila. }\end{array}$ \\
\hline $2: 00-2: 25$ & $\begin{array}{l}\text { Opens with a slow harp intro that leads into slow, romantic } \\
\text { music full of dramatic, descending long tones in the strings. }\end{array}$ \\
\hline $2: 27-2: 39$ & The same passage repeats again. \\
\hline
\end{tabular}

\section{Figure Skating Techniques}

Leaps out of starting pose with a hop to the right.

Double jump.

Leaps into a single jump.

Successive rotational spins across the ice.

Single jump.

Step sequence footwork.

Back-to-back single jumps.

Double axel.

Serpentine step sequence.

Single jump. ${ }^{11}$

Single jump $\rightarrow$ leap $\rightarrow$ single jump.

Flying camel spin into a one-foot spin.

Three strong glides in a halfcircle on the ice.

Single jump.

Fluid, balletic motion step sequence across the ice. Camel spin into attitude spin. Fluid, balletic motion step sequence across the ice.

\footnotetext{
${ }^{11}$ This is supposed to be a double axel, as performed at the 1968 U.S. Figure Skating Championships. She probably modified her jumps because she was so far ahead in the compulsory figures. https://www.youtube.com/watch?v=qxnWoQq9iMY\&t=100s

${ }^{12}$ In the original score, this passage does not repeat.
} 
2:54-3:00 Dramatic long tones from the strings that build tension by ascending to higher pitches. Then, the piece climaxes on a chorus of high pitched, romantic strings.

3:00-3:03 The aftermath of the piece's climax where the strings start to descend.

3:07-3:19

$3: 16$

$3: 21-3: 24$

$3: 30-3: 33$

$3: 34-3: 43$

$3: 43$

3:50-4:07

$4: 24-4: 34$
Music changes to the middle section of the overture to Rossini's La gazza ladra.

Bubbly, dancing winds that play doubled descending notes and give the sense of spinning or dancing.

Same as previous.

High winds (flutes, oboe) take the melody and play two sets of high note triplets that quickly fluctuate before ending on a single note a half-step above.

Music changes to the end of the overture to Rossini's $\mathrm{La}$ gazza ladra.

Grandiose orchestral music with percussion, cymbals, strings, brass, and winds playing $f+$.

The coda/outro, with strings repeating a series of notes until the last few chords are pronounced.
Outside spread eagle $\rightarrow$ Single jump $^{13} \rightarrow$ Spread eagle.

Outside-edge spread eagle into an inside-edge spread eagle. They

form an $\mathrm{S}$ on the ice.

Layback spin.

Ballet step sequence on toe picks.

Same as previous.

Sit spin into a scratch spin.

Leap $\rightarrow$ Single jump $\rightarrow$ Set of step sequence rotations $\rightarrow$ Hop $\rightarrow$ Single jump $\rightarrow$ Single jump Flying sit spin into a one leg spin.

${ }^{13}$ This is also supposed to be a double axel, as performed at the 1968 U.S. Figure Skating Championships. 


\section{APPENDIX B}

\section{Belousova/Protopopov's 1968 Winter Olympic Long Program}

\begin{tabular}{|c|c|}
\hline $\begin{array}{l}\text { Video } \\
\text { Timing }\end{array}$ & Music Heard (with specifics if possible) \\
\hline$-0: 25$ & $\begin{array}{l}\text { (Video with program: } \\
\text { https://www.youtube.com/watch?v=LrL54VzA1T4) })^{14}\end{array}$ \\
\hline $0: 26-0: 48$ & $\begin{array}{l}\text { Moonlight Sonata by Beethoven plays. In the key of C\# } \\
\text { minor. Arpeggios are played on the piano as an ostinato in the } \\
\text { right hand with chords sustained in the left hand. }\end{array}$ \\
\hline $0: 49$ & $\begin{array}{l}\text { The melody begins on a pick-up with a G\# dotted eighth and } \\
\text { sixteenth note at the end of a bar. In the following bar, the } G \\
\text { is sustained. The pattern then repeats at the end of the bar into } \\
\text { the following measure. }\end{array}$ \\
\hline $0: 51-0: 53$ & $\begin{array}{l}\text { Strings harmonize with the melody. The Protopopovs are } \\
\text { using a recording with an orchestration. }\end{array}$ \\
\hline $0: 53-1: 06$ & $\begin{array}{l}\text { Strings harmonize dramatic, sustained high notes with heavy } \\
\text { vibrato over the melody, arpeggios, and chords }\end{array}$ \\
\hline $1: 06-1: 12$ & $\begin{array}{l}\text { Strings continue harmonization over piano arpeggios and } \\
\text { chords. }\end{array}$ \\
\hline $1: 13-1: 25$ & $\begin{array}{l}\text { The music gets softer, specifically the orchestration, } \\
\text { emphasizing the melody in the piano. }\end{array}$ \\
\hline $1: 3$ & The strings rise into a crescendo and slowly decrescendo. \\
\hline $1: 41-1: 50$ & Same music as previous, but quieter. \\
\hline
\end{tabular}

1:51-2:01 Development of previous theme.

2:02-2:05 Development of previous theme continues with the strings slowly descending.

$2: 18$

$2: 18-2: 25$

$2: 26-2: 41$

$2: 41-2: 47$

2:47-3:03

3:03-3:08

$3: 08-3: 21$

$3: 22$

$3: 22-3: 38$

$3: 39-4: 04$
Music changes to the opening of Beethoven's fifth symphony.

The infamous first five measures of Beethoven's fifth symphony.

Rising tension in the strings on staccato notes that crescendo over time and culminate on three strong chords.

The final chord from the previous section is held out by the strings. Silence ensues for a brief moment before the opening theme comes back.

Just as before, the tension begins to build in the strings once again, albeit with different notes.

Loud, highly climactic sixteenth notes in the strings and long, booming tones from the brass and woodwinds.

All four measures of the opening theme play once again, but this time with more force and louder brass and woodwind instrumentation.

Music changes to something slow and romantic.

Harp arpeggios and light, romantic strings.

Just strings and woodwinds with very light brass at first, but after the percussion loudly enters, the brass becomes prominent.

\section{Figure Skating Techniques}

Start by standing face-to-face with one foot pointed out to either side.

Standing pose $\rightarrow 4$ glides $\rightarrow$

Slow circular revolution.

Serpentine step sequence.

Backwards serpentine step sequence.

Dual camel spin.

Hand-to-hand lift

Belousova dips to the inside edge of right skate with a short camel spin of one revolution.

Step sequence. Hand-to-hand lift with a spin of two revolutions.

Single jump $\rightarrow$ One full rotation on the ice to prep $\rightarrow$ Single jump. Step sequence with turns and crossovers into a single jump. Lift with two full rotations on the ice.

Step sequence with a brief sideways lift of Belousova by Protopopov.

Hand-to-hand lift with one full rotation on the ice.

Forward crossovers into a backward-inside death spiral (the Cosmic Spiral) of two full rotations.

Footwork.

Backward crossovers into a dual spiral.

\footnotetext{
14 This video was last accessible on March 28, 2020.
} 
4:10 Music changes to the end of Rachmaninoff's Piano Concerto

$4: 10-4: 16$

$4: 16-4: 24$

$4: 24-4: 33$

$4: 33-5: 00$

$5: 00-5: 12$

$5: 12-5: 24$

$5: 24-5: 35$
No. 3 in D Minor

Forceful, loud octaves played on the piano.

Whirling octave runs.

Strings play an emotional theme with the piano.

Strings continue playing an emotional theme with the piano, but it climaxes at a high-pitched, dramatic moment.

Happy, upbeat brass mixed followed by descending octave runs in the piano.

Piano octave runs and a brass-heavy ending of staccato notes.
Footwork and into a lift.

Two forward glides and backward crossovers into a by-the-waist lift. Rotational footwork into separate camel spins.

Dance-like footwork into a lift. Dance-like footwork with a highdifficulty lift.

Fancy, jazzy step sequence that goes in time with the music.

A brief spin in the air followed by forward and backward crossovers into a twist lift. 


\section{APPENDIX C}

\section{John Curry's 1976 Olympic Long Program}

Video Timing

0:22-0:27

0:27-0:31

$0: 32$

$0: 38-0: 52$

0:52-1:05

1:07-1:38-1:57

$1: 38-1: 57$

\section{Music Heard}

(Video with program:

https://www.youtube.com/watch?v=djadlQLK ow)

(Video with music from the score starting at 1:59:25:

https://www.youtube.com/watch?v=1k9j0KY2qoM)

(Pas de Quatre, pg. 153

Pas de Deux, pg. 157

Score:

http://ks.petruccimusiclibrary.org/files/imglnks/usimg/1/ 11/IMSLP113122-PMLP65356-Minkus -

Don_Quixote_PS_rsl.pdf)

Short, descending staccato chords that resolve upward. (mm. 1-3)

mm. 4-7 - A triplet and more descending, staccato chords, but they move upward on the fourth chord and then resolve downward on the sixth chord.

mm. 8-15

We hear a slurred triplet and an extra eighth note followed by an accented chord, then it repeats, and then we hear one more triplet with an extra eighth note followed by five pronounced chords.

No. 10, presto (Coda) mm. 1-16, first ending only. (pg. 164) $(2: 10: 10)$

mm. 1-20, second ending only. (pg. 164)

(2:01:33) No. 6, Andante mm. 24-33 (pg. 157)

Slow, graceful music. The line of the melody curves downward and then ascends upwards with slight pauses caused by sixteenth-note rests. The line then reaches its peak and slowly descends in measure 27. In m. 29, there is a turnaround heard in-between the tied eighth and sixteenth-note sounding on $\mathrm{D}$ at the beginning of the measure, followed by a leap up to an E-flat down to a $G$ and back up to a $\mathrm{D}$. The line slowly descends from $\mathrm{D}$ and the phrase ends on a dotted quarter note sounding on the tonic, E-flat.

The next phrase moves into a minor mode (?), as indicated by the C-flat in the bass in $\mathrm{m}$. 34 . Starting at $\mathrm{m} .33$, the line moves upwards in pitch and quickly pulls away by resolving downward. This is seen again in $\mathrm{mm}$. 34-35, this time with the dynamic increasing (crescendo) as the pitch increases, which is followed by a decrescendo and another leap downward. A push-andpull effect is created which climaxes in measure 38 on an enharmonically respelled Neapolitan chord that
Figure Skating Techniques Starting pose into short step sequence

Forward glides

Right walley $\rightarrow$ Triple toe loop

Step sequence $\rightarrow$ Walley jump $\rightarrow$ Double flip jump

Step sequence $\rightarrow$ Triple jump

Step sequence $\rightarrow$ forward camel spin $\rightarrow$ forward glide

Step sequence $\rightarrow$ Triple loop jump 
1:57-2:29

2:29-2:47

2:47-3:04

3:04-3:22

3:22-3:39

$3: 43-3: 52$

3:52-4:00

4:00-4:16

$4: 16-4: 33$

4:33-4:58

$4: 58-5: 21$ functions as an F-flat triad. It is also the only chord labeled triple-forte in the score. ${ }^{15}$

2:08:25 No. 8 Variation 2 (Allegro) (pg. 161) mm. 1-18

Written in $3 / 4$ as a waltz.

mm. 18-26 (with repeat)

mm. 27-42

2:08:47 (New score

http://ks4.imslp.info/files/imglnks/usimg/8/84/IMSLP30 799-PMLP65356-Minkus-DonQuixotePRmuz.pdf pg.

148)

This part of the score is excluded from the previously referenced video and score. Mm. 1-35, including beginning harp solo.

Harp - arpeggiated chords followed by solo run. mm. 1-9 with first ending (counting the harp solo as a pickup).

Broken chords grouped into three $32^{\text {nd }}$ notes and one eighth note, followed by a brief rest. After the first rest, the motive repeats with different notes and a $16^{\text {th }}$-note rest. A descending $16^{\text {th }}$-note scale follows. This repeats in a similar way twice more, but on the second repeat, the descending $16^{\text {th }}$-note scale is replaced with a series of descending broken chords. In the bass, there is an eighth-note ostinato.

mm. 1-10 with second ending

mm. 11-26

The ostinato bass continues with broken eighth-note chords in the melody followed by groups of four slurred sixteenth-notes. The first note of each group slowly descends in a scale and leap down to a neighbor-tone pattern for the other three notes in the group (FEF for the mm. 15-18 and m. 25, and GF\#G in mm. 23-24)

Back to the melody from mm. 1-10, but it's outlined differently in the provided score. In the score, it's the same melody as mm. 1-10, but with the repeat missing. Pg. 154, mm. 33-64 Continues the material from 0:381:05 (No. 10) starting with a strong, fast interlude. Pp. 155-56, mm. 81-106 Outro with big finale full of building tension, high pitches, and a back-and-forth ostinato that culminates on five strong ending chords. (pg. 155)
Step sequence $\rightarrow$ Forward camel/One-foot combospin Step sequence $\rightarrow$ Single jump $\rightarrow$ Step sequence $\rightarrow$ Single jump Step sequence $\rightarrow$ counterclockwise one-foot spin $\rightarrow$ clockwise two-foot spin Step sequence $\rightarrow$ Triple (?) jump Step sequence $\rightarrow$ Counterclockwise back camel
Step sequence

Step sequence with spins Counter-clockwise sit spin $\rightarrow$ Clockwise sit spin
Step sequence

Double lutz jump $\rightarrow$ Step sequence $\rightarrow$ Single jump Step sequence with an outside spread eagle $\rightarrow$ Double axel jump

\footnotetext{
${ }^{15}$ In the referenced score, the phrase from mm. 33-39 repeats in mm. 40-47, but this is not the case in either the referenced recording or the recording that Curry used. In those recordings, $\mathrm{mm}$. 39 flows straight into the outro at the end of m. 47.
} 


\section{APPENDIX D}

\section{Rodnina/Zaitsev's 1976 Olympic Long Program}

\author{
Video Timing \\ 0:06-0:08
}

0:08-0:24

$0: 24-0: 38$

$0: 38-0: 50$

0:50-1:05

1:05-1:53

1:53-2:08

2:08-2:17

$2: 17-2: 28$

$2: 28-2: 39$

2:39-2:50

2:50-3:09

3:09-3:41

3:41-3:54

$3: 54-4: 25$
Music Heard

(Video with program:

https://www.youtube.com/watch?v=2hezu89$\underline{\mathrm{XrY} \& \mathrm{t}=329 \mathrm{~s})}$

Fast-paced, intervallic upward motion that then descends. The notes are quick and the pace of the music is fast, as well.

The music continues to be quick and upbeat, with higher wind instruments carrying the ensemble through a series of descending and ascending runs.

Same passage as before repeated again.

Returns to the opening material with strong, fast-paced intervallic motion driven by the low-sounding strings. The music changes to a slow, emotional lament heavy with string sounds and low winds.

Silence as the music changes from one excerpt to another.

A fast-driving, strong ostinato in the horns with high string runs.

Music from previous section repeats.

The music gets more upbeat in this section and changes motives a few times. As the music gets faster and more complex, so do Rodnina and Zaitsev's movements.

The fast-paced melody briefly changes over to a slower, poignantly articulated theme. This excerpt concludes with a repeat of the beginning of the new theme and a few accented chords.

(https://www.youtube.com/watch?v=6V9m7psEcmI\&lis $\mathrm{t}=$ OLAK5uy 19zNjeswGwjA5YVYstDkyGvK joN3we Pc\&index $=10$ ) (Tsigany (Gypsies) from the Moiseyev Dance Company, 2:00-3:41, but Rodnina and Zaitsev have cut some of it out)

Slow, expressive music with dramatic low strings. There are "gypsy" scale tones in here and string slides that signal a Romani trope.

The strings quietly end one part of the excerpt and as Rodnina and Zaitsev finish their spin, the piano gently plays
Figure Skating Techniques Posing

Forward glides $\rightarrow$ Back crossovers $\rightarrow$ Two-handed lift turns into a one-handed lift Single axel jump $\rightarrow$ Double toe loop $\rightarrow$ Half loop $\rightarrow$ Double salchow

360-degree turn $\rightarrow$ 180-degree turn $\rightarrow$ Backward crossovers $\rightarrow$ Two-handed overheard lift with difficult dismount

Forward Glides/Backward Crossovers $\rightarrow$ Triple-flip twist Step-sequence $\rightarrow$ Double axel

Backward crossovers $\rightarrow$ Twohanded lift turns into a onehanded lift.

Quick, forward motion across the ice.

Assisted half loop $\rightarrow$ Assisted half loop $\rightarrow$ Two-handed overhead lift with changing leg positions

Serpentine step-sequence with change over from front crossovers to back crossovers $\rightarrow$ Turn $\rightarrow$ Star jump $\rightarrow$ Turn $\rightarrow$ Star jump $\rightarrow$ Double toe loop (?) Side-by-side butterflies $\rightarrow$ Lift

Double Flip

Step sequence $\rightarrow$ Lift $\rightarrow$ Death Spiral

Pair combination spin

Leap jump $\rightarrow$ Single jump 
(Tsigany (Gypsies) 3:45-4:46)

The music changes from the slow, emotional, and expressive music to a folk suite (Tsigany from the Moiseyev Dance Company). It starts out slow at first with a note held on a string instrument that transitions into a dotted rhythm with bowed notes in the high strings and pizzicato notes in the low strings.

$4: 41-4: 51$

4:51-5:05

5:05-5:18 4:41 and progressively gets faster.

Continuing the previous melody, but the music gets even faster.

Outro of Tsigany excerpt ending on two strong chords.
More of the instrumental ensemble joins the strings at
Step sequence

Flying camel $\rightarrow$ Forward sit spin

Step sequence $\rightarrow$ Double twist catch lift 


\section{Bibliography}

Abrams, Bill. "Olympics Didn't Give Big Boost to Ratings for ABC; Audience Slips 15\% from 1980." The Wall Street Journal, Feb 22, 1984.

Adams, Mary Louise. Artistic Impressions: Figure Skating, Masculinity, and the Limits of Sport. Toronto: University of Toronto Press, 2011.

Anderson, Carol. White Rage: The Unspoken Truth of Our Racial Divide. New York: Bloomsbury, 2017.

Anderson, E. and M. McCormack, "Intersectionality, Critical Race Theory, and American Sporting Oppression: Examining Black and Gay Male Athletes." Journal of Homosexuality 57, no. 8 (2010): 949-67.

Anderson, Sheldon. The Politics and Culture of Modern Sports. London: Lexington, 2015.

Ansari, Emily Abrams. The Sound of a Superpower: Musical Americanism and the Cold War. New York: Oxford University Press, 2018.

Arjen Molen. Cold War - Star Wars 1981-1988 - Part 22/24. YouTube video, September 24, 2015, https://youtu.be/uq-2BPTtp00.

Armstrong, John. "Rodion Shchedrin Carmen Suite Review." BBC, 2002, https://www.bbc.co.uk/music/reviews/v8cz/.

Arnaud, Pierre, and James Riordan. Sport and International Politics: Impact of Fascism and Communism on Sport. London: Routledge, 2015.

Aronowitz, Stanley. How Class Works: Power and Social Movement. New Haven, Connecticut: Yale University Press, 2004.

Atkins, Ross. "Katarina Witt Aims to Go for the Gold Again After Six Years Away from Competition, the Two-Time Olympic Skating Champion Is Training for Lillehammer." The Christian Science Monitor, December 14, 1993.

Ball, Alan M. Liberty's Tears Soviet Portraits of the "American Way of Life" during the Cold War. New York: Oxford University Press, 2016.

Barnhisel, Greg. "American Modernism in American Broadcasting: The Voice of (Middlebrow) America." In Cold War Modernists: Art, Literature, and American Cultural Diplomacy. New York: Columbia University Press, 2015: 217-248.

Bass, Amy. Not the Triumph But the Struggle: The 1968 Olympics and the Making of the Black Athlete. Minneapolis: University of Minnesota Press, 2002. 
Bateman, Anthony, and John Bale. Sporting Sounds: Relationships between Sport and Music. London: Routledge, 2010.

BBC News. "Battle of the Carmens" Katarina Witt - Witness - BBC News. YouTube video, February 9, 2014, https://www.youtube.com/watch?v=aiCLlAT0Idc.

Beacom, Aaron. International Diplomacy and the Olympic Movement: The New Mediators. New York: Palgrave, 2012.

Bean, Dawn Pawson. Synchronized Swimming: An American History. Jefferson: McFarland \& Co., 2005.

Bereznak, Alyssa. "Why Do So Many Figure Skaters Choose the Same Music?" The Ringer, February 13, 2018.

Berry, Scott M. “Gold Medals, Protests, and Trading Ratings: The 2002 Winter Olympics Figure Skating." Chance Chance 15, no. 2 (2002): 14-18.

Billings, Andrew C. Olympic Media: Inside the Biggest Show on Television. London; New York: Routledge, 2008.

Billings, Andrew C, James R Angelini, and Paul J MacArthur. Olympic Television:

Broadcasting the Biggest Show on Earth. New York: Routledge, 2018.

Bird, Dennis L. "Obituary: John Curry.” The Independent, April 16, 1994, https://www.independent.co.uk/news/people/obituary-john-curry-1370333.html.

Bissoux, Bunny. "From Yuzuru Hanyu to 'Yuri on Ice': Japan's Fascination With Figure Skating." Tokyo Weekender, March 5, 2018, https://www.tokyoweekender.com/2018/03/from-yuzuru-hanyu-to-yuri-on-ice-japansfascination-with-figure-skating/.

Black, David and Byron Peacock, "Sport and Diplomacy." In The Oxford Handbook of Modern Diplomacy, edited by Andrew F. Cooper, Jorge Heine, and Ramesh Chandra Thakur, 708-728. Oxford and New York: Oxford University Press, 2013.

Blutstein, Harry. Cold War Games: Espionage, Spies and Secret Operations at the 1956 Olympic Games. Australia: Bonnier Publishing, 2017.

Bohlman, Andrea and Alexander Rehding. "Doing the European Two-Step." In Empire of Song: Europe and Nation in the Eurovision Song Contest, edited by Dafni Tragaki, 281-298. Lanham: Scarecrow Press, 2013.

Bohlman, Philip. "The Ascent of Music and the 63rd Eurovision Song Contest." OUPblog (blog). July 5, 2018. 
— .The Politics of Power, Pleasure and Prayer in the Eurovision Song Contest." Muzikologija, no. 7 (2007): 39-67.

Boyle, Raymond and Richard Haynes. "Playing the Game: Media Sport and Gender." In Power Play: Sport, the Media and Popular Culture. Edinburgh University Press, 2009: 122-43.

. Power Play: Sport, the Media and Popular Culture. Cambridge: Cambridge University Press, 2013.

Butler, Nick. "ISU Vote to Abolish Anonymous Judging System in Figure Skating to 'Increase Transparency.'" Insidethegames.biz, June 8, 2016, https://www.insidethegames.biz/articles/1038244/isu-vote-to-abolish-anonymousjudging-system-in-figure-skating-to-increase-transparency.

Cahn, Susan. Coming on Strong: Gender and Sexuality in Women's Sport. Second edition, Urbana: University of Illinois Press, 2015.

Cervin, Georgia. Women's Artistic Gymnastics during the Cold War and Its Aftermath. Perth: University of Western Australia, 2016.

Clarey, Christopher. “"Rhapsody in Blue' or Rap? Skating Will Add Vocals.” The New York Times, February 18, 2014.

CoffeeOnIce. Gordeeva and Grinkov, "Carmen." YouTube video, July 24, 2007, https://www.youtube.com/watch?v=Ujb-2rRGMJA.

Coleman, Annie Gilbert. "The Unbearable Whiteness of Skiing." In Sport Matters: Race, Recreation and Culture, edited by John Bloom and Michael Nevin Willard, 141-167. New York: New York University Press, 2002.

Collins, Patricia Hill. Black Sexual Politics: African Americans, Gender, and the New Racism. New York: Routledge, 2004.

Coniglio, Bradley J. "In Defense of a Neoliberal America: Ronald Reagan, Domestic Policy, and the Soviet Boycott of the 1984 Los Angeles Olympic Games." In Defending the American Way of Life: Sport, Culture, and the Cold War, edited by Toby C. Rider and Kevin B. Witherspoon, 205-218. Fayetteville: University of Arkansas Press, 2018.

Copley-Graves, Lynn. Figure Skating History: The Evolution of Dance on Ice. Columbus, OH: Platoro Press, 1992.

Crist, Stephen A. "Jazz as Democracy? Dave Brubeck and Cold War Politics." The Journal of Musicology 26, no. 2 (2009): 133-74. 
Croft, Clare. Dancers as Diplomats: American Choreography in Cultural Exchange. Oxford: Oxford University Press, 2015.

Culshaw, Peter. "How Jazz Survived the Soviets." The Telegraph, November 14, 2006.

D'Agati, Philip A. The Cold War and the 1984 Olympic Games: A Soviet-American Surrogate War. New York: Palgrave, 2013.

Davenport, Lisa E. Jazz Diplomacy Promoting America in the Cold War Era. Jackson: University Press of Mississippi, 2009.

Dee 'Petal' Redley. Victor Petrenko 1988 Olympics LP. YouTube video, June 30, 2007, https://www.youtube.com/watch?v=52F11-qwewU.

Dixon Gottschild, Brenda. The Black Dancing Body: A Geography from Coon to Cool. New York: Palgrave Macmillan, 2003.

Douglas, Delia D.. "To Be Young, Gifted, Black and Female: A Meditation on the Cultural Politics at Play in Representations of Venus and Serena Williams." Sociology of Sport Online 5, no. 1 (2002).

Dudziak, Mary. Cold War Civil Rights: Race and the Image of American Democracy. Princeton: Princeton University Press, 2001.

Dufur, Mikaela J. "Gender and Sport." In Handbook of the Sociology of Gender, edited by Janet Saltzman Chafetz, 583-600. New York: Kluwer Academic/Plenum Publishers, 2006.

Dyreson, Mark. Crafting Patriotism for Global Dominance: America at the Olympics. London: Routledge, 2009.

Eaton, Joseph. "Decentering US Sports Diplomacy: the 1980 Moscow Boycott through Contemporary Asian-African Perspectives." In Sports and Diplomacy: Games Within Games. Edited by J. Simon Rofe. Manchester: Manchester University Press, 2018.

Edelman, Robert, Anke Hilbrenner, and Susan Brownell. "Sport Under Communism.” In The Oxford Handbook of the History of Communism. Oxford: Oxford University Press, 2014.

Edelman, Robert. Serious Fun: A History of Spectator Sports in the USSR. Oxford: Oxford University Press, 1993.

Els, Rozanne. "11 Things You Should Know About Olympic Figure-Skating Music." Vulture, February 20, 2018. 
Espy, Richard. Politics of the Olympic Games: With an Epilogue, 1976-1980. California: University of California Press, 2018.

Euphoria and Exhaustion: Modern Sport in Soviet Culture and Society. Edited by Katzer, Nikolaus, Sandra Budy, Alexandra Köhring, and Manfred Zeller. Frankfurt-on-Main: Campus Verlag, 2010.

Fabos, Bettina. "Forcing the Fairytale: Narrative Strategies in Figure Skating Competition Coverage." Sport in Society 4, no. 2 (Summer 2001): 185-212.

Fiske, Susan T. and Hazel Rose Markus. Facing Social Class: How Societal Rank Influences Interaction. New York: Russell Sage Foundation, 2012.

Fleming, Peggy and Peter Staminsky. The Long Program: Skating Toward Life's Victories. New York: Pocket Books, 2000.

floskate. Irina Rodnina \& Alexander Zaitsev 1976 Worlds LP. YouTube video, July 5, 2015, https://www.youtube.com/watch?v=rmPXpGyEN1U.

- John Curry - 50 Golden Days Part 3. YouTube video, February 9, 2008, https://www.youtube.com/watch?v=kPXsST9vGFg.

Ford, Bonnie D. “OTL: An Enduring Legacy for Ice Skating.” ESPN.Com (blog). http://www.espn.com/espn/eticket/story?page=110215/skatingcrash.

Fosler-Lussier, Danielle. Music in America's Cold War Diplomacy. Berkeley, University of California Press, 2015.

Frackman, Kyle and Larson Powell. Classical Music in the German Democratic Republic: Production and Reception. Rochester, New York: Camden House, 2015.

Friedersdorf, Conor. "Peggy Fleming and the 1968 Winter Olympics," The Atlantic, February 7, 2018, https://www.theatlantic.com/entertainment/archive/2018/02/peggyfleming-and-the-1968-winter-olympics/552635/.

Gaddis, John Lewis. The Cold War: A New History. London: Penguin, 2005.

Gammage, Marquita Marie. Representations of Black Women in the Media: The Damnation of Black Womanhood. New York: Routledge, 2016.

gem7ini. Irina Rodnina \& Alexander Zaitsev - 1976 Olympics - Long program. YouTube video, October 18, 2012, https://www.youtube.com/watch?v=2hezu89-XrY.

—. John Curry - 1976 Olympics - Free Skate. YouTube video, October 18, 2012, https://www.youtube.com/watch?v=ZP9EoSIEBgg\&t=57s. 
Ludmila Belousova \& Oleg Protopopov - 1968 Olympics - FS. YouTube video, May 12, 2012, https://www.youtube.com/watch?v=LrL54VzA1T4.

Peggy Fleming - 1968 Olympics - FS. YouTube video, May 12, 2012, https://www.youtube.com/watch?v=cEeKHqFUTqo.

Gerken, Tom. "Winter Olympics: Yuri On Ice Performed by Japanese Skaters." BBC News, February 9, 2018, sec. BBC Trending, https://www.bbc.com/news/blogs-trending$\underline{43003630 .}$.

Gleaves, John T. and Matthew P. Llewellyn. "The 'Big Arms' Race: Doping and the Cold War Defense of American Exceptionalism." In Defending the American Way of Life: Sport, Culture, and the Cold War, edited by Toby C. Rider and Kevin B. Witherspoon, 49-66. Fayetteville: University of Arkansas Press, 2018:.

GoldenAgeofFS. Debi Thomas - 1988 U.S. Figure Skating Championships - Long Program. YouTube video, November 12, 2018, https://www.youtube.com/watch?v=SdNrD6ysX2A.

- Here's Peggy Fleming (1968) TV Special. YouTube video, July 1, 2015, https://www.youtube.com/watch?v=xnyVYYFfMmk.

-. Peggy Fleming - 1968 U.S. Figure Skating Championships - Long Program.

YouTube video, November 22, 2014, https://www.youtube.com/watch?v=qxnWoQq9iMY\&t=100s.

Gordeeva, Ekaterina. My Sergei: A Love Story. Translated by E. M. Swift. New York: Hachette, 2009.

Graham, Bradley. "Soviet Skaters Defect.” Washington Post, September 25, 1979, https:/www.washingtonpost.com/archive/politics/1979/09/25/soviet-skatersdefect/0d2f2711-c9c9-4ace-a2ac-c8067a6b91a8/.

Grant Walter. Don Quijote Pas de Deux R Nureyev Y Morishita NYC TV. YouTube video, September 8, 2017, https://www.youtube.com/watch?v=GcgY4qWRI-M\&t=299s.

Grossberger, Lewis. “The Protopopovs.” Washington Post, February 5, 1980, https://www.washingtonpost.com/archive/lifestyle/1980/02/05/theprotopopovs/854f7f52-97c3-4a93-bced-c71d77fc274e/.

Hardy, Stephen. "Remembering and Forgetting America's Hockey Miracles." In Replays, Rivalries, and Rumbles: The Most Iconic Moments in American Sports, edited by Steven Gietschier, 171-179. Urbana: University of Illinois Press, 2017.

Hargreaves, Jennifer. Sporting Females: Critical Issues in the History and Sociology of Women's Sports. London: Routledge, 1994. 
Hanley, Elizabeth A. "No Passion at the Palavela': Sonia Bianchetti Garbato and Figure Skating's New Judging System." In Cultural Imperialism in Action: Critiques in the Global Olympic Trust, edited by Nigel B. Crowther, Robert K. Barney, and Michael K. Heine, 145-156. London, ON: International Centre for Olympic Studies, 2006.

Heutsche, Anne. "Thomas, Debi." In Black Women in America. Oxford: Oxford University Press, 2005.

Hilton, Lisette. "Fleming Launched Modern Era of Figure Skating." ESPN Classic, http://www.espn.com/classic/biography/s/Fleming_Peggy.html.

Hines, James R. Figure Skating in the Formative Years: Singles, Pairs, and the Expanding Role of Women. Urbana: University of Illinois Press, 2017.

Hodgson, Godfrey. The Myth of American Exceptionalism. Yale University Press, 2009.

Hoffer, Richard. Something in the Air: American Passion and Defiance in the 1968 Mexico City Olympics. Lincoln: University of Nebraska Press, 2018.

Hofmann, Annette R. "Katarina Witt: The Many Faces of a Showcase Athlete." More than Cricket and Football: International Sport and the Challenge of Celebrity, edited by Joel Nathan Rosen and Maureen M. Smith, 278-296. Jackson: University Press of Mississippi, 2016.

hooks, bell. "The Oppositional Gaze: Black Female Spectators." In bell hooks, Black Looks: Race and Representation, 115-132. $2^{\text {nd }}$ ed. New York: Routledge, 2015.

Hunt, Thomas M. Drug Games: The International Olympic Committee and the Politics of Doping, 1960-2008. Austin: University of Texas Press, 2011.

Hunt, Thomas B. "Sport and American Foreign Policy during the 1960s." In Defending the American Way of Life: Sport, Culture, and the Cold War, edited by Toby C. Rider and Kevin B. Witherspoon, 189-204. Fayetteville: University of Arkansas Press, 2018.

International Ice Hockey Federation. "Story \#17.” http://webarchive.iihf.com/iihf-home/theiihf/100-year-anniversary/100-top-stories/story-17/.

International Olympic Committee. "Canadian Pair Break Figure Skating's Mould with 'Death Spiral.'” Olympic.org, February 7, 1948, https://www.olympic.org/news/canadian-pair-break-figure-skating-s-mould-with-deathspiral.

_. "Figure Skating - Winter Olympic Sport." Olympic.org, https://www.olympic.org/figure-skating/?section=ajax-area$\underline{6780872 \text { eede } 3420 \mathrm{fa} 60 \mathrm{~b} 0 \mathrm{f} 0043 \mathrm{a} 84400 \& \text { section=ajax }- \text { area- }}$ 
6780872eede3420fa60b0f0043a84400\&id=boxb680567d08be4889ad97a95ac24b03e1\&id=boxb680567d08be4889ad97a95ac24b03e1.

. "John Curry - Olympic Figure Skating | Great Britain." Olympic.org, January 31, 2017, https://www.olympic.org/john-curry.

_ . "Katarina Witt - Olympic Figure Skating | Germany." Olympic.org, December 18, 2018, https://www.olympic.org/katarina-witt.

International Skating Union. "International Skating Union Constitution and General Regulations." Last modified June, 2018.

Iriye, Akira. "Historicizing the Cold War." In The Oxford Handbook of the Cold War, 2013, https://doi.org/10.1093/oxfordhb/9780199236961.013.0002.

Jackson, Timothy L. Tchaikovsky, Symphony no. 6 (Pathètique). Cambridge: Cambridge University Press, 1999.

JohnCurry1. The Real John Curry Part 1. YouTube video, February 23, 2010, https://www.youtube.com/watch?v=FBpyePyCpjs.

JohnCurry1. The Real John Curry Part 2. YouTube video, February 23, 2010, https://www.youtube.com/watch?v=IPDmczkp 8s.

JohnCurry1. The Real John Curry, Part 3. YouTube video, February 23, 2010, https://www.youtube.com/watch?v=5kGiobYYXoA\&t=7s.

Johnson, Molly Wilkinson. Training Socialist Citizens: Sports and the State in East Germany. Leiden: Brill, 2008.

Jones, Bill. Alone: The Triumph and Tragedy of John Curry. London, UK: Bloomsbury Sport, 2015.

Kelly, Elaine and Amy Wlodarski. Art Outside the Lines: New Perspectives on GDR Art Culture. Leiden, The Netherlands: Brill, 2011.

Kerrigan, Nancy, and Mary Spencer. Artistry on Ice: Figure Skating, Skills and Style. Champaign: Human Kinetics, 2003.

Kestnbaum, Ellyn. "Critiques of Skating's Feminine Ideals." In Culture on Ice: Figure Skating and Cultural Meaning. Middletown: Wesleyan University Press, 2003.

- Culture on Ice: Figure Skating \& Cultural Meaning. Middletown: Wesleyan University Press, 2003. 
King, Richard C. "Staging the Winter White Olympics: Or, Why Sport Matters to White Power." Journal of Sport and Social Issues 31, no. 1 (2007): 89-94.

Kobierecki, Michal Marcin. Sports Diplomacy: Sports in the Diplomatic Archives of States and Non-State Actors. London: Lexington, 2020.

Koch, Jordan and Douglas Brown. "Ringleaders: Olympic Athletes who Donned, Inked, and Embodied the Olympic Logo in the Cold War." Olympika 20 (2011): 1-30.

Kondrashina, Evgeniya. "Soviet Music Recordings and Cold War Cultural Relations." In Entangled East and West: Cultural Diplomacy and Artistic Interaction during the Cold War. Edited by Simon Mikkonen, Jari Parkkinen, and Giles Scott-Smith. Berlin and Boston: De Gruyter, 2019.

Kramer, Lawrence. Musical Meaning: Toward a Critical History. Berkeley: University of California Press, 2002, eBook.

Krause, Elizabeth L. "“The Bead of Raw Sweat in a Field of Dainty Perspirers': Nationalism, Whiteness, and the Olympic-Class Ordeal of Tonya Harding."

Transforming Anthropology 7, no. 1 (1998): 33-52.

Lawrence, Kelly. Skating on Air: The Broadcast History of an Olympic Marquee Sport. Jefferson, NC: McFarland, 2011.

Leonard, David J. "Dilemmas and Contradictions: Black Female Athletes." In Out of Bounds: Racism and the Black Athlete, edited by Lori Latrice Martin, 209-230. Santa Barbara: Praeger, 2014.

Lieser, Josh R. "Los Angeles and the 1984 Olympic Games: Cultural Commodification, Corporate Sponsorship, and the Cold War." PhD diss., University of California, Riverside, 2014.

lillyvippomi. Don Quixote-Pas de Deux. YouTube video, December 24, 2008, https://www.youtube.com/watch?v=jdWfKuedOMk.

Litsky, Frank. "Ludmila Belousova, Russian Who Skated With Husband to Olympic Gold, Dies at 81." The New York Times, October 2, 2017, sec. Obituaries, https://www.nytimes.com/2017/10/02/obituaries/ludmila-belousova-dead-championrussian-figure-skater-with-husband-protopopov.html.

Lenskyj, Helen. Gender Politics and the Olympic Industry. New York: Palgrave, 2013.

Lenskyj, Helen and Stephen Wagg. The Palgrave Handbook of Olympic Studies. New York: Palgrave Macmillan, 2012,

http://public.eblib.com/choice/publicfullrecord.aspx?p=1330901. 
Letellier, Robert I. The Ballets of Ludwig Minkus. UK: Scholars Publisher, 2008.

Levering, Ralph B. The Cold War: A Post-Cold War History. Third edition. Chichester: Wiley \& Sons, 2016.

Levin, Simon. "Beethoven in Soviet Musicology from 1917 to 1970." The Beethoven Newsletter 5, no. 1 (1990): 10-18.

Lipsitz, George. The Possessive Investment in Whiteness: How White People Profit from Identity Politics. Philadelphia: Temple University Press, 2018.

Lohr, Ryan, Jennifer Allen, and Randy Salas. "And the Gold Medal for Figure Skating Goes to Classical Music." Classicalmpr, February 7, 2018.

Louise, Lins. Carmen - Svetlana Zakharova - Bolshoi Ballet COMPLETE, 2012. https://www.youtube.com/watch?v=yJlyGNitxz0\&t=72s.

Loy, John W., Fiona McLachlan, and Douglas Booth. "Connotations of Female Movement and Meaning: The Development of Women's Participation in the Olympic Games." Olympika 18 (2009), 1-24.

Macdonald, Hugh. "Samson et Dalila." In Grove Music Online, 2002. https://wwwoxfordmusiconlinecom.www.libproxy.wvu.edu/grovemusic/view/10.1093/gmo/9781561592630.001.0001/ omo-9781561592630-e-5000904621.

Mayne, Judith. "Fear of Falling." In Framed: Lesbians, Feminists, and Media Culture. Minneapolis: University of Minnesota Press, 2000: 103-114.

McClary, Susan. Feminine Endings: Music, Gender, and Sexuality. Minneapolis: University of Minnesota Press, 2002.

—. Georges Bizet, Carmen. Cambridge: Cambridge University Press, 1992.

McConnell, Stephanie W. "Jimmy Carter, Afghanistan, and the Olympic Boycott: The Last Crisis of the Cold War?," Ph.D. diss., Bowling Green State University, 2001.

McLeod, Ken, Stan Hawkins, and Lori Burns. We Are the Champions: The Politics of Sports and Popular Music. Farnham: Taylor \& Francis Group, 2011.

Mertin, Evelyn. "Steadfast Friendship and Brotherly Help: The Distinctive Soviet-East German Sport Relationship with the Socialist Bloc." In Diplomatic Games: Sport, Statecraft, and International Relations Since 1945, edited by Evelyn Mertin and Andrew L. Johns, 53-84. Lexington, University Press of Kentucky, 2014. 
Milner, Adrienne N. and Jomills Henry Braddock II. Women in Sports: Breaking Barriers, Facing Obstacles. Santa Barbara: ABC-CLIO, LLC, 2017.

Montoya, Daniel. "The Eurovision Song Contest: Singing for the Political Upper Hand." Harvard International Review 38, no. 4 (2017): 7-10.

Moormann, P. P. "Choreography Styles in Figure Skating." Journal of Creative Behavior 40 (2006): 265-87.

Moran, Alicia Hall. Battle of the Carmens. YouTube video, May 7, 2016, https://www.youtube.com/watch?v=4RRN5LMH3vw.

Muhammad, Khalil Gibran. The Condemnation of Blackness: Race, Crime, and the Making of Modern Urban America. Cambridge, MA: Harvard University Press, 2011.

Murray, Stuart. Sports Diplomacy: Origins, Theory, and Practice. London: Taylor and Francis, 2018.

Muther, Christopher. "The Ice Rink Becomes the Runway for Female Figure Skaters." BostonGlobe.com, January 11, 2014, https://www.bostonglobe.com/lifestyle/style/2014/01/11/the-ice-rink-becomes-runwayfor-female-figure-skaters/ZfSFpCEEKGGPrwzAcvnGRN/story.html.

Nichols, Nikki. Frozen in Time: The Enduring Legacy of the 1961 U.S. Figure Skating Team. Cincinnati: Clerisy Press, 2008.

O'Callaghan, Eoin. “Adam Rippon, John Curry and Figure Skating's Complex History with Gay Athletes." The Guardian, February 17, 2018, sec. Sport, http://www.theguardian.com/sport/2018/feb/17/adam-rippon-lgbt-figure-skaters-johncurry.

Olson, Laura. Performing Russia: Folk Revival and Russian Identity. New York: Routledge, 2004.

Olympic. Katarina Witt - The Diva on Ice with a Huge Heart | Legends Live On. YouTube video, February 6, 2018, https://www.youtube.com/watch?v=wK0MgQpxvrg.

. The Full Grenoble 1968 Winter Olympic Film | Olympic History. February 25, 2015. https://www.youtube.com/watch?v=PnwAYJWygYY.

O'Mahony, Mike. Sport in the USSR: Physical Culture-Visual Culture. London: Reaction Books, 2006.

Orita, Helen. "Making a Medley: Genre and Form in Music Arranged for Figure Skating Programs.” M.A. thesis, University of North Carolina at Chapel Hill, 2017. 
Osborne, Richard. "Gazza Ladra, La.” In Grove Music Online, 2002. https://wwwoxfordmusiconlinecom.www.libproxy.wvu.edu/grovemusic/view/10.1093/gmo/9781561592630.001.0001/ omo-9781561592630-e-5000002717.

Parker, Roger. “Traviata, La.” In Grove Music Online, 2002. https://doiorg.www.libproxy.wvu.edu/10.1093/gmo/9781561592630.article.O005794.

Parks, Jenifer. The Olympic Games, the Soviet Sports Bureaucracy, and the Cold War: Red Sport, Red Tape. Lanham: Maryland Lexington Books, 2017.

. "Welcoming the 'Third World': Soviet Sport Diplomacy, Developing Nations, and the Olympic Games." In Diplomatic Games: Sports, Statecraft, and International Relations Since 1945, edited by Evelyn Mertin and Andrew L. Johns, 85-116. Lexington: University Press of Kentucky, 2014.

Petkevich, John Misha. Sport Illustrated Figure Skating: Championship Techniques. New York: Sports Illustrated, 1989.

Pfister, Gertrud. "Cold War Diplomats in Tracksuits: The Fräuleinwunder of East German Sport." In Militarism, Sport, Europe: War without Weapons, edited by J.A. Mangan, 226256. London: Frank Cass, 2003.

Phillips, Victoria. Martha Graham's Cold War: The Dance of American Diplomacy. New York: Oxford University Press, 2019.

Pieper, Lindsay Parks. "Policing Womanhood: The International Olympic Committee, Sex Testing and the Maintenance of Hetero-Femininity in Sport." Ph.D. diss., The Ohio State University, 2013.

—_ “Wolves in Skirts?': Sex Testing in Cold War Women's Sport." In Defending the American Way of Life: Sport, Culture, and the Cold War, edited by Toby C. Rider and Kevin B. Witherspoon, 85-98. Fayetteville: University of Arkansas Press, 2018.

Plisetskaya, Maya, Antonina W. Bouis, and Tim Scholl. "How Carmen Suite Was Born.” In I, Maya Plisetskaya. New Haven: Yale University Press, 2001, eBook.

Prevots, Naima. Dance for Export: Cultural Diplomacy and the Cold War. Middletown: Wesleyan University Press, 1998.

Prozumenshikov, Mikhail. "Action in the Era of Stagnation: Leonid Brezhnev and the Soviet Olympic Dream." In The Whole World Was Watching: Sport in the Cold War, edited by Robert Edelman and Christopher Young. Stanford: Stanford University Press, 2020.

Rand, Erica. Red Nails, Black Skates: Gender, Cash, and Pleasure On and Off the Ice. Durham: Duke University Press, 2012. 
Redihan, Elizabeth. "Winning Hearts and Medals: The Olympics and the Cold War, 19481968.” Ph.D. diss., Clark University, 2015.

- The Olympics and the Cold War, 1948-1968: Sport as Battleground in the U.S.Soviet Rivalry. Jefferson: McFarland \& Co., 2017.

Rider, Toby C. Cold War Games: Propaganda, the Olympics, and U.S. Foreign Policy. Urbana: University of Illinois Press, 2017.

Riordan, James. Soviet Sport: Background to the Olympics. Oxford: Blackwell, 1980.

- Sport in Soviet Society: Development of Sport and Physical Education in Russia and the USSR. Cambridge: Cambridge University Press, 1977.

Riordan, Jim. "The Rise and Fall of Soviet Olympic Champions." Olympika 2 (1993), 2544.

Ritzarev, Marina. Tchaikovsky's Pathètique and Russian Culture. Farnham: Ashgate, 2014.

Romano, Stefan. "Politicizing Music in Communist Romania: The Personal Memories of a Witness." The Beethoven Journal 14, no. 1 (1999): 27-30.

—. Sport, Politics, and Communism. New York: Manchester University Press, 1991.

Rosenberg, Danny and Kelly L. Lockwood. "Will the New Figure Skating Judging System Improve Fairness at the Winter Olympics?” Olympika 14 (2005): 69-84.

Routledge Handbook of Sport and Politics. Edited by Alan Bairner, John Kelly, and Jung Woo Lee. London: Taylor \& Francis, 2016.

Rowe, Jonathan. "Calgary Olympics: The Games that TV built." Christian Science Monitor, February 16, 1988.

Ryan, Joan. Little Girls in Pretty Boxes: The Making and Breaking of Elite Gymnasts and Figure Skaters. New York: Warner, 2000.

Sarkar, Pritha. "Sotnikova Win Raises Judging Questions.” Reuters, February 20, 2014, https://uk.reuters.com/article/us-olympics-figureskating-judgingidUKBREA1J2DJ20140220.

Sausa, Christie. "Skating: Protopopovs, Dick Button Reunite at Tribute." The Adirondack Almanack, September 6, 2011, https://www.adirondackalmanack.com/2011/09/skatingprotopopovs-dick-button-reunite-at-tribute.html. 
Schantz, Otto. "The Olympic Ideal and the Winter Games Attitudes Towards the Olympic Winter Games in Olympic Discourses - from Coubertin to Samaranch." https://web.archive.org/web/20130505052232/http://www.coubertin.ch/pdf/schantz.pdf

Schlueter, Roger. "This Is How Figure Skaters Choose the Music for Their Performances." Belleville News Democrat. 2018. https://www.bnd.com/living/liv-columnsblogs/answer-man/article204131139.html.

Schmelz, Peter J. "Introduction: Music in the Cold War." The Journal of Musicology 26, no. 1 (2009): 3-16.

Schwarz, Boris. Music and Musical Life in Soviet Russia, 1917-1981. Bloomington: Indiana University Press, 1983.

Searcy, Anne. Ballet in the Cold War: A Soviet-American Exchange. New York: Oxford University Press, 2020.

. "The Recomposition of Aram Khachaturian's Spartacus at the Bolshoi Theater, 1958-1968." The Journal of Musicology 33, no. 3 (July 1, 2016): 362-400.

Seifried, Chad. "An Exploration into Melodrama and Sport: The 'Miracle on Ice' and the Cold War Lens." Olympika 19 (2010): 111-138.

Senn, Alfred Eric. Power, Politics, and the Olympic Games. Champaign: Human Kinetics, 2018.

Sex, Gender, and Sexuality in Sport: Queer Inquiries. Edited by Vikki Krane. London: Taylor \& Francis, 2019.

Shay, Anthony. The Igor Moiseyev Dance Company: Dancing Diplomats. Bristol: Intellect, 2019.

—. "The Spectacularization of Soviet/Russian folk dance: Igor Moiseyev and the Invented Tradition of Staged Folk Dance." In The Oxford Handbook of Dance and Ethnicity, edited by Anthony Shay and Barbara Sellers-Young. Oxford: Oxford University Press, 2016.

Shulman, Carole. The Complete Book of Figure Skating. Champaign: Human Kinetics, 2002.

Sisario, Ben. "Beyoncé Songs Come to the Olympics. But Who Pays for the Rights?" The New York Times, February 14, 2018.

Skinner, Frederick W. "Lenin and Beethoven: Beyond the 'Appassionata' Affair." In The Beethoven Journal 18, no. 2 (2003): 62-65. 
Skinner, Kiron K., Pavel Palazhchenko, and George P. Shultz. Turning Points in Ending the Cold War. Stanford: Hoover Institution Press, 2007.

Smith, Beverley, and Dan Diamond. Figure Skating: A Celebration. Toronto: McClelland \& Stewart, 1994.

Soares, John. "“Our Way of Life against Theirs': Ice Hockey and the Cold War.” In Diplomatic Games: Sports, Statecraft, and International Relations Since 1945, edited by Evelyn Mertin and Andrew L. Johns, 251-296. Lexington: University Press of Kentucky, 2014.

Sport and Diplomacy: Games within Games. Edited by J. Simon Rolfe. Manchester: Manchester University Press, 2019.

Sport and National Identity in the Post-War World. Edited by Adrian Smith and Dilwyn Porter. London: Routledge, 2004.

Sport and the Transformation of Modern Europe: State, Media and Markets 1950-2010. Edited by Alan Tomlinson, Christopher Young, and Richard Holt. London: Routledge, 2011.

Suri, Jeremi. Power and Protest: Global Revolution and the Rise of Detente. Cambridge: Harvard University Press, 2005.

Taruskin, Richard. Defining Russia Musically. Princeton: Princeton University Press, 2000.

—. On Russian Music. Berkeley: University of California Press California, 2010.

Taubman, William. Gorbachev: His Life and Times. New York: W.W. Norton \& Company, Inc., 2018.

Tchaikovsky Research. "Symphony No. 6." Tchaikovsky-research.net. http://en.tchaikovsky-research.net/pages/Symphony_No._6.

The Cold War: A History in Documents and Eyewitness Accounts. Edited by Hanhimäki, Jussi and Off Arne Westad. Oxford: Oxford University Press, 2004.

The Editors of Encylopaedia Britannica. "Oleg Protopopov and Lyudmila Belousov." Encylopaedia Britannica, https://www.britannica.com/biography/the-Protopopovs.

The Oxford Handbook of Dance and Ethnicity. Edited by Anthony Shay and Barbara Sellers-Young. Oxford: Oxford University Press, 2016.

The Oxford Handbook of Sports History. Edited by Robert Edelman. Oxford: Oxford University Press, 2017. 
The Oxford Handbook of the Cold War. Edited by Richard H. Immerman and Petra Goedde. Oxford: Oxford University Press, 2013.

The Oxford Handbook of the History of Communism. Edited by Stephen A. Smith. Oxford: Oxford University Press, 2014.

Thomas, Damion L. "Playing Politics: The Formation of the U.S. Cold War-Era Athletic Foreign Policy." In Globetrotting: African American Athletes and Cold War Politics. Urbana: University of Illinois Press, 2012.

Timm, Annette F. “"The Most Beautiful Face of Socialism': Katarina Witt and the Sexual Politics of Sport in the Cold War." In The Whole World Was Watching: Sport in the Cold War. Edited by Robert Edelman and Christopher Young. Stanford: Stanford University Press, 2020.

Torres, Cesar R. and Mark Dyreson. "The Cold War Games." In Global Olympics: Historical and Sociological Studies of the Modern Games. Edited by Kevin Young and Kevin B. Wamsley. Bingley: Emerald, 2005: 59-82.

Tragaki, Dafni, and Franco Fabbri. Empire of Song: Europe and Nation in the Eurovision Song Contest. Lanham: Scarecrow Press, 2013.

Tsipursky, Gleb. "Jazz, Power, and Soviet Youth in the Early Cold War, 1948-1953." Journal of Musicology 33, no. 3 (2016): 332-61.

Uhler, Andy. "The Beatles and Beyoncé Are Now Part of Olympic Figure Skating, but Who Pays for It?” Marketplace (blog). February 16, 2018.

UskateIskate1. John Curry - Maestro Documentary Part 4.. YouTube video, December 9, 2010, https://www.youtube.com/watch?v=mMojWgjmupU.

Vuletic, Dean. Postwar Europe and the Eurovision Song Contest. London: Bloomsbury Academic, 2019.

Vox. How Figure Skaters Choose Their Music, Explained with Adam Rippon, 2018. YouTube video. https://www.youtube.com/watch?v=VA_P3p7MI98.

Walker, James Russell. The Politics of performance: Soviet participation in the Olympic games, 1952-1984. Ann Arbor: University Microfilms International, 1992.

Wamsley, Kevin B. and Gertrud Pfister. "Olympic Men and Women: The Politics of Gender in the Modern Games." In Global Olympics: Historical and Sociological Studies of the Modern Games. Edited by Kevin Young and Kevin B. Wamsley. Bingley: Emerald, 2005: 103-126. 
Wenn, Stephen R. "Growing Pains: The Olympic Movement and Television, 1966-1972." Olympika 4 (1995), 1-22.

. "Rivals and Revolutionaries: Avery Brundage, the Marquess of Exeter and Olympic Television Revenue." Sport in History 32 (2012): 257-268.

_. "Television Rights and the 1976 Montreal Olympics." Sports Historical Review 27 (1996): 111-138.

Whannel, Garry. "The Five Rings and the Small Screen: Television, Sponsorship, and New Media in the Olympic Movement." In Global Olympics: Historical and Sociological Studies of the Modern Games, edited by Kevin Young and Kevin B. Wamsley, 161-178. Bingley: Emerald, 2005.

Wilken, Lisanne. "The Eurovision Song Contest as Cultural Diplomacy during the Cold War: Transmitting Western Attractiveness." In Machines of Persuasion: European Soft Power and Public Diplomacy during the Cold War, edited by Óscar J. Martín García and Rósa Magnúsdóttir, 171-190. Oldenbourg: De Gruyter, 2019.

Wilson, Doug and Jody Cohan. The World Was Our Stage: Spanning the Globe with ABC Sports. CreateSpace, 2013: 45-49.

Wilson, Jonathan. Behind the Iron Curtain: Travels in Eastern European Football. London, Orion, 2006.

Witherspoon, Kevin B. “"An Outstanding Representative for America': Mal Whitfield and America's Black Sports Ambassadors in Africa." In Defending the American Way of Life: Sport, Culture, and the Cold War, edited by Toby C. Rider and Kevin B.

Witherspoon, 129-140. Fayetteville: University of Arkansas Press, 2018.

Women on Ice: Feminist Essays on the Tonya Harding/Nancy Kerrigan Spectacle. Edited by Cynthia Bauman. New York: Routledge, 1995.

Wood, Mihaela Andra. "Superpower: Romanian Women's Gymnastics during the Cold War.” Ph.D. diss., University of Illinois at Urbana-Champaign, 2010.

Wu, Samuel S., and Mark C. K. Yang. "Evaluation of the Current Decision Rule in Figure Skating and Possible Improvements.” The American Statistician 58, no. 1 (2004): 4654.

Young, Simon. "Playing to Win: The Moscow Olympics and the Augmentation of Soviet Soft Power during the Brezhnev Era, 1975-1980." In Machineries of Persuasion: European Soft Power and Public Diplomacy during the Cold War, edited by Óscar J. Martín García and Rósa Magnúsdóttir, 61-84. Oldenbourg: De Gruyter, 2019. 
Zhang, Jieqian. "Winter Olympics 2018: How Music in Figure Skating Has Changed." The Wall Street Journal, February 9, 2018.

Zirin, Dave. "The Uses of Sports: How People in Power Exploit the Games." In Welcome to the Terrordome: The Pain, Politics and Promise of Sport. New York: Haymarket Books, 2007.

3Axel1996. Debi Thomas (USA) - 1988 Calgary, Ladies' Long Program. YouTube video, November 2, 2009, https://www.youtube.com/watch?v=gW4LqC33TiU.

. Katarina Witt (GDR) - 1988 Calgary, Figure Skating, Ladies' Long Program (US $A B C)$. YouTube video, https://www.youtube.com/watch?v=57R7aAY5QiM.

"Carmen." The Ballet Bag (blog), May 8, 2010, http://www.theballetbag.com/2010/05/08/carmen/.

"Carole Banbury Shulman - St Louis Park Historical Society." http://slphistory.org/banburycarole/.

"Debi Thomas." Biography, November 10, 2015, https://www.biography.com/athlete/debithomas.

"Ekaterina Gordeeva \& Sergei Grinkov / Programs / G\&G." http://www.gordeeva.com/programs/english/index.shtml

"Incidental Music." In Grove Music Online, January 20, 2001, https://doiorg.www.libproxy.wvu.edu/10.1093/gmo/9781561592630.article.43289.

"Introduction." In The Oxford Handbook of the Cold War. Ed. Richard H. Immerman and Petra Goedde, Oxford: Oxford University Press, 2013.

"Irina Rodnina | Soviet Figure Skater." Encylopaedia Britannica, https://www.britannica.com/biography//rina-Rodnina.

"Katarina Witt: Biography.” Biography, https://www.katarina-witt.de/en/biography.html.

“1972 Winter Olympics.” February 11, 2017, https://www.infoplease.com/sports/winterolympics-through-years/1972-olympics.

"1992 Albertville Winter Games." Sports-Reference.com, April 17, 2020, https://web.archive.org/web/20200417042616/https://www.sportsreference.com/olympics/winter/1992/.

“Свиридов Георгий Васильевич," http://www.warheroes.ru/hero/hero.asp?Hero_id=10696. 
“Легендарная Советская Фигуристка.” People, September 12, 2018, https://www.peoples.ru/sport/fskating/rodnina/.

"Роднина - Это Эпоха - Россия,"

https://web.archive.org/web/20090917185908/http://russianews.ru/newspaper/26869/26 $\underline{965 /}$. 